\title{
Performance targets from supervisors' and employees perspectives
}

Citation for published version (APA):

Feichter, C. (2016). Performance targets from supervisors' and employees perspectives. [Doctoral Thesis, Maastricht University]. Datawyse / Universitaire Pers Maastricht. https://doi.org/10.26481/dis.20161117cf

Document status and date:

Published: 01/01/2016

DOI:

$10.26481 /$ dis.20161117cf

Document Version:

Publisher's PDF, also known as Version of record

\section{Please check the document version of this publication:}

- A submitted manuscript is the version of the article upon submission and before peer-review. There can be important differences between the submitted version and the official published version of record.

People interested in the research are advised to contact the author for the final version of the publication, or visit the DOI to the publisher's website.

- The final author version and the galley proof are versions of the publication after peer review.

- The final published version features the final layout of the paper including the volume, issue and page numbers.

Link to publication

\footnotetext{
General rights rights.

- You may freely distribute the URL identifying the publication in the public portal. please follow below link for the End User Agreement:

www.umlib.nl/taverne-license

Take down policy

If you believe that this document breaches copyright please contact us at:

repository@maastrichtuniversity.nl

providing details and we will investigate your claim.
}

Copyright and moral rights for the publications made accessible in the public portal are retained by the authors and/or other copyright owners and it is a condition of accessing publications that users recognise and abide by the legal requirements associated with these

- Users may download and print one copy of any publication from the public portal for the purpose of private study or research.

- You may not further distribute the material or use it for any profit-making activity or commercial gain

If the publication is distributed under the terms of Article $25 \mathrm{fa}$ of the Dutch Copyright Act, indicated by the "Taverne" license above, 
Christoph Feichter

\section{PERFORMANCE TARGETS FROM SUPERVISORS' AND EMPLOYEES' PERSPECTIVES}

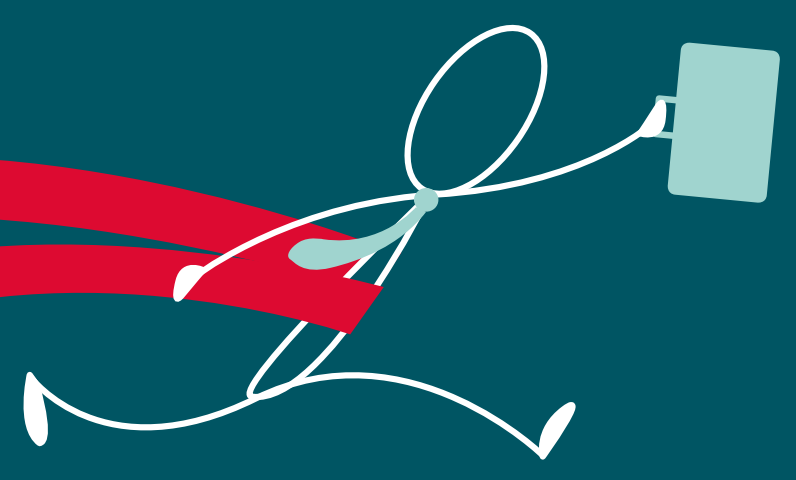


(C) Christoph Feichter

Printing: Datawyse/Universitaire Pers Maastricht ISBN: 9789461596239 


\section{Performance targets from supervisors' and employees' perspectives}

\section{DISSERTATION}

to obtain the degree of Doctor at Maastricht University,

on the authority of the Rector Magnificus, Prof. Dr. Rianne M. Letschert, in accordance with the decision of the Board of Deans, to be defended in public on Thursday, November 17, 2016, at 10.00 hours

by

Christoph Feichter 


\section{Supervisor}

Prof. Dr. Frank. Moers

\section{Co-Supervisor}

Dr. Alexander Brüggen

\section{Assessment Committee}

Prof. Dr. Ann Vanstraelen (Chair)

Prof. Dr. Eddy Cardinaels (KU Leuven, Belgium)

Prof. Dr. Arno Riedl

Prof. Dr. Alan Webb (University of Waterloo, Canada) 


\section{Acknowledgements}

When you start your PhD studies you think you know what to expect. You have heard all the stories from your colleagues and friends about their experiences, saw their ups and downs, and you try to learn from their problems. At the end of your $\mathrm{PhD}$ time you realize that this is just the natural flow and you can avoid some, but not all of them. However, what helps is to know that there are people around you who fully support you through this process. I want to use the following paragraphs to thank some of these people who made sure I did not get lost on my way.

First of all, I would like to thank the best supervisor team ever, Frank Moers and Alexander Brüggen. Both of them gave me the freedom to follow my own directions, but at the same time guided and pushed me further when necessary. Frank, your door was always open (not only literally). I don't know how often I came to you to talk about all kind of issues, starting with: "Frank... do you have a minute for me". Luckily you always had more than a minute. Our discussions inspired me, gave me invaluable insights, especially in economic reasoning, and most important, every time I got out of your office I had a plan what to do next. Alex, I really appreciate that you take the things as they are and try to make the best out of it. Especially for someone who is tempted to spend time thinking about the "what ifs", it was important to have someone like you who helps to look at possible solutions instead of problems. I am very happy to have both of you not only as supervisors, but also as friends.

I also want to thank Michael Williamson, who, after he gave a seminar in Maastricht during my first $\mathrm{PhD}$ year, became a co-author, friend, and mentor. Luckily he managed to invite me to spend four months at the University of Texas at Austin. It was this stay and the collaboration with Michael that changed my way of thinking and conducting behavioral accounting research. I also thank Alan Webb who gave me the chance to spend four months at the University of Waterloo. During our discussions I enlarged my understanding of how to specify predictions precisely and the importance of theory in developing them. I also want to thank Gerhard Speckbacher, from WU Vienna. I not only appreciate that he supported me in my transition to Maastricht University, but also his approach to research. I learned that it is most important to work on projects that I am personally interested in and that you should never lose sight to practice. I also want to thank all the members of my assessment committee, Ann Vanstraelen (Chair), Eddy Cardinaels, Arno Riedl, and Alan Webb for evaluating my thesis and providing helpful comments that will help to improve my papers in the future.

Further, I want to thank Isabella, who has agreed to serve as my paranymph. Being her research assistant and master thesis ("Diplomarbeit") student in Vienna, she already gave me insights into the world of research before I even started my PhD (luckily research consists not always of follow-up calls for survey research). Most importantly, she supported me and believed in me even during the times where I started to doubt everything - I think it is friends like this that you need to finish a dissertation. I also thank Patrick. At work, but especially also during all the outside work activities such as our regular beer tasting evenings, trips to diverse festivals and cities, and regular pub-nights he spent hours of listening to me talking about my smaller and bigger problems. Even though I might not have always appreciated it on the spot, most of the time he came up with good suggestions. Thus, while he might not be the best sports-partner, he is definitely the best friend one needs as support throughout the $\mathrm{PhD}$ journey. I was also lucky to share my office for four years with Lars, who also agreed to be my paranymph. Over the years we got to know each other quite well, knew when we could disturb each other, and most importantly, talk about more and less important stuff. I remember countless discussions about philosophy of science or the underwater internet cable between Europe and North America. Even though he is not an accounting researcher (as he never gets 
tired to highlight), I am proud that after so many years he even started to talk positively about management accounting research.

Further, I also want to thank many other colleagues and friends that I met during my PhD time. Together with Patrick, Jonas and Thomas formed the perfect environment to start my $\mathrm{PhD}$ studies in Maastricht. Besides providing helpful comments on my research and being kind of "work related role models", both of them also showed me the social benefits of being a $\mathrm{PhD}$ candidate in Maastricht. The numerous parties we attended and trips to Bratislava and Porto leave me with a lot of enjoyable memories. I also thank Judith for spreading her happiness across our hallway, joining all the fun activities, and of course to ensure that we never forgot any birthday present. Further, I thank her for providing me feedback on the first drafts of my papers and reading through them with all the spelling and grammar mistakes (even though we do not always agree on what is right and what is wrong). Katlijn, despite the fact that we were not employed by the same university, knowing that someone goes through the same process at the same time really helps. Also I want to thank Lars H., not only for his Karaoke performance in Düsseldorf, but also for bringing a different style and background to our lunch table. And Britt, I am already looking forward to next Indonesian dinner at your place. All of them, but also many others like Anant, Bene, Franzi, Lei, Lu, Nadine, Réka, Ronny, Simone, and Ulrike, made sure that the social activities such as Chinese hot-pot parties, cycling and running events, moving days, climbing evenings, squash, poker, and bar evenings, provided me with the necessary distraction, enriched my life as $\mathrm{PhD}$ student, and most importantly leave me with many unforgettable moments. Thanks to all friends who joined me in these activities! I also want to thank all the members of the Accounting and Information Management Department. The atmosphere at our department has always been great. It sometimes feels like a big family, where I enjoy coming to the office every single day. A special thanks also goes to Tanja and Marjo, who always organize the money for my experiments on time, even though I let them know way too late. I am looking forward to keep on working with all of you in the future.

Luckily, I also have friends and family outside university who help me to get a necessary distance from work, and provide me with insights for my research (even though they might not even know it). I am thankful to my Austrian friends, Armin, Christoph, Marco, and Thomas for always taking their time to meet me when I am in Vienna and for coming to visit me regularly in Maastricht. Your carnival trips are already legendary and I am looking forward to having you here soon again.

I also want to thank my parents and their families for all the support and patience they showed. Knowing that my parents support me in everything I am doing and that they always stand behind me really helped over the last years. Moreover, what was very important for me too was to know that they also have persons in life that take care of them. Finally, I want to thank Andreas and Birgit. While it is for sure not the most important impact my older brother Andreas had on me, I probably would have never thought of doing a $\mathrm{PhD}$ without him. Besides being there for me my whole life, I have always admired his motivation and discipline for intellectual (and physical) challenges. Please make sure you never lose them. And Birgit, I really don't know where to begin. I don't know how many evenings, weekends and holidays I spent working, all the frustrations and bad moods I brought home, or the pure fact that we spend a couple of years in a long-distance relationship because I came up with the idea to move to Maastricht for my PhD. However, instead of complaining you always showed unconditional support. You visited me wherever I was, encouraged me in everything I was doing, and most importantly, when I was frustrated you were there to build me up again. I am not sure if I can ever do something similar for you, but I promise that I will try my best every day. 
When I started to work on my dissertation my goal was to write a perfect $\mathrm{PhD}$ thesis. I am afraid it didn't turn out to be perfect. However, after many years, and many ups and downs, I finally can hand in a thesis where I am proud to say that I tried my best to get it as perfect as possible. This would have never been possible without the help of all of you! Thank you!

Christoph 



\section{Table of Contents}

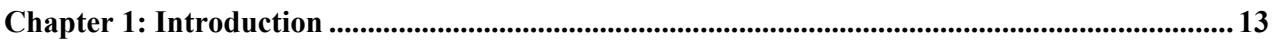

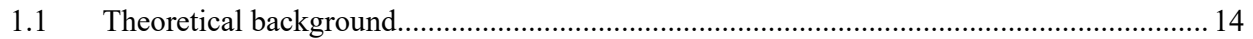

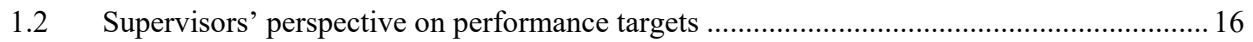

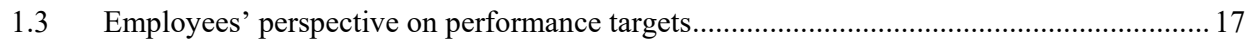

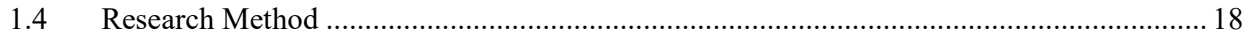

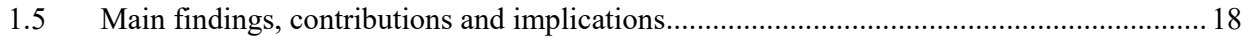

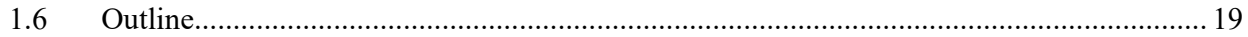

Chapter 2: The effect of supervisors' prior task experience on employees' targets ......................21

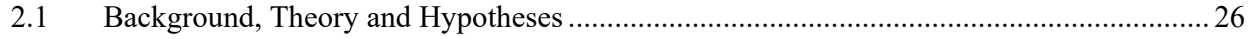

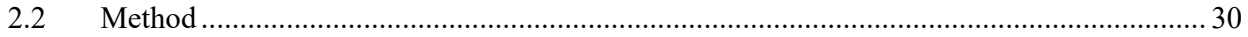

2.2.1 Part I -Experimental tasks and Manipulations........................................................... 31

2.2.2 Part II - Principals' target setting decision ................................................................... 33

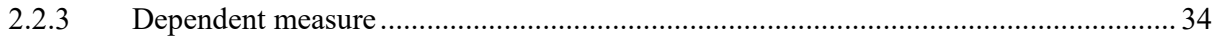

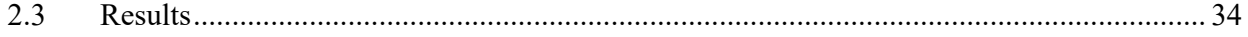

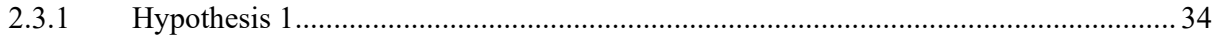

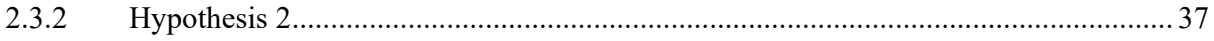

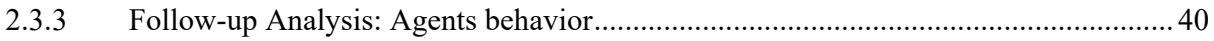

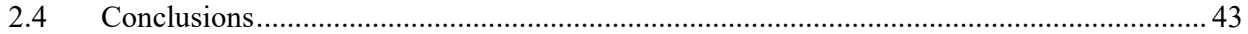

Chapter 3: The Influence of Target Ratcheting on Employees' Investment Behavior...................47

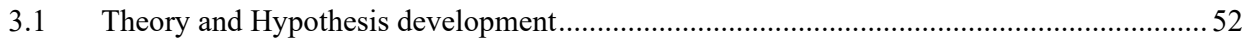

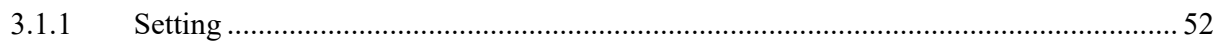

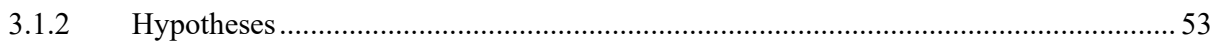

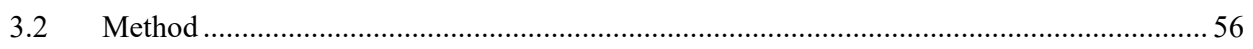

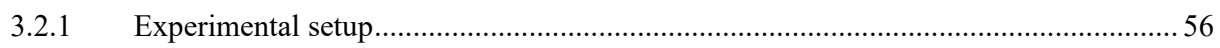

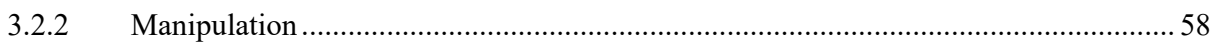

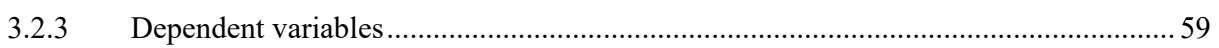

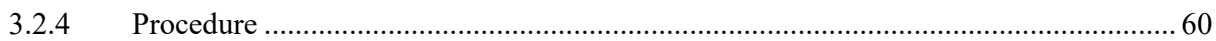

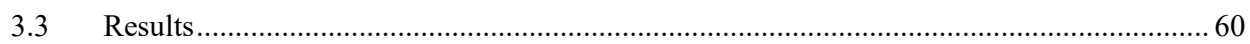

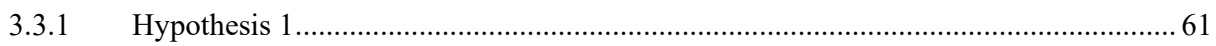




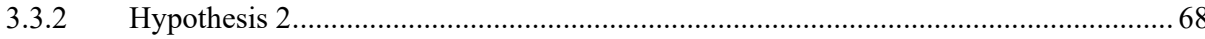

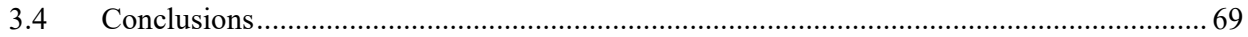

\section{Chapter 4: The Effect of Input and Output Targets for Routine Tasks on Creative Task}

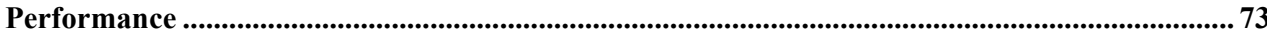

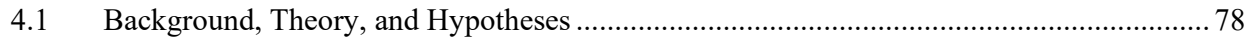

4.1.1 Input (Time) Targets for Routine Tasks....................................................................... 79

4.1.2 Easily Achievable Output Targets for Routine Tasks................................................... 80

4.1.3 Complementary Role of Output Targets and Input Targets ........................................... 81

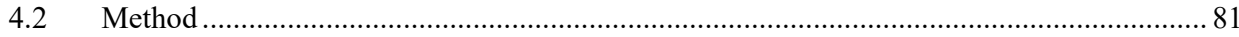

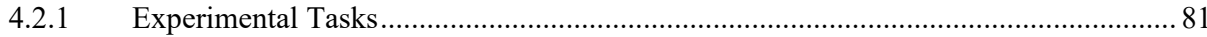

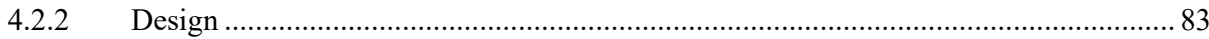

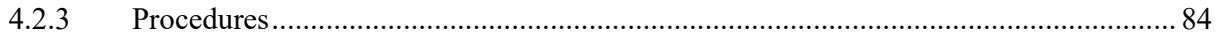

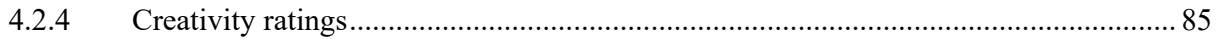

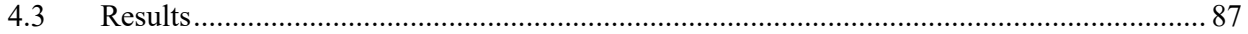

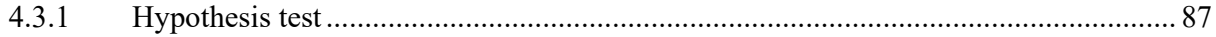

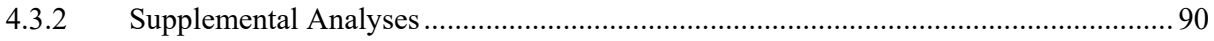

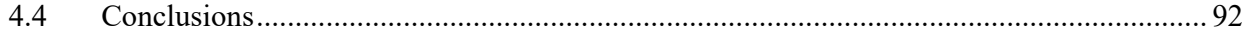

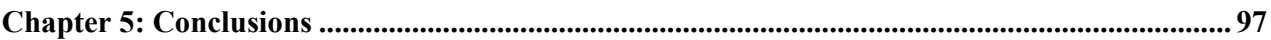

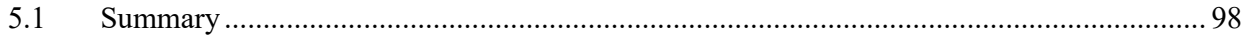

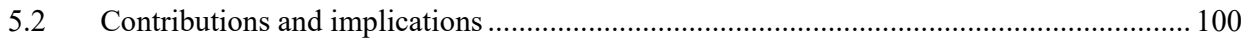

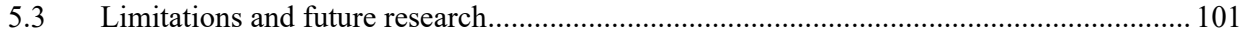

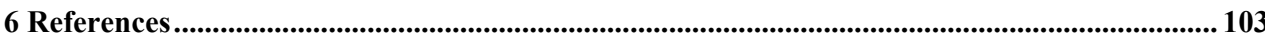

7 Appendix A - Experimental Details for Chapter 2 .............................................................109

7.1 Instructions for Part I of the experiment (treatment without task experience)..................... 109

7.2 Instructions for part II of the experiment (the same for all treatments): .............................. 111

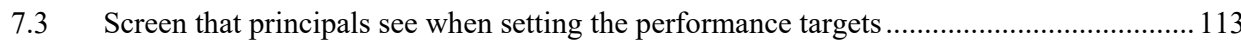

8 Appendix B - Experimental Details Chapter 3 ...................................................................115

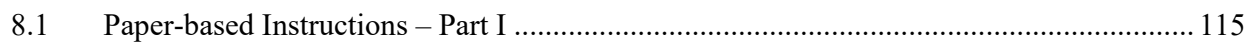

8.2 Paper-based instructions Part II (target ratcheting treatment).............................................. 116

8.3 Screen that participants saw during the productive task ...................................................... 118

8.4 Screen that participants saw during the investment task ....................................................... 119 
9 Appendix C - Experimental Details for Chapter 4................................................................121

9.1 Paper-based instructions (for Input and Output Target Treatment) ................................... 121

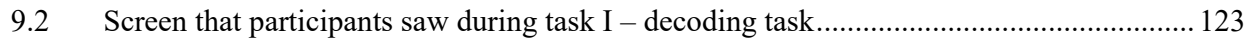

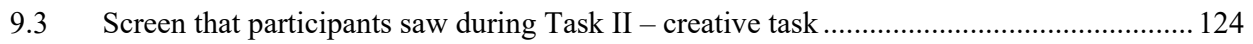

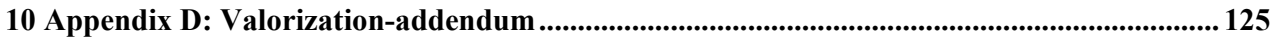



Chapter 1: Introduction 


\section{Introduction}

As part of the company's management control systems, performance targets play a major role in managing the organization and implementing the firm's strategy. Engaging managers to think about future developments of the firm when setting performance targets facilitates organizational planning and coordination. Translating the overall strategy in operational plans guides employees in taking the right actions for the firm. And setting specific performance targets also directly impacts the motivation of employees. Thus, performance targets cannot only mitigate problems resulting from a lack of direction, but can also problems from a lack of motivation (Merchant and Van der Stede 2007). This ultimately helps organizations to achieve the overall objectives of the firm.

Despite the substantial time and effort that planning and budgeting systems require and the ongoing criticism and discontent about them (Jensen 2001) - almost all companies use budgets and performance targets as one tool to manage their companies (Locke 2004; Merchant and Van der Stede 2007). For example, studies show that up to 97 percent of the companies use formal budgeting mechanisms (Umapathy 1987). Furthermore, in academic studies and business reports managers consistently highlight the importance of budgeting and target setting to facilitate planning, control, and motivation of employees (Libby and Lindsay 2010; Hansen and Van der Stede 2004; Chartered Insitute of Management Accountants 2004). This also manifests itself in the time and effort that companies spend on these issues. For example, Libby and Lindsay (2010) find in Canadian and US samples that the median firm requires 6 to 10 weeks to develop their budgets, where the median manager spends 3 to 4 weeks per year on issues related to budgets. Hansen and Van der Stede (2004) show in their sample that the mean number of iterations to derive the final budget is 4.25 times, with a maximum of 25 iterations. Identifying potential problems and specifications that increase the efficacy of such target setting systems can improve the effectiveness of these systems and thus ensure that the funds invested in this resource intensive process are well spent for the companies.

In this dissertation I examine performance targets from both supervisors' and employees' perspectives. In three studies I experimentally examine (1) how the background of supervisors (i.e., experience on the employees' task) influences the targets they set for their employees, (2) how using past performance information in setting performance targets influences employees' long-term investments, and (3) how different targets around routine work influence the creative task performance of employees.

\subsection{Theoretical background}

In principal-agent settings a principal (i.e., supervisor, employer) hires an agent (i.e., employee, subordinate) to perform tasks for the principal. As performing the task is costly for the agent, the agents' interest is to keep effort as low as possible while at the same time maximize the payments. In contrast, the principal's interest is to maximize the output from the agent while keeping the payments for the agent as low as possible. Thus, both parties follow their own interests which are not perfectly aligned with each other. As the agent's effort is unobservable by the principal, the principal needs to find other ways to assure that 
the agent is working in the principal's favor (i.e., spend sufficient level of effort). One common mechanism to achieve this is by paying agents according to their performance.

However, in practice, companies mostly do not pay their employees just based on the output they achieve, but employees receive a bonus depending on the performance relative to a performance target (Murphy 2001; Anderson et al. 2010). Specifically, once employees achieve a certain performance threshold they receive a fraction of the excess output. If performance is below this threshold, then employees do not receive a bonus. Figure 1 shows such a typical pay-for-performance contract as it is used at different levels of the organization.

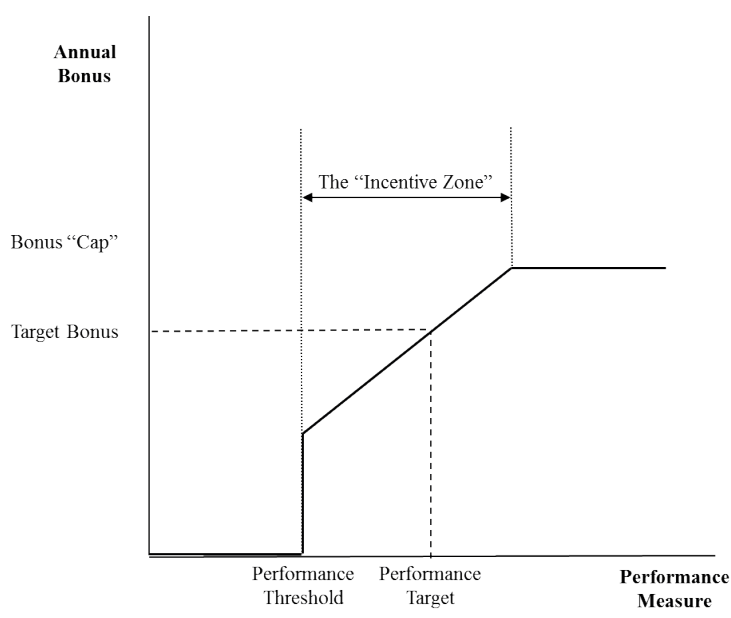

Figure 1: Typical pay-for-performance contract (Source: cf. Murphy 2001)

By incorporating performance targets that are often directly linked to the budgets in the compensation contracts, companies can increase employees' accountability and effectiveness of budgetary control systems. As employees have to achieve a threshold in order to be eligible for a bonus payment, this provides a clear incentive to achieve this minimum level of performance. Thereby, performance targets facilitate the coordination of actions across individuals and departments. Additionally, Murphy (2001) argues that by providing performance targets companies can achieve a high pay-for-performance sensitivity at high levels of effort, while at the same time meeting the employees' reservation wage. This implies that, once employees achieve the performance targets, they have higher monetary incentives to provide higher performance compared to a situation without a performance standard where just a piece rate would be provided.

Moreover, psychology and behavioral accounting research have also shown that performance targets induce a lot of behavioral reactions of employees. For example, goal setting theory predicts that there is a positive effect of setting specific targets on the motivation of individuals. In fact, studies show that setting a specific target leads to higher performance than just telling people that they should do their best (Locke and Latham 2002). By directing attention towards achieving a target, individuals can better focus on the task and 
do not get distracted so easily. Furthermore, the target itself can also have an energizing function that induces the motivation of individuals to achieve it. Thus, goal setting theory also implies that higher target levels increase the motivation of employees. However, as the targets get too challenging, individuals lose their commitment to achieve them and give up, which could result in substantial costs for the firm (Latham and Locke 1991; Merchant and Van der Stede 2007; Locke and Latham 2002). Figure 2 gives a graphical depiction of this relationship.

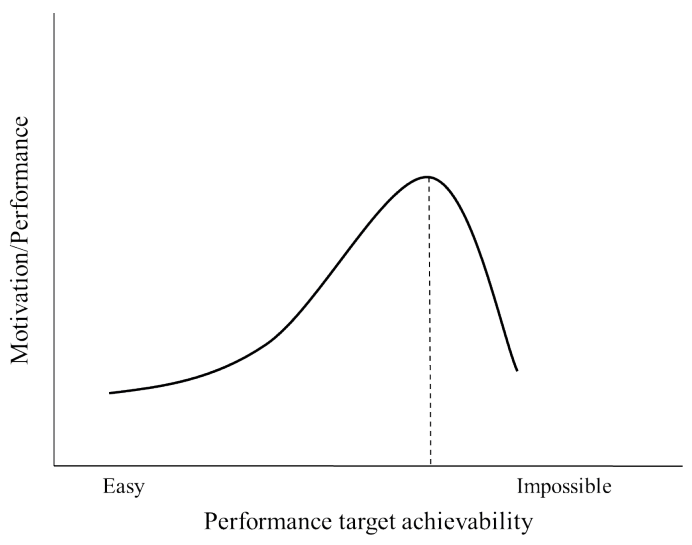

Figure 2: Relationship between performance target achievability and Motivation/Performance (Source: c.f. Merchant 1998)

\subsection{Supervisors' perspective on performance targets}

One of the main tasks of supervisors during the target setting process is to decide on the level of the performance target for the employees. The discussion above implies that when supervisors set the performance targets for their employees, they need to find a balance between setting high targets that maximize the employees' motivation, and not setting them too high to avoid that employees give up. In line with this notion, prior studies have shown that supervisors often include slack into performance targets to ensure that employees are highly likely to achieve their targets. For example, Merchant and Manzoni (1989) show in their field study that their profit center managers achieved targets around 70-90 percent of the time. Bol et al. (2010) find comparable percentages of target achievements in their studies.

To define proper target levels for employees, supervisors have multiple sources of information available such as past performance information, peer performance information, market studies about future developments, and other information (Merchant and Van der Stede 2007; Aranda et al. 2014). However, which information sources supervisors take into account and how they weigh this information is mostly in their discretion. Hence, in the first study of my dissertation I examine supervisors' target setting decisions. Specifically, I examine whether supervisors who have worked themselves on the task that they supervise set different target levels for their employees than supervisors who have never worked on the employees' task. Furthermore, I not only examine how their own experience on the employees' task influences the target levels that they set for their employees, but also how 
their experiences influence the extent to which they incorporate information about future environmental changes in targets.

\subsection{Employees' perspective on performance targets}

The targets that supervisors set for their employees should also guide employees in the actions that they take and motivate them in the best way to work in favor of the company (Merchant and Van der Stede 2007). Thus, I also examine performance targets from an employees' perspective. While prior studies show that targets often include slack, they also discuss various reasons why supervisors deliberately include such slack. One of the major reasons to do so is to provide employees with the flexibility to follow activities that could increase the productivity of the firm in the future (Merchant and Manzoni 1989). This is insofar important as organizations often need to find a balance to increase output and profitability in the short-run, and invest in in the future to be successful in the long-run. Consequently, often employees are not just responsible for maximizing current output, but next to that are also supposed to perform other tasks that build the basis for the firm's future success (e.g., long-term investments, creative tasks). However, as these investments can be unobservable or their success is highly uncertain, companies often do not directly incorporate measures and incentives for such long-term investments in the contracts of their employees but try to find other ways to assure that employees perform such activities. I examine in two studies the role of performance targets around the short-term output tasks to foster such longterm activities.

Specifically, in my second study I examine how the use of employees' past performance information in setting targets affects employees' tradeoff between short term output maximization and long-term investments. Studies have shown that past performance information of employees is one of the major information sources for supervisors when setting performance targets for their employees (Murphy 2001). That said, as budgeting and target setting is usually not a one-time event but recurs every year, the use of past performance information also creates a dynamic incentive problem for individuals. As employees know that outperforming a target could increase the target for next period (i.e., target ratcheting), they might withhold potential excess effort to prevent targets from rising (Bouwens and Kroos 2011; Weitzman 1980). However, especially as targets often include considerable amounts of slack, companies want to assure that employees use these slack resources in the best interest of the firm. Therefore, I examine in a multi-period setting in how far the use of prior performance information influences the level of long-term investments that employees undertake.

Finally, in the third study of my dissertation I investigate how the structure of targets around the routine task influences the creative task performance. Thus, while in my second study I test how using past performance information affects the level of investments, in this study I examine how the structure of the targets around routine tasks can increase the efficacy of these investments in form of creative task performance. As studies suggest, supervisors often deliberately include budgetary slack in order to provide employees with the freedom and time to pursue such long-term investments that ultimately can provide the basis for the 
future success of the company. On the other hand, popular business press highlights policies where companies provide their employees across rank and file the opportunity to spend a certain amount of time away from their day-to-day routine tasks to pursue creative activities (e.g., Google, 3M, Caterpillar). Therefore, I examine how input (time) and output targets around the routine task affect the creative task performance of individuals.

\subsection{Research Method}

To examine my specific research questions, I performed three laboratory experiments with students from Maastricht University. In laboratory experiments researchers create controlled abstract settings where they hold everything constant except for the manipulations they are interested in. Furthermore, participants are randomly assigned to the different treatments. Therefore, the experimental method allows to isolate the effects under scrutiny and to test cause and effect relationships. In practice it would not be possible to find such controlled settings where everything is constant except for the specific treatments that I investigate in this dissertation. Furthermore, examining individuals' behavior in response to the specific policies mentioned above would require data that might not even be available in companies (e.g., unobservable investments). Consequently, experiments are the proper method to examine my research questions. I provide the details of the experiments in the respective chapters.

\subsection{Main findings, contributions and implications}

The findings of my dissertation show that the background of the supervisor matters for their target setting decisions and how they use the information available. Specifically, the results of my first study indicate that supervisors who worked on the subordinates task before discount relevant information about expected performance of their employees and overemphasize their own experiences. Consequently, high performing supervisors with experience set higher targets than supervisors with task experience and low performance, and supervisors without task experience. Furthermore, supervisors with task experience and low performance are overly sensitive to environmental changes and incorporate the information of environmental changes more than good performing supervisors with task experience, and supervisors without task experience. These findings show that the background of supervisors and their prior performance matters for how they set targets for their employees and how they incorporate environmental information. It further implies that individuals are inclined to draw inferences from their own performance and project them on others, even though they would have better information available. Finally, it shows that self-serving attributions to justify own performance do not only affect the conclusions about their own performance, but also that these biased perceptions influence the targets that they set for their employees.

Furthermore, I develop and test theory suggesting that taking employees' past performance information into account affects the long-term investment decisions of employees. My second study shows that a target ratcheting system, where past performance information influences new performance targets, mitigates the horizon problem of investments and thereby leads to higher investment levels. Thus, while prior studies have mainly focused on the negative consequences from target ratcheting where employees withhold effort once they achieved their target, I show that target ratcheting can actually 
induce long-term investments if they are responsible for both short-term output and long-term investments. Consequently, by incorporating past performance information into new targets, firms can increase the level of investments that build the basis for the future success of the company.

Besides examining how the use of past performance information affects the long-term investment levels of employees, I also examine how the structure of the target setting system around the routine task (i.e., short-term output) affects the creativity of individuals that can build the ground for future success. The findings of my third study show that a combination of input and output targets around the routine task leads to higher creative task performance than just providing an input or output target, or no target at all. This is consistent with theories suggesting that an output target provides individuals with cognitive closure on the routine task, so that individuals are fully focused on the creative activities, while an input target assures that they reserve enough time for creative work. This suggests that companies can increase the efficacy of the growing practice to allow individuals to spend a certain amount of time away from their routine task to pursue creative activities by also letting them know what specifically they should achieve on the routine task.

Thus, together these studies give insights in what kind of information supervisors use when setting performance targets for their employees, how employees invest in the future depending on the information used for determining targets, and finally, how the target setting system around the routine task can increase the efficacy of the long-term investments in the form of creative output.

\subsection{Outline}

Each of the following three chapters describes one of the aforementioned studies. Chapter 2 presents the first study about the supervisors own experience on the employees' task, and how this experience influences their target setting decisions. Chapter 3 describes the second study about using employees' past performance information to determine targets and the effect on employees' long-term investments. Chapter 4 presents the third study, examining the role of input and output targets around the routine task on the creative task performance of individuals. Finally, in Chapter 5, I summarize the main findings of these studies, contributions and implications, discuss their limitations and provide directions for future research. 

Chapter 2: The effect of supervisors' prior task experience on employees' targets 


\begin{abstract}
I examine whether supervisors who themselves have performed the task of their employees set different targets than supervisors without such experience on the employees' task. Based on projection theory and self-serving attribution bias I argue that supervisors with task experience discount relevant information about employees' performance potential and overemphasize their own experiences. As such, good performing supervisors with task experience tend to set too high targets for their employees, while low performing supervisors with task experience react overly sensitive to changes in the environment. In a laboratory experiment I manipulate the supervisors' task experience between subjects, but hold the knowledge about the task itself and the information about expected employees' performance constant. The findings support the prediction that high performing supervisors with task experience discount relevant information and set higher targets for their employees than supervisors with experience and low performance, and supervisors without task experience. Moreover, low performing supervisors with task experience incorporate environmental information overly strong as the operating environment changes. This study contributes to a better understanding of how supervisors use their discretion during the target setting process and shows potential problems arising from policies where companies require their managers to gain experiences in various areas and functions within a company (e.g., job rotation, internal labor markets, and long-term training programs).
\end{abstract}




\section{Introduction}

I examine whether supervisors who themselves have performed the task that they currently supervise set different targets for their employees than supervisors without such experience on the same task. Companies frequently install policies where their future managers gain experience in various areas and functions within an organization (e.g., job rotation, internal labor markets, trainee programs, long-term trainings). These policies can increase managers' understanding of the company and the business model. In addition, they also have implications for the target setting and budgeting systems of organizations, where supervisors often have discretion about what information to use and how to weigh the different information (Dekker et al. 2012; Aranda et al. 2014; Bol et al. 2010). While, having own experience on employees' tasks can increase supervisors' understanding of the task requirements and decrease information asymmetry between the supervisor and the employee, research also suggests that individuals often tend to project their own characteristics and experiences on others (Kawada et al. 2004). As such, supervisors with own experience on employees' tasks might overemphasize their own experiences and discount other - more informative - information. Holding the knowledge about a task constant, I examine the effect of own task experience on the level of the target they set for their employees, and the extent to which they incorporate information about future environmental changes in the targets.

Performance targets fulfill multiple purposes in organizations, where motivating employees is one of the main purposes. For example, prior literature has shown a positive relationship between the target level and the motivation of employees, up to a certain point where targets get too challenging and employees give up (Latham and Locke 1991; Merchant and Van der Stede 2007). Furthermore, in typical pay-for-performance contracts employees are eligible for bonus compensation only if they reach certain minimum thresholds (Murphy 2001; Anderson et al. 2010). Hence, supervisors often aim to set targets that are challenging, but achievable for their employees (Merchant and Manzoni 1989). Given the importance of setting proper target levels, supervisors use different information like past performance, peer performance, or other information to form expectations about employees' future performance (Merchant and Van der Stede 2007; Murphy 2001; Aranda et al. 2014). Importantly, as performance is usually the result of internal (i.e., ability, effort) and external (i.e., task difficulty, random noise) factors, the single performance of one employee does not allow drawing inferences about the future performance of another employee. Only the combination of multiple years and employees would allow doing so. As such, especially in stable environments, internal information systems that store the historical performance information of multiple employees and/or years, can give supervisors good indications about the expected performance of employees.

However, based on projection theory (Kawada et al. 2004; Holmes 1978) and selfserving attribution bias (Mezulis et al. 2004), I argue that supervisors with task experience examine the usefulness of the historical performance information of others in light of their own performance. Thereby, own task experience distorts the use of relevant signals about future performance of employees in two ways. First, if supervisors' performance was higher than the historical task performance of others, they discount the importance of the historical 
performance information and overemphasize their own performance ${ }^{1}$ when setting targets for their employees, even though it provides only very limited information about the performance potential of other employees. Consequently, they set higher targets that potentially get too challenging for employees. In contrast, supervisors with low task performance attribute their own failure to external factors (such as environmental factors or bad luck). Hence, they put less weight on their own task performance, but mainly rely on the historical performance information of others which provides the best estimate for defining the employees' targets. Likewise, supervisors who never worked on the task of their employees have no experience that provides insights in what to expect from their employees. Thus, they also fully rely on the historical data and will set a similar target level as those supervisors with task experience and low performance.

Second, own task experience can distort the extent to which supervisors incorporate information about expected environmental changes in the targets. As the operating environment of employees changes, the output they generate with the same level of input might also change (e.g., different compilation of customers, increased regulation requires additional time, new machines make the production more efficient). Thus, to keep the goal difficulty for employees constant, superiors need to adequately incorporate the expected change of the environment in the targets. However, as supervisors with low task performance on the employees' task attribute their own failure mainly to the external factors, they grant the operating environment a relatively large stake in explaining performance outcomes. This also means that any change in the operating environment should have a relatively strong impact, and consequently, they will change target levels to a greater extent than supervisors with experience and high performance. In contrast, supervisors without task experience were not exposed to internal or external factors on the task of their employees. Hence, their own prior performance they achieved on a different task should not affect the extent to which they incorporate new environmental information.

I test my predictions in an experiment where participants have the role as principal or agent. Agents work on a real-effort task (i.e., counting zeros in tables) under a budget linear contract and the principals' role is to set performance targets for the agent. Before the principals set the targets, I manipulate the principals' task experience between participants and measure their relative task performance. Specifically, while in the first part of the experiment all agents work on the task of counting zeros, half of the principals also work on this task. The other half of the principals work on an unrelated memory task. I then compare the principals' performance on their respective tasks to the mean performance of 20 randomly selected participants from a pre-test. I also give the summary performance information of these 20 random participants to the principals to increase the awareness of their own relative performance.

Then, in the second part of the experiment, all principals have to set performance targets for their agents for the counting zeros task. Specifically, to capture the principals'

\footnotetext{
${ }^{1}$ Throughout the entire study superiors' performance refers to the performance a superior achieved on the tasks prior to setting targets for their employees and not their performance as a supervisor.
} 
decision on the target levels and the incorporation of new environmental information, I use the strategy method where principals have to set targets for three different scenarios. Either the task difficulty of the counting zeros task stays the same as in the first part, the task difficulty falls, or it increases. Only one of these scenarios is actually played out by the agents in the second part. To keep the information about the expected agents' performance constant, all principals receive the information about the performance on the counting zeros task of the 20 randomly selected participants from the pre-test.

In line with my first hypothesis, the results show that good performing principals on the counting zeros task set higher targets than principals who performed below average on that task, and principals who worked on the memory task. As predicted, there is no difference among the targets of the low performing principals on the counting zeros task, and the high and low performers on the memory task. Furthermore, consistent with my second hypothesis, the results show that low performing principals on the counting zeros task incorporate environmental changes more in the targets than high performing principals on the counting zeros task, while there is no such difference between the high and low performers on the memory task. These findings support my two main predictions. In additional analyses, I also examine the agents' behavior. While I find no overall difference in the agents' performance between the treatments, it seems that agents are more likely to give up if their principal worked on the counting zeros task. When I exclude the agents who gave up from the analysis, agents exert significantly more effort if their principal worked on the counting zeros task and set relatively low targets than if their principal worked on the memory task. This suggests that also the motivation of employees can be affected by the experience level of the supervisor.

This study contributes to theory and practice in several ways. By showing that supervisors' previous performance on the employees' task affects the target setting decisions for their employees later on, I contribute to the literature on subjectivity in target setting. While prior studies find that supervisors set targets differently for individual subordinates based on subordinates' characteristics such as their status, their operating environment, or their relative past performance (Bol et al. 2010; Aranda et al. 2014), my study shows that also the supervisors' background and prior performance matters for how they use their discretion. In particular, I show that supervisors with task experience and high performance on that task set higher standards for their employees later on, despite own performance being uninformative for employees' future performance in my experiment. This finding is important as studies have shown that too challenging targets increase the likelihood of employees giving up (Latham and Locke 1991; Merchant and Van der Stede 2007). Thereby, my study helps to better identify those supervisors who are most likely to set highly challenging targets. Furthermore, in today's fast changing business environment, it is important for companies to know how their supervisors react to changes in the operating environment. My study shows that supervisors with experience and low performance are especially sensitive to changes in the environment and might even overestimate the impact of such changes.

This study also contributes to the literature about self-serving attributions and projections. Specifically, while studies about the self-serving attribution bias mainly focus on 
how individuals justify their performance and how this influences the expectations they form about their own future performance (e.g., Libby and Rennekamp 2012), I extend this line of literature and show that individuals also project these expectations on others. However, in situations where supervisors' experience on the employees' tasks is based on short-term experiences, own performance might only provide limited information about future expectations of their employees. Increasing managers' awareness of this issue can improve the target setting effectiveness in organizations.

Finally, my study helps companies assessing the costs and benefits of policies where they require their future managers to gain experience in various positions in the organization. For example, professional service firms usually require their future managers to advance within the firm (Moritz 2014). Furthermore, in large retail companies (e.g., H\&M, Aldi) managers also often need to undergo long-term training programs where they gain experience in various areas of the company, including the shop-floor levels. Other companies install formal policies for internal labor markets or job rotation within the organization (Cappelli 2013). While all these policies can increase the managers' understanding of the company and business model, it is important to know how they impact the managers' budgeting and target setting behavior.

The remainder of the paper is structured into four sections. In section two, I discuss the theory and develop the hypotheses. Section three presents the experiment I use to test my hypotheses. Section four shows the results of the study. In section five, I provide a summary and discuss the results of the study.

\subsection{Background, Theory and Hypotheses}

Performance targets serve many purposes in organizations. Studies in psychology and accounting have shown that targets influence employees' motivation and performance (Latham and Locke 1991; Merchant and Manzoni 1989; Merchant and Van der Stede 2007). In typical pay-for-performance contracts, employees' bonuses are conditional on achieving predefined targets (Anderson et al. 2010; Murphy 2001). Moreover, these targets also often serve as budgets, which are used for coordinating actions within organizations. Therefore, setting appropriate targets is important for the motivation of employees and coordination within organizations.

One issue that has received considerable attention in the management accounting literature is the difficulty level of the target. Theoretically, an adequate target level is often defined as the best estimate of an employee's future performance potential (Dekker et al. 2012; Murphy 2001; Van der Stede 2000). However, as the performance is a combination of many aspects, such as ability, effort, task difficulty, or environmental factors, estimating the future performance can be challenging. Therefore, supervisors use a combination of different information sources like past performance information, estimates of future developments, peer performance, forecasting models, and other information when setting the targets (Merchant and Van der Stede 2007; Milgrom and Roberts 1992; Dekker et al. 2012). Which 
information supervisors take into account and how they weigh the different information is often at their discretion. For example, Aranda et al. (2014) show that depending on the branch managers' relative performance compared to their peers, supervisors use the branch managers' past performance differently in the new targets. Bol et al. (2010) show that supervisors use their discretion and set relatively lower targets for store managers operating in uncertain environments or store managers with higher social status. Anderson et al. (2010) find that store managers with higher incentives for budgetary slack end up with lower targets than store managers without such incentives. While all these studies indicate that supervisors use their discretion to adjust targets for subordinates, they do not explain to what extent supervisors use their discretion differently depending on their own background.

Before I discuss the theory and hypotheses in detail, I highlight two key features of my study. First, I examine a setting where the supervisor sets a target for the employee who works under a budget based contract. The contract involves a target for which the supervisor has discretion about the level, and that this level affects both the supervisor and subordinate. ${ }^{2}$ Thus, the supervisor aims to set a target that motivates the employee in the best way, but at the same time makes sure that the employee does not give up as the target is too difficult to achieve. Second, to examine the potential distortions of targets coming from task experience, I create a stylized setting where the task experience on the employees' task does not increase the understanding of the task itself. As such, I abstract away from practice where the task experience might increase the understanding of the task and reduce information asymmetry about the task challenges. However, the aim of this study is to show that over and on top of such effects, supervisors' task experience can also distort their use of relevant information when setting performance targets for their employees.

\subsubsection{Hypotheses Development}

Although I refer to a situation where own performance does not provide additional insights about the expected performance of the employees, I argue that own performance influences the targets that supervisors set for their employees. According to projection theories individuals tend to ascribe their own characteristics on other people (Kawada et al. 2004). Projections are processes "by which persons attribute personality traits, characteristics, or motivations to other persons as a function of their own personality traits, characteristics, or motivations" (Holmes 1978, p. 677). For example, if individuals have limited or ambiguous information about the behavior and traits of others, studies have shown that they often presume that others share the same beliefs as they do (Sherman et al. 1984), follow the same goal orientation as they themselves do (Kawada et al. 2004; Oettingen et al. 2014), and assume that others will behave like them in cooperation games (Krueger 2008). Furthermore, despite having no additional information about another individual, Alicke et al. (1995) show that the relatively stable tendency to feel "better-than-the-average" decreases when

\footnotetext{
${ }^{2}$ Even though Fisher et al. (2000) show that negotiated budgets are usually set lower than unilaterially set budgets by the supervisor, the theory I develop in this study would likely also apply to participatively set targets. As supervisors with experience emphasize their own experience and discount relevant other information, these superiors also would not dissolve their priors because of the information they receive from their employees. Hence, while it might influence the magnitude of the differences, the general tendency of my predictions would remain unchanged in a participative budgeting setting.
} 
individuals compare themselves to another real person instead of a group average (including traits such as intelligence, resourceful, dependable). This also suggests that by making a comparison against another individual, people project their own characteristics on others. As such, supervisors who have task experience could also project their own characteristics (i.e., ability) and behavior on that task on others. This would mean that they expect their employees to achieve a performance level that is rather similar to what they themselves achieved, and hence, incorporate their own performance into the targets they set for their employees.

However, based on a self-serving attribution bias, I argue that the projection of their own performance on others depends on the relative performance level that supervisors achieved on the employees' task. According to attribution theory individuals attribute the outcome of an event to internal (ability and effort) and external sources (task difficulty and luck) (Weiner 1985). That said, research also shows that they do not do these attributions in a consistent manner, but that the attributions change with the level of the outcome. If individuals' performance is good, they tend to attribute it relatively more to internal sources. If individuals' performance is bad, they attribute it more to external sources. This effect is commonly referred to as self-serving attribution bias (Libby and Rennekamp 2012; Mezulis et al. 2004).

Consistent with this self-serving attribution bias, I expect that supervisors with task experience who achieved a good performance explain their good performance mainly with internal sources. As individuals tend to project their own characteristics (i.e., ability) on others, these supervisors will suspect that others were not spending the maximum effort possible if they receive information that indicates relatively low performance of others. ${ }^{3}$ Consequently, they discount the historical information of others and emphasize their own performance that they achieved on that task. This means that they expect their employees to match their own, higher standards, which translates into high targets that might even decrease employees motivation. ${ }^{4}$ In contrast, supervisors with experience on the employees' task but low performance attribute their outcome to external factors such as task difficulty or having bad luck. Therefore, their own performance seems to be less reliable for forming expectations about employees' future performance and they mainly rely on the collection of historical task performances they receive about others. This means that low performing supervisors with experience will set relatively lower targets than high performance supervisors with task experience.

\footnotetext{
${ }^{3}$ Be aware that the suspicion about the lack of effort is particularly strong with easy tasks where ability differences are limited. However, even if ability differences get larger, projection theory would still argue that individuals engage in projecting own characteristics (i.e., ability) on others.

${ }^{4}$ While I examine a setting where superiors set targets for their employees once, in multi-period relationships superiors could learn about their employees characteristics and behavior over time. However, even in such situations the extent to which supervisors incorporate the information from their employees would depend on their own task experience. As such, supervisors with task experience and high performance would not trust that their employees spend the maximum effort if they report lower performance, but still stress their own higher performance. Thus, even though this effect might decrease over time, I would not expect that it disappears completely.
} 
Supervisors without task experience could also engage in such self-serving attributions. However, the experiences they made on different tasks do not allow them to draw inferences about the expected performance on the task they supervise now. For example, Bandura (1986) argues that the experiences of an individual on one task create very task specific feelings of mastery. While some beliefs about own abilities could describe abilities in multiple aspects of life, the extent to which these perceptions are transferred across tasks depends on the overlap of the skills required to master these tasks. Consistent with this notion, Woodruff and Cashman (1993) show that self-efficacy scales that are specific to certain areas are not well suited to describe the performance on a different task dimension. Similarly, Lent et al. (1997) show that the perceived self-efficacy on mathematical algebra tasks does not simply transfer to more general perceptions of academic success and vice-versa. Furthermore, individuals often tend to feel above the average on relatively simple tasks; however, they perceive themselves as below the average on more difficult tasks (Moore 2007). Thus, as the nature of the task changes and the associated skills differ, own perceptions about ability and relative task performance are not directly transferred across tasks. As such, supervisors without task experience will not interpret the historical task performance information in light of their own relative performance. Thus, they do not discount the importance of this information but they fully rely on this information, irrespective of their performance on a different task. In fact, as all of them base their targets solely on the historical performance information of others - similar to low performing supervisors with task experience - the targets set by supervisors without task experience will be at the same level as the targets set by the low performing supervisors with task experience.

Therefore, I predict that supervisors with task experience who performed well set higher targets than low performing supervisors with task experience, and supervisors without task experience. Formally, I test the following hypothesis:

H1: Supervisors with experience and high performance on the employees' task set higher targets than supervisors with experience and low performance, and supervisors without experience.

Furthermore, I also examine how supervisors' task experience on the employees' task affects the extent to which supervisors incorporate information about environmental changes in the targets. As the operating environment of employees changes, this can impact the task productivity of employees. Consequently, with the same level of effort, the output will be different. To account for this change in the expected performance, supervisors need to adjust ${ }^{5}$ the targets that they set for their employees accordingly.

I argue that the extent to which supervisors incorporate new environmental information is affected by their own prior performance on the employees' task. As the selfserving attribution bias suggests that low performing supervisors with task experience

\footnotetext{
${ }^{5}$ I use the term adjust targets to reflect the difference in the targets that superiors would set if the operating environment stays the same versus when the operating environment changes. Thus, in contrast to an ongoing stream of accounting literature examining ex-post goal adjustments (e.g., Kelly et al. 2014; Arnold and Artz 2015), I examine the incorporation of new environmental information in the targets that are set at the beginning of the period.
} 
attribute their failure mainly to external factors they concede the environment a high impact in explaining the performance, while internal factors play only a minor role. This means that any change in the operating environment would also have a relatively strong impact on the expected performance. To account for such a large change in the expected performance, supervisors will also change the targets to a larger extent. In contrast, supervisors who achieved high performance on the employees' task, concede the operating environment a smaller stake in explaining their own good performance and consequently any change also has a smaller impact. Thus, I expect that supervisors with task experience and low performance change targets to a larger extent than supervisors with task experience and high performance.

Supervisors without task experience have not had any exposure to the external influences on the task they supervise now. Thus, similar to the reasoning in hypothesis 1 , their experiences on a different task do not provide them with additional insights about the expected change in the performance on the employees' task as the operating environment changes. Especially as the tasks are in a different domain and require a different skills set, superiors are aware that their experiences on a different task cannot help them in updating the expectations about the employees' task. Consequently, the performance that supervisors achieved on another task they did before will not influence the way they react to changes in the operating environment of their employees later.

This leads to my second hypothesis where I expect that low performing supervisors with task experience react stronger to changes in the operating environment than high performing supervisors with task experience, whereas I do not expect that own performance matters when it was on a different task. ${ }^{6}$

H2: While supervisors with experience and low performance on the employees' task incorporate information about future environmental changes to a larger extent in targets than supervisors with experience and high performance, there is no such difference between high and low performing supervisors if it was on a different task (i.e., without task experience).

\subsection{Method}

I recruit 144 students from a large European University to participate in my experiment, which lasts for about 50 minutes. Participants receive on average 15.2 EUR for their participation. 68 percent of the participants are female and the average age of participants is 21.1 years. With the exception of the paper-based instructions (Appendix A), participants complete the experiment using a z-Tree computer program (Fischbacher 2007). The experiment consists of two separate parts and a post-experimental questionnaire. In the first

\footnotetext{
${ }^{6}$ In the development and testing of the hypothesis I do not distinguish between environments that get more or less challenging. While it might be that overall supervisors are more likely to adjust target upwards than downwards, the theory I develop is about the interactive effect of task experience and task performance on the incorporation of new information. This interaction would not be affected by the direction of the change. In the results section I provide some additional analyses that further justify this rationale.
} 
part, participants get acquainted with the tasks and I introduce my manipulations. In the second part, participants perform the actual experiment that I use for testing the predictions. Figure 3 summarizes the exact procedure as laid out in the following sections.

\subsubsection{Part I -Experimental tasks and Manipulations}

Of the 144 participants, 72 play the role of a principal (labeled Player A in the instructions), the other 72 will work as an agent (Player B). They keep their role throughout the entire experiment. Between participants, I manipulate the experience that principals gain on the agents' task. Therefore, all agents and half of the principals work on a simple counting zeros task during part I, while the other half of the principals works on an unrelated memory task during the same time.

\section{Time-line of the experiment}

\begin{tabular}{|c|c|c|}
\hline $\begin{array}{l}\text { Part I (learning the task and } \\
\text { experimental manipulation): } \\
\text { 1. Random assignment to treatments } \\
\text { 2. Paper based instructions for part I } \\
\text { (including the between-participants } \\
\text { task experience manipulation) } \\
\text { 3. Random assignment of role as } \\
\text { principal or agent }{ }^{1 .} \\
\text { 4. Understanding quiz } \\
\text { 5. } 8 \text { minutes to work on Counting Zeros } \\
\text { or Memory Task } \\
\text { 6. Performance feedback (including the } \\
\text { relative performance manipulation } \\
\text { for principals }{ }^{4} \text { ) }\end{array}$ & $\begin{array}{l}\text { Part II (main part of experiment incl. } \\
\text { the target choices): } \\
\text { 1. Paper based instructions } \\
\text { 2. Understanding quiz } \\
\text { 3. Principals receive target setting } \\
\text { information and have to set targets } \\
\text { for the three different scenarios } \\
\text { 4. Randomly determined which } \\
\text { scenario is played out by agent } \\
\text { 5. Agents work for } 8 \text { minutes on } \\
\text { counting zeros task } \\
\text { 6. Principals and agents learn the } \\
\text { compensation for that part }\end{array}$ & $\begin{array}{l}\text { 1. Post-experimental questionnaire } \\
\text { (including the manipulation } \\
\text { check for the relative } \\
\text { performance }{ }^{5} \text { and the } \\
\text { understanding of different task } \\
\text { productivities }{ }^{6} \text { ) } \\
\text { 2. Payment of participants }\end{array}$ \\
\hline \multicolumn{3}{|l|}{ 1. Labelled as Player A or $\mathrm{B}$} \\
\hline \multicolumn{3}{|c|}{$\begin{array}{l}\text { 2. In case a participant provides a wrong answer to a question, a message explaining the right solution pops up and the participant has to solve } \\
\text { the question again. Once all questions are answered correctly, the participant can proceed. }\end{array}$} \\
\hline \\
\hline \multicolumn{3}{|l|}{ 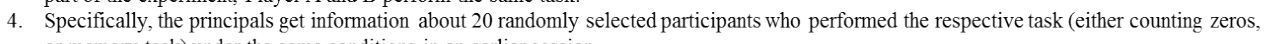 } \\
\hline \multicolumn{3}{|c|}{$\begin{array}{l}\text { 5. The exact question is as follows: How satisfied were you with your performance on that task? }(1-\text { Not at all, } 7-\text { Very much). The mean } \\
\text { response of the participants above (below) the mean is } 5.7(3.3) \text {. The difference is statistically significant (p-value }<0.01 \text {, t-value }=8.42)\end{array}$} \\
\hline \multicolumn{3}{|c|}{$\begin{array}{l}\text { 6. The exact question is as follows: The higher the probability of an easy task, the more tables you can solve in a given time period. }(1- \\
\text { Strongly disagree, } 7-\text { Strongly agree). The average response of the principals is } 6.13(\mathrm{SD}=1.21) \text {, which is statistically different from } 4 \text {, the } \\
\text { theoretical midpoint of the scale (p-value }<0.01 \text {, t-value }=14.9) \text {. Furthermore, there is no statistically significant difference among the } \\
\text { experimental groups. }\end{array}$} \\
\hline
\end{tabular}

Figure 3: Procedure and Time-Line of Experiment

The counting zeros task, which is performed by all agents and half of the principals, is adapted from Abeler et al. (2011) where participants have to count the number of times a zero shows up in tables consisting of zeros and ones. The tables consist either of 2 rows with 10 columns (easy), or 4 rows with 10 columns (difficult tables). There is a 50 percent probability that the next table to solve will be an easy one. One table solved counts as one unit of output, irrespective of the difficulty level. Per correct table participants receive 0.1 EUR. Participants have 8 minutes to solve as many tables as possible. This task fulfills several requirements to 
powerfully test my theory. It is an easy task where performing the task does not increase the understanding of the task and ability differences play a limited role. Furthermore, participants solve multiple problems instead of one big problem, which allows setting clear quantitative targets. Finally, while the task difficulty is determined by the probability of an easy task, there is still random noise included as it is not clear whether a specific agent was exposed to exactly 50 percent easy tables, or more or less.

The other half of the principals works on an unrelated memory task. There, they read a short text about plastics for 5 minutes, and then have 3 minutes to answer 12 multiple choice questions about the text. For every correct answer they receive 0.50 EUR. This task requires different skills and is rather insensitive to effort. Thus, performing this task does not allow drawing conclusions about the potential performance on the counting zeros task. Furthermore, the text about plastics included many historical facts about the discoveries in plastics, the major persons and firms contributing, and names of chemicals. These are facts that the typical participant of experiments in that laboratory (consisting mainly of business and economics students) is neither familiar with, nor is this task overly exciting relative to the counting zeros task. ${ }^{7}$ By letting these participants work on a task, instead of just letting them do nothing, I keep the treatments as constant as possible (e.g., time in the laboratory, exhaustion, expected compensation) and can also test the interactive effect of task experience and relative performance.

For the second independent variable, I measure and inform the principals about the relative performance they achieved during this first part. Specifically, for the treatments with task experience (Counting Zeros Task treatment), I compare the principals' performance on the counting zeros task with the mean performance of the 20 randomly selected participants from a pre-test. ${ }^{8,9}$ These participants also performed the Counting Zeros task for 8 minutes with a 50 percent probability of an easy task and a piece rate of 0.10 EUR per correct table. The mean performance of these 20 participants was 47.6 tables (median $=46.5$, $\min =31$, $\max =79, \mathrm{sd}=12.7)$. Similarly, for the Memory Task treatments, I compare the principals' performance on the memory task with the mean performance of 20 randomly selected participants from the pre-test. The mean performance of the 20 random participants on the Memory task was 6.7 correct answers (median $=6, \min =5, \max =11, \mathrm{sd}=1.6$ ). I classify those principals that perform above the mean on the respective task as high performers, and those below the mean as low performers. To inform the principals about their own relative performance, I provide them with the performance information of the 20 randomly selected

\footnotetext{
${ }^{7}$ In fact, there is no significant difference in the principals' task interest during part I between the counting zeros group $($ mean $=3.97, \mathrm{sd}=0.32)$ and the memory task group $($ mean $=3.90, \mathrm{sd}=0.22, \mathrm{p}$-value $>0.5$, $\mathrm{t}$-value $=$ $0.178)$.

${ }^{8}$ In total 56 individuals participated in the pre-test. 44 participants worked on the counting zeros task with a mean performance of 48.2 tables solved $(\mathrm{sd}=10.2) .34$ participants worked on the memory task with a mean performance of 6.4 correct answers $(\mathrm{sd}=1.54) .22$ participants worked on both the counting zeros and the memory task. The correlation between their performance on the counting zeros and the memory task was 0.365 , $\mathrm{p}$-value $=0.094$.

9 The results are qualitatively similar when I compare the principals' performance to the median instead of the mean performance. However, given that in the post-experimental questionnaire many participants indicated that they compared it to the mean, I focus on the mean comparison in the main analysis.
} 
participants on the respective task. The information they receive about them is the group mean, median, minimum, maximum, and standard deviation.

This leads to a 2 (task experience) x 2 (relative task performance) full factorial design with four different groups, (1) Memory low, (2) Memory high, (3) Counting zeros low, and (4) Counting zeros high, with 22, 14, 12, and 24 participants, respectively. The number of participants varies across treatments as I measure the principals' relative performance compared to the 20 random participants from the pre-test instead of ranking the actual performance (or manipulating it ex-post). However, by comparing it to the random participants from the pre-test, I can increase the salience of their own relative performance while at the same time I hold the information that principals receive about the performance of others constant across all experimental sessions. ${ }^{10}$ Importantly, testing for random assignment shows that there is no significant difference among the four groups with respect to the gender, age, year of study, type of study, or risk preference.

\subsubsection{Part II - Principals' target setting decision}

In the second part (main part) of the experiment, agents work under a budget linear contract again for 8 minutes on the counting zeros task, while the principals' task is to set a performance target for their agents. The agents receive a fixed wage of 3 EUR plus a piece rate of 0.1 EUR for every unit beyond the target. In case the agent does not achieve the output target set by the principal, he is left with the 3 EUR fixed salary. Formally the agents' (Comp Agent) compensation is defined as follows: ${ }^{11}$

$$
\begin{aligned}
& \text { if Output } \geq \text { Target } \rightarrow \text { Comp Agent }=3 \text { EUR fixed salary }+(\text { Output }- \text { Target }) * 0.10 \text { EUR } \\
& \text { if Output }<\text { Target } \rightarrow \text { Comp Agent }=3 \text { EUR fixed salary }
\end{aligned}
$$

The principal's compensation (Comp Principal) consists of a piece rate of the agent's output minus the compensation she has to pay to the agent. Additionally, the principal also gets a 3 EUR base wage to cover the agent's fixed wage (assuring that there is no loss possible):

$$
\begin{aligned}
\text { Comp Principal } & =3 \text { EUR base wage }+ \text { Revenue }- \text { Comp Agent } \\
& =3 \text { EUR base wage }+(0.20 \text { EUR } * \text { Output })-\text { Comp Agent }
\end{aligned}
$$

\footnotetext{
${ }^{10}$ The experiment was conducted in 7 experimental sessions. Including the experimental session as covariate is neither significant, nor does it change any of the inferences of the main analyses.

${ }^{11}$ As the participants work on a real-effort task, I do not impose universal costs of effort, as they might differ among agents. I thus do not formally derive an optimal target. However, as in expectation the agents and their associated costs of effort are randomly distributed across principals and treatments, the costs of effort cannot explain any treatment effect. Consequently, instead of a formal optimal target, the responses of the group without task experience serve as benchmark for the targets that principals set without the potential distortions coming from own task experience.
} 
The principals' task is to set the performance targets for the agents. ${ }^{12}$ To elicit the target level that principals set for their agents and the extent to which they incorporate new environmental information, I use a strategy method where each principal has to set targets for three different scenarios. In the base setting, the agents again have a 50 percent probability of an easy task (similar to the probability in part I). In the other scenarios the task difficulty either decreases ( 70 percent probability of an easy task), or increases ( 30 percent probability of an easy task). Each principal has to set targets for all three scenarios, but only one randomly selected will be to be played out by the agent. ${ }^{13}$ Appendix A gives an example of the screen as it appears to principals.

To assure that all principals have the same relevant information about the expected performance of their agents, all principals receive performance information on the Counting Zeros task of the 20 random participants from the pre-test. The information that the principals receive about this group is the mean, median, minimum, maximum performance and standard deviation. In addition, principals with task experience also receive detailed information about their own performance during part I, including the total number of tables solved, and the number of easy and difficult tables. The other half of the principals (i.e., those without task experience) receive detailed information about one randomly selected individual (out of the 20) on the counting zeros task, to rule out that principals anchor on the pure number instead of using their own performance. Furthermore, it increases the awareness of the fact that the task consist of easy and difficult tables and the potential impact that could come from the different probabilities in the three scenarios.

\subsubsection{Dependent measure}

To examine the first hypothesis - how supervisors' own task experience and performance influence the target levels that they set for their employees - I measure the Target that principals set for their agents in the base setting (i.e., a 50 percent probability of an easy target). To examine the second hypothesis - how principals' incorporate new environment information - I measure the mean difference between the base setting, and the targets that the principals set for the other scenarios (Change). Specifically, I use the mean of the downward changes (ChangeDown $=$ Target for 50 percent probability - Target for 30 percent probability) and upward changes (Change $U p=$ Target for 70 percent probability Target for 50 percent probability).

\subsection{Results}

\subsubsection{Hypothesis 1}

In the first hypothesis, I predict that supervisors with experience and high performance on the employees' task will set higher performance targets for their employees than supervisors with experience and low performance, and supervisors without task

\footnotetext{
${ }^{12}$ To assure that all participants have a good understanding of the payoff structure, all participants have to answer a series of questions where they calculate the compensation for principals and agents for various scenarios. In case they provide a wrong answer, they have to do the payoff calculation again until they solve all of them correctly.

${ }^{13}$ As the input for the different scenarios is on the same screen, the ordering of the different scenario inputs is randomized to prevent any ordering effects.
} 
experience. To test this hypothesis, I examine the targets that principals set for their agents in the base setting (50 percent probability of easy task). Table 1 shows the descriptive statistics for the Target choice of the principals by experimental condition. Figure 4 gives a graphical depiction of the mean Target that the principals set for their agents by experimental condition. Consistent with my prediction, in the Memory Low, the Memory High and the Counting Zeros Low group, principals set the target at 45.0, 44.6, and 44.5, respectively, while the average target that participants set in the Counting Zeros High group is 50.1 .

Table 1: Target for base setting (50 percent probability of easy target)

\begin{tabular}{|c|c|c|c|c|}
\hline \multicolumn{5}{|c|}{ Panel A: Mean and Standard Deviation of Target choice } \\
\hline \multirow{5}{*}{ Memory Task } & & \multicolumn{2}{|c|}{ Performance Part I } & \multirow[b]{2}{*}{ Total } \\
\hline & & Low & High & \\
\hline & Mean & 45.0 & 44.6 & 44.9 \\
\hline & $\mathrm{SD}$ & 14.3 & 7.8 & 12.0 \\
\hline & $\mathrm{n}$ & 22 & 14 & 36 \\
\hline \multirow[t]{3}{*}{ Counting Zeros } & Mean & 44.5 & 50.1 & 48.2 \\
\hline & SD & 3.8 & 16.0 & 13.4 \\
\hline & $\mathrm{n}$ & 12 & 24 & 36 \\
\hline \multirow[t]{3}{*}{ Total } & Mean & 44.8 & 48.1 & 46.5 \\
\hline & $\mathrm{SD}$ & 11.6 & 13.7 & 12.8 \\
\hline & $\mathrm{n}$ & 34 & 38 & 72 \\
\hline \multicolumn{5}{|c|}{ Panel B: ANOVA model for target with a $50 \%$ probability } \\
\hline Source & $d f$ & Mean Square & $F$ & $p$-value \\
\hline Model & 4 & 427.972854 & 2.9 & 0.0282 \\
\hline TaskExperience & 1 & 271.865587 & 1.84 & 0.1792 \\
\hline AbMeanPerformance & 1 & 202.351072 & 1.37 & 0.2457 \\
\hline $\begin{array}{l}\text { TaskExperience* } \\
\text { AbMeanPerformance }\end{array}$ & 1 & 212.381129 & 1.44 & 0.2345 \\
\hline Risk Preference & 1 & 1258.06404 & 8.53 & 0.0048 \\
\hline Residual & 67 & 147.551994 & & \\
\hline Total & 71 & 163.350352 & & \\
\hline
\end{tabular}

Panel C: Assigned contrasts Memory Low/Memory High/Counting Low/Counting High: -1/-1/-1/3

\begin{tabular}{lccc}
\hline Source & $d f$ & $F$ & $p$-value \\
\hline Contrast & 1 & 5.64 & 0.0205 \\
Error & 67 & & \\
\hline
\end{tabular}

Target $=$ Target assigned for a $50 \%$ probability of an easy task

TaskExperience $=1$ if principal worked on counting zeros task, 0 for memory task (no task experience)

AbMeanPerformance $=1$ if own performance in pre task was higher than mean, 0 otherwise

Risk Preference $=$ response to answer: How do you see yourself: are you generally a person who is fully 
prepared to take risks or do you try to avoid taking risks? 1 (not at all willing to take risk) - 7 (very willing to take risk)

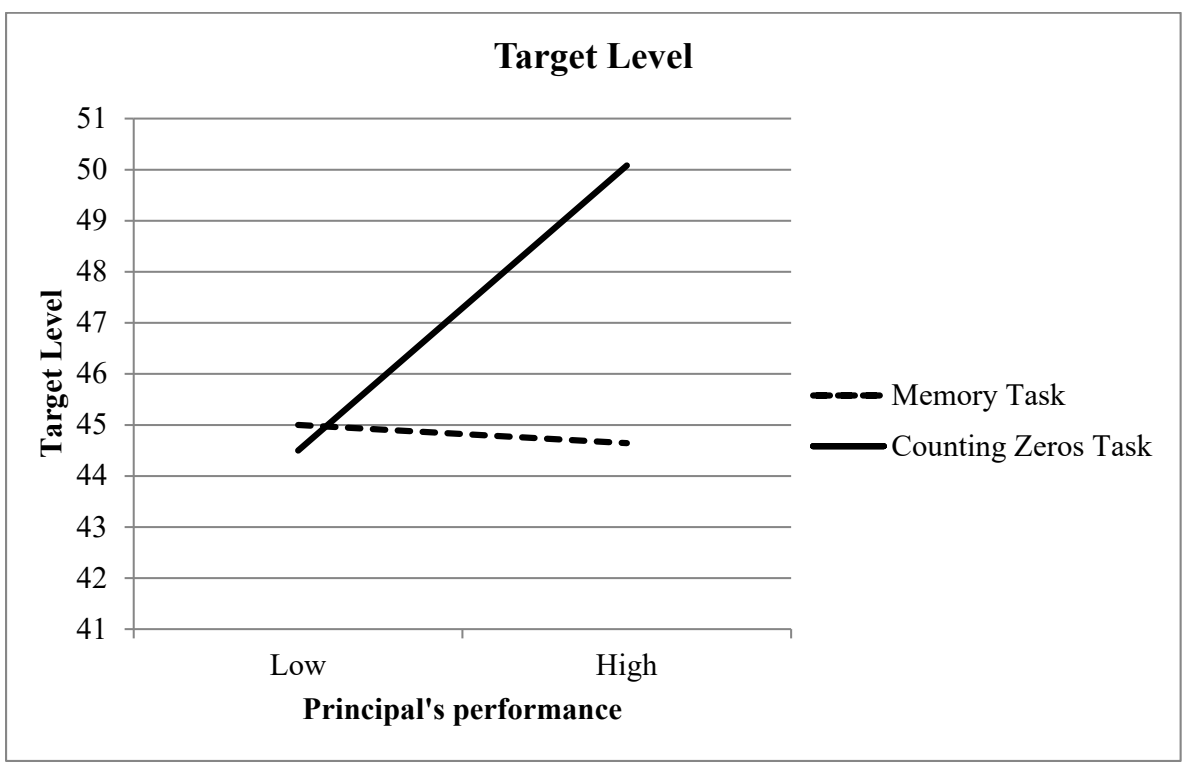

Figure 4: Target level for base setting (50 percent probability of easy tasks)

To formally test my hypothesis I perform an ANOVA with planned contrasts. ${ }^{14}$ Buckless and Ravenscroft (1990) show that contrast coding is suited for testing ordinal interactions as it increases the power of the test, while keeping the Type I error constant. Therefore, consistent with my hypothesis, I attach the values of $-1,-1,-1$, and 3 to the experimental conditions Memory Low, Memory High, Counting Zeros Low, and Counting Zeros High, respectively.

I also include the risk preference of principals as a covariate to increase the efficiency of the analysis. Given the setup of the experiment, some principals might overestimate the risk of agents giving up as a reaction to too challenging targets, and as a result incorporate additional slack in the targets. ${ }^{15}$ That said, while I do not expect that risk preferences influence the targets differently across treatments, I expect it increases the within treatment variances. To elicit the participants risk preference I include the following question in the post-experimental questionnaire,

\footnotetext{
${ }^{14}$ The inferences do not change when I compare the target level of the counting zeros high group with the average target from the counting zeros low, and memory task groups using a Wilcoxon-Mann-Whitney test (one-tailed p-value $<0.01$ ), after controlling for the participants' risk preferences.

${ }^{15}$ In practice, other management control mechanisms - in the extreme case even quitting an employee - would be available for the supervisor to prevent subordinates from not working at all.
} 
How do you see yourself: are you generally a person who is fully prepared to take risks or do you try to avoid taking risks? 1 (not at all willing to take risk) - 7 (very willing to take risk)

This measure is based on Dohmen et al. (2011) where they show that it predicts individuals' risky behavior in a lottery experiment affecting their payouts. Furthermore, it provides a reliable predictor of risk taking in various different domains of life, such as health issues, career choices, and financial matters (Dohmen et al. 2011). In my experiment, the principals' average response to this question is 4.4. There is no significant difference among the four experimental conditions ( $\mathrm{p}$-value $>0.2$ ). ${ }^{16}$

Table 1, Panel B shows the results of the two-way ANOVA, indicating that the principal's risk preference indeed has a significant impact on the Target that principals set ( $\mathrm{p}$ value < 0.01). ${ }^{17}$ Table 1 , Panel $\mathrm{C}$ shows the results of the ANOVA contrast for testing hypothesis 1 . The results show that the pattern of the Target that principals set for their agents is consistent with my prediction $\left(\mathrm{F}_{1,67}=5.64\right.$, p-value $\left.=0.02\right)$. Furthermore, to test whether there are differences in the targets of the Memory Low, Memory High and Counting Zeros Low group, I run an ANOVA with Target as dependent variable and the remaining three treatments as independent variable and the risk preference as covariate. The untabulated ANOVA shows that there is no significant difference between the treatments $\left(\mathrm{F}_{2,44}=0.01\right.$, $\mathrm{p}$ value $>0.9)$, while there is again a significant effect of the covariate risk preference $\left(\mathrm{F}_{1,44}=\right.$ 7.05 , p-value $<0.05$ ). Together, these results support Hypothesis 1 that supervisors with task experience and high performance set higher targets for their employees than supervisors with task experience and low performance, and supervisors without same task experience. ${ }^{18}$

\subsubsection{Hypothesis 2}

Hypothesis 2 predicts that supervisors with experience and low performance on the employees' task incorporate environmental information more than supervisors with experience and high performance, while there is no such difference between low and high performing supervisors if it was on a different task (i.e., without task experience). To examine the incorporation of new environmental information, I measure the mean differences in the targets (Change) that principals set for agents if the task difficulty stays at a 50 percent probability of an easy task, compared to the settings with a lower (70 percent) or higher (30 percent) task difficulty. Table 2, Panel A shows the descriptive statistics of the Change variable. Figure 5 shows the graphical illustration of the means. Consistent with my hypothesis, principals in the Counting Zeros Low group change their targets by 12.5 units, while principals in the Counting Zeros High group change targets only by 8.9 units. In the Memory Low and Memory High group, principals change their targets by 7.7 and 9.3 units.

\footnotetext{
${ }^{16}$ Mean responses per group: Memory Low $=4.7$, Memory High $=4.6$, Counting Zeros Low $=4.4$, Counting Zeros High $=4$.0. Furthermore, when I include interaction variables for risk preference and the treatment variables in the main analysis, none of the interaction variables with risk preference is statistically significant.

${ }^{17}$ An untabulated regression shows that the coefficient of risk preference is positive. This indicates that, in line with the expectation, the more willing principals are to take risk, the higher the targets they set for their employees.

${ }^{18}$ Without including the Risk Preference covariate to the ANOVA contrast analysis, the planned contrast has a p-value of $0.10\left(\mathrm{~F}_{1,68}=2.75\right)$.
} 
Table 2: Incorporation of New Environmental Information

\begin{tabular}{|c|c|c|c|c|}
\hline \multicolumn{5}{|c|}{ Panel A: Mean and Standard Deviation of Change } \\
\hline & & \multicolumn{2}{|c|}{ Performance Part I } & \multirow[b]{2}{*}{ Total } \\
\hline & & Low & High & \\
\hline \multirow[t]{3}{*}{ Memory Task } & Mean & 7.7 & 9.3 & 8.3 \\
\hline & Mean in $\%$ of Target 1 & $17 \%$ & $21 \%$ & $18 \%$ \\
\hline & SD & 7.2 & 4.8 & 6.4 \\
\hline \multirow[t]{3}{*}{ Counting Zeros } & Mean & 12.5 & 8.9 & 10.1 \\
\hline & Mean in $\%$ of Target 1 & $28 \%$ & $19 \%$ & $22 \%$ \\
\hline & SD & 6.4 & 7.7 & 7.4 \\
\hline \multirow[t]{3}{*}{ Total } & Mean & 9.4 & 9.0 & 9.2 \\
\hline & Mean in $\%$ of Target1 & $21 \%$ & $20 \%$ & $20 \%$ \\
\hline & $\mathrm{SD}$ & 7.2 & 6.7 & 6.9 \\
\hline
\end{tabular}

Panel B: ANOVA model for Change

\begin{tabular}{lcccc}
\hline Source & $d f$ & Mean Square & $F$ & $p$-value \\
\hline Model & 4 & 74.008 & 1.6 & 0.186 \\
TaskExperience & 1 & 118.320 & 2.55 & 0.115 \\
AbMeanPerformance & 1 & 9.326 & 0.2 & 0.655 \\
$\begin{array}{l}\text { TaskExperience* } \\
\text { AbMeanPerformance }\end{array}$ & 1 & 98.084 & 2.11 & 0.076 \\
Risk Preference & 1 & 109.006 & 2.35 & $\begin{array}{c}\text { (one-tailed) } \\
\text { Residual }\end{array}$ \\
& 67 & 46.378 & & \\
\hline Total & & & & \\
\hline
\end{tabular}

Panel C: Simple main effects analysis

\begin{tabular}{lcc}
\hline Source & $F$ & $p$-value \\
\hline $\begin{array}{l}\text { Effect of AbMeanPerformance } \\
\text { at Memory task }\end{array}$ & .52 & .469 \\
$\begin{array}{l}\text { Effect of AbMeanPerformance } \\
\text { at Counting Zeros Task }\end{array}$ & 1.74 & $\begin{array}{c}.094 \\
\text { (one-tailed) }\end{array}$ \\
\hline
\end{tabular}

Change $=($ ChangeDown + ChangeUp $) / 2$

ChangeDown $=$ Target $50 \%$ probability of easy target - Target $30 \%$ probability of easy target ChangeUp $=$ Target $70 \%$ probability of easy target - Target $50 \%$ probability of easy target

TaskExperience $=1$ if principal worked on counting zeros task, 0 for memory task (no task experience)

AbMeanPerformance $=1$ if own performance in pre task was higher than mean, 0 otherwise 


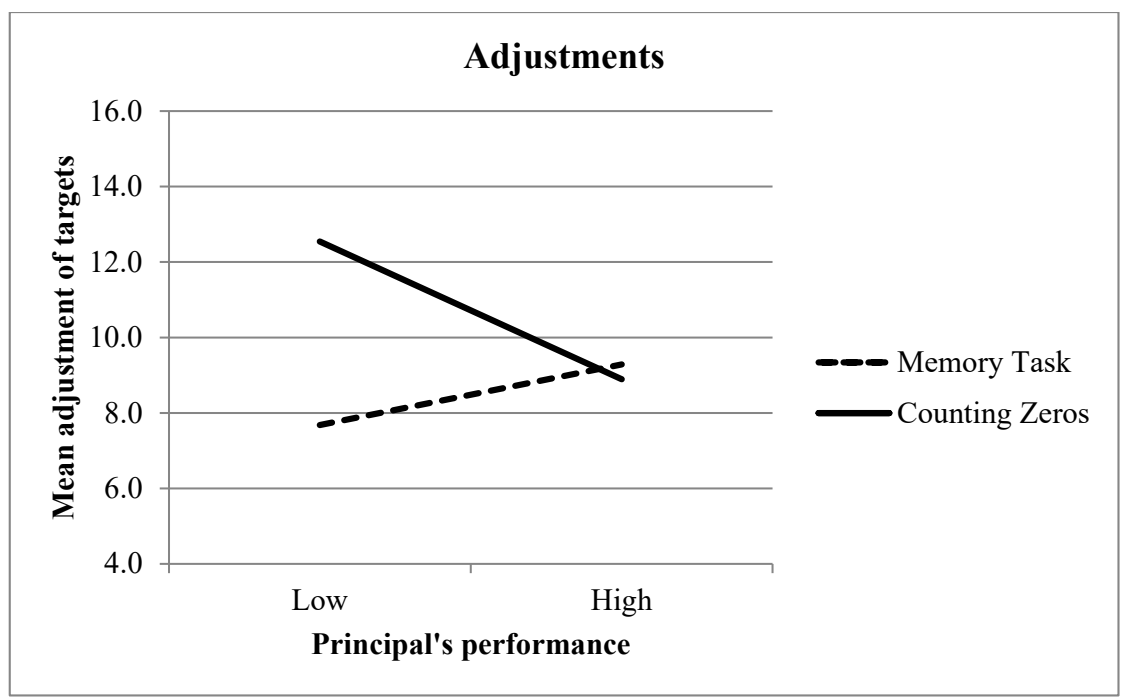

Figure 5: Change of targets for task difficulty changes

To test my prediction, I use an ANOVA and simple main effect analysis. Specifically I run an ANOVA with the Change as dependent variable and the TaskExperience and relative performance during stage one (AbMeanPerformance) as independent variables. I also include the principals' risk preference as covariate (Risk Preference). The results are shown in Table 2, Panel B. As predicted, the interaction of TaskExperience $x$ AbMeanPerformance is statistically significant $\left(\mathrm{F}_{1,67}=2.11\right.$, one-tailed p-value $\left.=0.076\right)$. To analyze the interaction in more detail, I perform a simple main effects analysis of AbMeanPerformance at different levels of TaskExperience. The results in Table 2, Panel $\mathrm{C}$ show that there is no significant effect of AbMeanPerformance for the Memory Task treatment ( $\mathrm{p}$-value $=0.469$ ), while there is a significant effect of AbMeanPerformance for the Counting Zeros Task (one-tailed pvalue $=0.094$ ). These findings support hypothesis 2 , which indicates that low performing supervisors with task experience incorporate environmental information to a larger extent than high performing supervisors with task experience, while own performance does not influence the incorporation of new information when it was achieved on a different task (i.e., without task experience). ${ }^{19}$

Furthermore, to examine whether low performing supervisors are overly sensitive to changes in the environment or high performing supervisors do not incorporate them enough, I perform two follow up analyses. First, I compare the Change of the targets from the two groups with experience with the Change of the principals without experience. As the principals without experience where not exposed to the environment in the counting zeros

\footnotetext{
${ }^{19}$ Without including the Risk Preference covariate to the ANOVA the results show a similar pattern. Again, the simple main effect of AbMeanPerformance for the memory task is not significantly different ( $\mathrm{p}$-value $=0.495)$, while for the counting zeros task the effect is statistically significant (one-tailed p-value $=0.067$ ). Furthermore, when I include RiskPreference and interact this variable with the treatment variables, neither the main effect of RiskPreference nor any of the interactions with RiskPreference is significant.
} 
task themselves, their response serves as benchmark. The results show that there is no statistically significant difference between the changes of the targets of the high performing principals with experience $($ mean $=8.9, \mathrm{sd}=1.57)$ and the groups without experience (mean $=8.31, \mathrm{sd}=1.06, \mathrm{p}$-value $>0.7, \mathrm{t}$-value $=0.32$ ). In contrast, the low performing supervisors with experience $($ mean $=12.54$, sd $=1.84)$ change their targets significantly more than the groups without experience $(\mathrm{p}$-value $=0.05, \mathrm{t}$-value $=1.99)$. Second, I compare the mean changes of the targets with the expected changes in performance based on the 20 random participants from the pre-test. Therefore, I compute the seconds that it takes these participants to solve easy or difficult tables and calculate the expected performance for the three different scenarios. Based on this calculation, the expected change in performance is 7.45 tables. When I compare this expected change to the means from the Memory low, Memory high, or Counting Zeros high groups, there is no statistically significant difference (all p-values > 0.17). However, when I compare the mean from the Counting Zeros low group to this expected performance change, the two tailed $\mathrm{p}$-value is 0.02 ( $\mathrm{t}$-value $=2.76$ ). These analyses indicate that low performing supervisors with task experience are inclined to react overly sensitive to changes in the operating environment, while there is no difference between the high performing supervisors with experience and the control group without experience or the expected change in performance based on the pre-test.

\subsubsection{Hypothesis 2 - Supplemental analyses}

The argument in Hypothesis 2 is that low performing supervisors attribute their own failure to external factors rather than internal factors and hence changes in the environment should have a stronger impact on their target changes. As this theory does not differentiate between changes that increase or decrease the task difficulty, I pool the upward and downward changes together by taking their mean. To support this choice also empirically, I perform two supplemental analyses.

First, I compare the upward changes of the targets (mean $=9.7$, sd $=8.3)$ with the downward changes (mean $=8.7, \mathrm{sd}=6.8$ ), overall. A t-test shows that this difference is not statistically significant $(\mathrm{p}$-value $=0.161$, t-value $=1.42)$. Second, I also test whether the difference between the high and low performing principals on the counting zeros task changes with the direction of the change. An untabulated regression shows that there is neither a significant main effect of the direction of the change, nor the interaction of the direction of the change and the relative task performance is statistically significant. Together, these findings suggest that the direction of the change does not affect the changes of the targets.

\subsubsection{Follow-up Analysis: Agents behavior}

While the focus of the paper is on the supervisors' behavior, the supervisors' task experience might also affect the employees' behavior. For instance, knowing that supervisors have worked on the task themselves can increase their perceived legitimacy and increase motivation. At the same time, employees might perceive higher targets as even more unfair, as these supervisors "should have known better". Therefore, in this section I examine how principals' task experience affects agents' effort. 
As the actual task difficulty scenario played by the agents is randomly determined, I cannot compare the absolute performance (number of tables solved) directly, but need to transform the variable first. Therefore, I create an indicator variable (AbMedianPerf) that is one if the agent performed above the median performance in a given scenario, or zero if the agent performed below the median. ${ }^{20}$ Furthermore, to divide the analysis by agents receiving a relatively high or low target, I create the variable AbMedianTarget that is one if the target was above the median target for that scenario, and zero if it was below. Table 3 shows the descriptive statistics of the percentage of participants above the median performance per treatment and relative target level. Figure 6 provides the graphical depiction.

Table 3: Agents' performance

\begin{tabular}{lcccc}
\hline \multicolumn{5}{l}{ Panel A: Percent of agents that performed above the median } \\
\hline \multicolumn{4}{c}{ AbMedianTarget } \\
& Low & High & Total \\
\hline Memory Task & Above the median & $46.2 \%$ & $60.9 \%$ & $55.6 \%$ \\
& $\mathrm{n}$ & 13 & 23 & 36 \\
Counting Zeros & Above the median & $56.3 \%$ & $40.0 \%$ & $47.2 \%$ \\
& $\mathrm{n}$ & 16 & 20 & 36 \\
Total & Above the median & $51.7 \%$ & $51.2 \%$ & $51.4 \%$ \\
& $\mathrm{n}$ & 29 & 43 & 72 \\
\hline
\end{tabular}

Panel B: Regression results agents behavior

\begin{tabular}{|c|c|c|}
\hline & $\underline{\text { AbMedianPerf }}$ & $\underline{\text { AbMedianPerf }}$ \\
\hline \multirow[t]{2}{*}{ TaskExperience } & 0.218 & $0.393 * *$ \\
\hline & $(0.158)$ & $(0.160)$ \\
\hline \multirow[t]{2}{*}{ AbMedianTarget } & 0.130 & 0.148 \\
\hline & $(0.146)$ & $(0.138)$ \\
\hline \multirow{2}{*}{$\begin{array}{l}\text { TaskExperience * } \\
\text { AbMedianTarget }\end{array}$} & -0.242 & $-0.380^{*}$ \\
\hline & $(0.203)$ & $(0.204)$ \\
\hline \multirow[t]{2}{*}{ PreTaskCorrect } & $0.027 * * *$ & $0.028 * * *$ \\
\hline & $(0.005)$ & $(0.005)$ \\
\hline \multirow[t]{2}{*}{ _cons } & $-1.047 * * *$ & $-1.078^{* * *}$ \\
\hline & $(0.291)$ & $(0.285)$ \\
\hline$R^{2}$ & 0.34 & 0.43 \\
\hline$N$ & 72 & 60 \\
\hline
\end{tabular}

$* p<0.1 ; * * p<0.05 ; * * * p<0.01$, two-tailed

Standard Errors in parentheses

AbMedianPerf $=1$ if number of tables solved is at or above the median performance in the scenario played, 0 if it is below

TaskExperience $=1$ if principal worked on counting zeros task, 0 for memory task (no task experience)

\footnotetext{
${ }^{20}$ The inferences do not change when I run the analyses on the absolute performance of the agents and include dummy variables for the different scenarios.
} 
AbMedianTarget $=1$ if target that is played by agent is above the median in that scenario, 0 if it is below the median PreTaskCorrect $=$ Number of tables solved correctly during part I

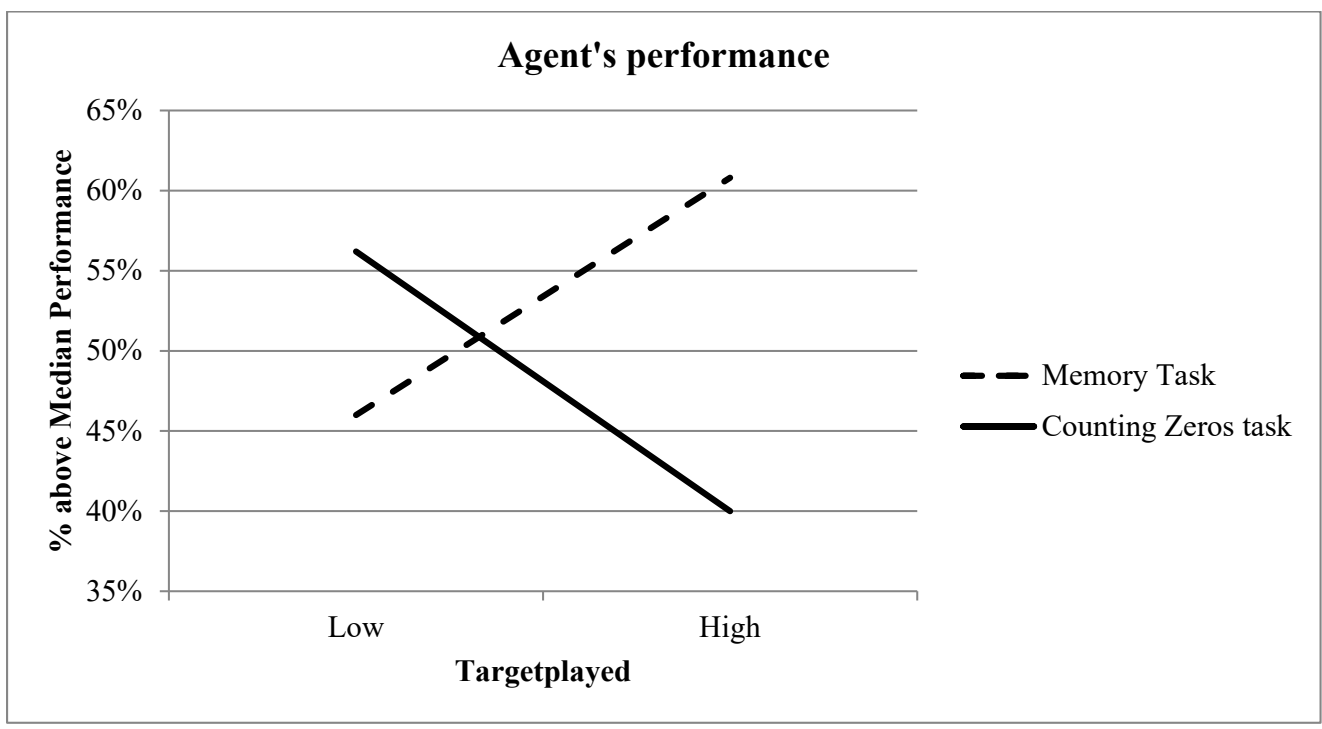

Figure 6: Agent's performance

To statistically analyze the results, I run an OLS regression ${ }^{21}$ with the AbMedianPerf as dependent variable, and the TaskExperience (1 if the principal worked on the counting zeros task, 0 if the principal worked on the memory task), the AbMedianTarget, and an interaction of the TaskExperience $x$ AbMedianTarget as independent variables. I further include a control variable for the task performance of the agent during part one of the experiment (PartICorrect), since testing for random assignment showed that agents in the Counting Zeros Task treatment performed significantly lower than agents in the Memory Task treatment (50.4 vs. 56.2, p-value $=0.023$, t-value $=2.33)$.

Table 3, Panel B, Column 1 shows the results of the regression. The results show that there is no statistically significant effect of the TaskExperience (coef. 0.218, p-value $=0.172$ ) or the interaction term of the TaskExperience $x$ AbMedianTarget (coef. -0.242 , p-value $=$ 0.238 ), indicating that there is no effect of the principal's task experience on the overall performance of the agents.

However, in this analysis there are 12 (out of 72) participants that solve just 15 or less tables during the main stage of the experiment. Given that this is not even half of the minimum that has been solved by the 20 random participants, and the fact that none of these 12 agents solves any table during the last 60 seconds of the game, these agents could be classified as giving up (Giveup). In practice, supervisors would have other management control mechanisms to prevent employees from giving up (up to the extreme case where these

${ }^{21}$ The inferences do not change when I use a logistic regression instead of an OLS regression. 
employees get fired). Therefore, I run the same regression as before and exclude these 12 participants from the analysis. As can be seen in the results in Table 3, Panel B, Column 2, while the AbMedianTarget has no statistically significant effect (coef. 0.148 , p-value $=0.288$ ) on the performance, the TaskExperience (coef. 0.393, p-value $=0.017$ ) and the interaction of TaskExperience $x$ AbMedianTarget (coef. $-0.380, \mathrm{p}$-value $=0.068$ ) are statistically significant. However, the sum of TaskExperience and the interaction of TaskExperience $x$ AbMedianTarget is not statistically significant from zero. This indicates that while supervisors' task experience can positively affect subordinates' performance for relatively low targets, for higher targets there is no significant difference between the Counting Zeros and the Memory Task treatment.

Interestingly, out of the 12 agents that were classified as giving up, 9 agents are from the Counting Zeros Task treatment (5 from low performing principals, 4 from high performing supervisors), while only 3 agents are from the Memory Task treatment (all three from low performing superiors). Performing a t-test shows that the likelihood of giving up is higher in the Counting Zeros Task treatment than in the Memory Task treatment (mean 0.250 vs. 0.083 , $\mathrm{p}$-value $=0.059$, $\mathrm{t}$-value $=1.91$ ).

To conclude, while principals' task experience positively affects the agents' effort when the targets are relatively low, it also seems that agents' are more likely to react negatively to targets that they perceive as unfair. However, given the small sample size, combined with the endogenous target choices of the principals (and the associated loss of control in the experiment), the results just serve as initial exploratory step of the agents' behavior.

\subsection{Conclusions}

I examine how supervisors' own task experience on the task they supervise affects the target level that they set for their subordinates and the incorporation of new information as the operating environment changes. I report the results of a laboratory experiment where principals set targets for agents working on a task where they have to count zeros in tables. To set appropriate targets, all principals receive the same signals about the expected performance of employees on that task. I manipulate between participants the experience that principals have on the task as half of the principals work on the counting zeros task before they set the targets for their agents, while the other half of the principals works on an unrelated memory task.

Consistent with my predictions, the results show that principals with experience on the employees' task discount relevant information and overemphasize their own experiences. As a consequence, superiors who performed above the mean on the counting zeros task set higher targets for their agents than principals who performed below the mean on the same task, and principals who worked on the memory task (irrespective of their performance). Furthermore, below average performing supervisors on the counting zeros task react overly sensitive to changes in the operating environment and change the targets more as the 
environment changes than above average supervisors on the counting zeros task. In contrast, there is no significant difference in the target changes in the memory task groups. Examining also the agents response to the targets set by the principals, follow-up analyses suggest that agents' behavior is affected by the task experience of the principals too. Specifically, the results indicate that agents who get engaged in a task (i.e., those who do not give up immediately) show higher performance when their principal worked on the counting zeros task and set a low goal, than if their principal worked on the memory task. However, the likelihood that employees give up is also higher in the groups where principals have task experience, compared to the groups without task experience of the principal.

The findings of this study have important implications for theory and practice. While prior research mainly examines how factors associated with the subordinate (i.e., status, operating environment) affect the targets they receive, I examine how individual supervisors use their discretion differently when setting targets for their employees. Thereby, I show that the own experience of supervisors on the employees task influences and potentially distorts their target setting decisions. Specifically, my study implies that depending on the performance they achieved on the employees' task, superiors overemphasize their own experience and discount other relevant information about employees' future performance potential. This not only influences the general level of the targets that they set, but also the way how they incorporate information about potential changes in the operating environment. Given the importance of target setting for the motivation of employees and the fast changing business environments we observe in today's economy, it is important for companies to know how their supervisors set targets and react to changes in the environment. Thus, these findings can help companies in increasing the effectiveness of their target setting and budgeting practices.

Moreover, this study also has implications for companies that consider implementing policies to increase supervisors' task experiences at various levels and areas within the company, such as job rotation, long-term training programs, or internal-hiring rules. While these policies increase the understanding of the company and the business model, they also can influence the expectations that supervisors develop about others. Thus, one potential side effect could be that supervisors draw biased inferences from their own performance during their work in the different areas, influencing their future expectations. Increasing the awareness of such potential side effects can help companies to cope with these effects and better analyze the costs and benefits of such policies.

This study also has limitations that provide avenues for future research. The experimental setup uses a real-effort task where participants count zeros in tables or work on a memory task. As counting zeros is a very simple task, ability differences play a limited role. Hence, performance differences could be mainly explained by differences in effort and random noise, which could influence the level of projections and self-serving attributions. Furthermore, the skills required to solve the counting zeros problems and the memory tasks differ widely. In practice, different tasks might have a stronger overlap as such that skills on one task can also be informative about other tasks. While these design choices allow me to 
best test the theory developed, future research could verify the findings of my study using different settings.

Besides, in my experiment supervisors gain experience on the employees' task, where they then set targets immediately afterwards. As supervisors would perform the task for multiple rounds and/or if there is a longer time span between the task experience and the target setting process, this might also impact the effect size of task experience and own performance on the target setting decisions of the supervisor. Although I would not expect that the effect would vanish entirely over time, the level might be different. Additionally, similar to previous experiments in budgeting and target setting (Fisher et al. 2002; Fisher et al. 2006), the participants in my experiment are graduate- and undergraduate students with limited experience in target setting. Even though self-serving attributions and projections occur across various populations and contexts (e.g., Mezulis et al. 2004; Robbins and Krueger 2005), a potential concern could be that experience with performance targets would decrease the extent to which supervisors' own high performance leads to higher targets for their employees. To address this concern, I examine in additional analyses whether the variation in the work experience of my participants or their stage of study affects the target levels they set. The untabulated results show that neither the number of month worked in practice, nor if they are graduate or undergraduate students affects the target levels they set or the relation between own task experience with high performance and the target level they set. This gives some indication that their experience with performance targets has no effect. However, future research can provide further evidence that the findings of this study also hold for more experienced managers.

Finally, the focus of the study is on the supervisors' behavior. In the follow-up analyses I start examining the effect that supervisors' task experience has on employees' behavior. It seems that supervisors' experience affects the employees' motivation, but also the willingness to give up. Future research can focus on the employees' behavior and identify the determinants of their decision to give up as well as examining the motivational aspects in more depth. 

Chapter 3: The Influence of Target Ratcheting on Employees' Investment Behavior 


\begin{abstract}
$^{22}$
In this study we examine how target ratcheting affects employees' tradeoff between shortterm output and long-term investments. We hypothesize that while using past performance information in setting new targets (i.e. target ratcheting) decreases individuals' short-term output, it increases investments in future productivity improvements by mitigating the negative consequences of the horizon problem. We test our prediction in a multi-period experiment, where we manipulate in a nested between subjects design the target setting procedure and within subjects the individuals' time horizon. The results support our hypotheses that as individuals' time horizon decreases, the exogenously determined target groups lower their investment and put more attention to the short-term output task, while participants in the target ratcheting condition keep their initial strategy and invest relatively more in future productivity improvements. Therefore, this study provides a plausible explanation for the widespread use of an alleged dysfunctional practice, i.e., target ratcheting, and helps to reconcile seemingly disparate findings of prior literature.
\end{abstract}

22 This chapter is based on a working paper together with Alexander Brüggen and Frank Moers. 


\section{Introduction}

In this study we investigate the impact of target ratcheting on employees' trade-off between short-term output and long-term investments. Target ratcheting has received increased attention from academics in recent years. While past performance should be incorporated in performance standards if it is informative about agents' future performance potential, this creates a dynamic trade-off for employees between current rewards and future losses due to higher target levels (Weitzman 1980; Murphy 2001). In response, employees withhold current performance to avoid higher targets in the next period, which is often referred to as the ratchet effect (Indjejikian and Nanda 1999; Indjejikian et al. 2014b). Recently, research has started to examine factors that mitigate such potential problems in organizations (e.g., Aranda et al. 2014; Bol and Lill 2015; Charness et al. 2011). We take a different approach and test one potential benefit from target ratcheting, which is that it is supposed to increase long-term investments (Leone and Rock 2002). Thereby, we develop and test theory suggesting that in a multi-task environment where employees are responsible for both shortterm output and long-term investments, target ratcheting increases long-term investments by reducing the negative effect of employees' horizon problems.

Although prior literature in target ratcheting mainly focuses on single task settings, employees are often responsible for both maximizing short-term output and long-term investments that influence the productivity in the future. By giving employees the possibilities to conduct long-term investments, companies can capitalize on the employees' superior knowledge about the existing work practices in place and generate ideas that set the ground for future success (e.g. improving existing processes, performing R\&D tasks, or acquiring new customer groups) (Nonaka 1991). That said, due to information asymmetries, principals cannot always anticipate the right investment choice for agents. Moreover, the investments might be unobservable and its outcomes are highly uncertain. Therefore, companies often refuse to include these investments in explicit performance contracts but include slack resources in the budget based contracts, which employees should use in the best way for the company (Merchant and Manzoni 1989). Under such contracts, employees need to trade-off the costs of investing now (including potentially foregone bonus payments) with the uncertain future benefits from the investment. In situations where managers' time horizon is long, there is enough time to enjoy the benefits of such an investment. However, if the managers' time horizon is short, there is less time to reap the benefits of an investment and consequently, they often tend to focus on maximizing short-term output at the expense of long-term success of the firm (Dechow and Sloan 1991). Therefore, budget based contracts focusing on short-term financial performance are often alleged to cause myopic behavior of employees (Bebchuk and Stole 1993).

However, in this paper we argue that applying target ratcheting in a budget based compensation scheme can mitigate such horizon problems and thus, can lead to higher longterm investments compared to target setting schemes where targets are solely based on exogenous factors. Therefore, we investigate how individuals who are confronted with a budget-linear compensation contract where the targets are either adjusted based on prior performance information (i.e., target ratcheting) or where the firm commits to ignore such 
information, allocate their effort between a productive task leading to short-term benefits and an investment task leading to uncertain future benefits.

According to theoretical models, employees working under a target ratcheting scheme reduce their effort once they reach their performance target, whereas employees where the firm commits to ignore past performance information when setting new targets are more likely to outperform targets. However, most if not all of these models focus on the short-term output dimension of individuals and do not consider potential long-term investment effects. We predict that due to the horizon problem, employees working under targets that are not related to past performance are more likely to focus on the short-term output and reduce their investments in future productivity improvements relatively early. In contrast, when companies apply a target ratcheting scheme, employees have an incentive to invest until the last period of their employment relation as they can reap all the benefits of their investment in the last period. Thus, by mitigating the horizon problem, employees in the target ratcheting condition will invest more in future productivity improvements than in the exogenously determined target condition.

We investigate our predictions in a multi-period experiment, where participants can allocate time between two different tasks. The first task is the productive task that influences current performance and the second task is the investment task that influences their future productivity with uncertainty. The compensation is based on a budget-linear compensation plan that pays a bonus when the performance target on the productive task is achieved. In a nested between-subjects design, we manipulate the periodic target setting procedure in three ways. Participants in one experimental condition get a full asymmetric target ratcheting system where prior performance directly influences the future goals. In conditions two and three, the targets are determined exogenously, independent of past performance. In particular, while in condition two the targets remain the same during all periods, in condition three the targets increase over time, without any relation to past performance of the individual.

The results of our experiment show that initially there are only minor differences in the behavior of participants between the three conditions. However, as the time horizon gets shorter, participants in the exogenously determined conditions focus more on the short-term output task and reduce their investments in future productivity improvements. In contrast, in the target ratcheting condition, participants do not reduce their investments but keep it at the high initial level even as the time horizon gets shorter. This supports our hypothesis that target ratcheting mitigates the negative effects of the horizon problem and thus leads to higher levels of investment.

We contribute to the academic literature and managerial practice in several ways. First, despite the well-known negative effects of target ratcheting on employees short-term effort, most firms base their targets on past performance (Murphy 2001; Jensen 2001). This indicates that either the negative consequences of the ratchet effect are small or that there are other benefits coming from target ratcheting systems. Recently research has started to examine factors that mitigate such potential problems (e.g., Aranda et al. 2014; Bol and Lill 2015; Charness et al. 2011), but they do not examine the potential benefits that could arise 
from target ratcheting. We test one of the suggested benefit, which is that target ratcheting provides an incentive for long-term investments (Leone and Rock 2002; Kim and Shin 2016). Studies using archival data face inherent challenges of separating the effects of target ratcheting resulting from accounting conservatism, target ratcheting to induce investments, or reverse causality where firms with higher growth opportunities also update targets more upwards. Examining the effect of target ratcheting on the investment behavior in a controlled laboratory allows to isolate the effects and establish such a causal link. Thus, we take the target setting scheme as exogenous and investigate under which circumstances target ratcheting leads to increased long-term investments and when it does not. As firms can choose different ways of setting targets and budgets in practice, showing the effect that these systems have on employees' behavior can help academics and practitioners in studying and designing budgeting and target setting systems.

Second, this study helps to reconcile potentially conflicting evidence of target ratcheting that has been documented in prior literature. On the one hand, anecdotes and studies based on single company data suggest that companies ratchet up targets as a result of good past performance (Leone and Rock 2002; Bouwens and Kroos 2011; Holthausen et al. 1995). On the other hand, studies find that there is a positive serial correlation in the achievement of targets, indicating that there is a commitment that targets are not fully ratcheted up (Indjejikian and Nanda 2002; Indjejikian et al. 2014a). Consistent with this, a recent working paper by Mahlendorf et al. (2015) finds that even if nominal targets ratchet, the target difficulty might not increase. We show that the target ratcheting mechanism induces investments that improve the productivity of the resources in place, and therefore, provide a plausible explanation for these seemingly inconsistent findings in prior literature. Specifically, as the increased investments resulting from target ratcheting improve their own productivity, the target difficulty stays the same (or even decreases) even though targets ratchet up. Consequently, managers still have the same chance of achieving the target as before, despite a higher target level.

Third, whereas prior literature in target ratcheting has mainly focused on effortmaximizing incentives on the short-term output dimension of jobs (Bouwens and Kroos 2011; Chow et al. 1991), we examine how target ratcheting affects the long-term investment decisions of individuals. Leone and Rock (2002) argue that in a situation where actions for transitory and permanent earnings increases are equally costly, target ratcheting systems fosters permanent earnings increases. We extend their study and show that in situations where managers long-term investments require upfront investments - that raise concerns of employees' horizon problems and myopic behavior - , target ratcheting can actually reduce such problems and keep investments at high levels. Given that companies are subject to potential horizon problems and myopic behavior of employees in many circumstances, showing how target setting processes can mitigate such problems inherent in finite employment relationships has important implications for firms and future research.

Finally, our study has also implications for continuous improvement processes of organizations. While managers often rely on innovation and process improvements brought up by their employees, it is not always desirable to prescribe these efforts to employees or 
explicitly incentivize them (Tate 2012; Webb et al. 2013; Sprinkle and Williamson 2004). In this study, we show that target ratcheting can provide an alternative concept to induce continuous improvements in such situations besides establishing explicit mechanisms like for example gainsharing programs.

The paper proceeds as follows. In the next section we lay out the setting of our study and develop our hypotheses. In section three we describe our experiment. In the fourth section we present our results. Finally, section five concludes the paper and discusses the implications.

\subsection{Theory and Hypotheses development}

In recent years target setting has received a lot of attention in the management accounting literature and related fields. Murphy (2001, p. 247) states that "performance standards arise from the desire to provide incentives while simultaneously paying competitive expected levels of compensation." By introducing performance targets firms can provide a higher payperformance-sensitivity while still meeting reservation wages of the employees (Murphy 2001). Thus, performance targets allow paying competitive pay levels and incentivizing high performance at the same time.

There are a number of ways to set targets. Besides negotiated targets, Merchant and Van der Stede (2007) mention quantitative models and basing targets on historical performance as a method for setting performance standards. This is also in line with Fisher et al. (2006), who highlight that budgeting cannot be viewed as a static one-time event, but is a dynamic process recurring periodically, and Murphy (2001), who shows that most companies use internal performance targets that either are based directly on past performance or heavily rely on it.

However, using past performance information when setting new targets causes a dynamic incentive problem where agents trade-off current bonus payments and increased future targets. As a response, agents withhold effort once they achieved their output targets to avoid higher targets (Weitzman 1980). Indjejikian and Nanda (1999) show that this ex ante inefficiency of target ratcheting comes from a missing commitment of firms to ignore past performance information when setting new performance targets. If firms would commit to disregard information gathered from past performance of individuals, agents would not withhold effort but would show maximum performance in all periods. In this paper we argue that the advantage of using past performance information in setting new targets, i.e., ratcheting, is that it mitigates the negative consequences of the horizon problem and thus leads to higher investment in future productivity improvements.

\subsubsection{Setting}

Before we discuss our hypotheses in detail, we first describe the setting of our study. Consider an agent who is responsible for short-term output and conducting long-term 
investments that improve the efficiency of the resources in place in the future. ${ }^{23}$ Effort on both of these two tasks is unobservable, but the principal does observe the output $\left(y_{t}\right)$ on the short-term production task. This output is a function of the individual's ability, the effort spent on the productive task $\left(e_{t}\right)$, and the productivity of the resources in place in the current period $\left(p_{t}\right)$. In line with wide organizational practice (Murphy 2001), the agent's compensation is determined by a budget-linear contract depending on performance $y_{t}$ with the following form:

$$
\begin{aligned}
\text { if } & y_{t} \geq b_{t} \quad \text { then } & C_{t}=\left(y_{t}-b_{t}\right) * c+l \\
\text { if } & y_{t}<b_{t} \quad \text { then } & C_{t}=0
\end{aligned}
$$

where $b_{t}$ is the performance target. If the output exceeds the output target in a certain period $\left(y_{t} \geq b_{t}\right)$, then the agent gets the fraction $c$ of the excess units as well as a lump sum bonus payment $l$. However, if the agent does not achieve the output target, he does not get any compensation for that period. Given the nature of this budget-linear compensation contract, an agent has the incentive to reach the minimum threshold of the productive task in every period. ${ }^{24}$ However, once the target is achieved and there is still capacity left, the agent can decide how to allocate the extra capacity between increasing the short-term output or investing in future productivity improvements. By spending the capacity left on the productive task, the agent increases the short-term performance and hence, compensation in the current period. Investing the remaining capacity in future productivity improvements does not increase current compensation but stochastically increases the future productivity of the resources in place, which leads in expectation to higher performance in the future.

\subsubsection{Hypotheses}

Compensation plans that reward managers for short-term performance are often alleged to cause managers to overly focus on short-term projects instead of long-term investments (Bebchuk and Stole 1993). When making the decision about how to allocate effort between productive effort and investing in future productivity improvements, agents need to consider the costs and benefits of the investment. Once the performance target has been achieved, the cost for conducting the investments consists of two different parts. First, the costly effort that agents spend on the investment task $i_{t}$. Second, the lost short-term bonus payments from having less time for productive effort $e_{t}$. On the other hand, the benefit of an investment is a potential increase in the productivity that persists in all future periods (e.g. a company invents

\footnotetext{
${ }^{23}$ Our theory applies to any employee who has to decide between short-term output and long-term investment (e.g. a production worker who increases effort intensity or tries to improve the efficiency of the work processes, a sales agent who decides whether to sell additional products to the existing customer base or try to gain new customer groups, an administrative worker who takes additional training that make his further work more efficient).

${ }^{24}$ In line with findings from prior field studies (e.g., Merchant and Manzoni 1989; Bol et al. 2010) we assume the targets are set at relatively easy levels, assuring that employees with various ability levels can achieve them and still have discretion about how to allocate the excess capacity. That said, ability differences and the associated costs of effort could affect the level of excess capacity available to each individual. However, given our operationalization, where participants are randomly assigned across conditions in an experiment, ability differences might explain differences within the target setting schemes, but not across the schemes. Consequently, for simplicity, we leave out the costs of effort in our theory development.
} 
a new production technology that increases efficiency persistently). Agents benefit from such an increased productivity in such a way that, for a given level of effort on the productive task, the output will be higher and thus also expected compensation will be higher in future periods.

Consequently, when there are more periods left in a work relationship, there are more periods for an agent to enjoy the benefits of the investment. In contrast, as the time horizon of agents decreases, there are fewer periods to reap the benefits of an investment. In the extreme case, agents would only bear the costs of an investment but not receive any benefit from the investments. This represents a horizon problem, where agents reduce investments the closer they get to the end of a work relationship (Dechow and Sloan 1991). As long as the investment in productivity improvements is beneficial for agents they will invest. However, at some point in time the costs of the investment exceed the potential increase of the productivity factor and associated future benefits and as a result agents will invest less.

In exogenously determined target conditions the firm ex ante commits to ignore past performance information of individuals when setting new targets. As agents outperform their targets they get a bonus payment while their future targets are not affected by this high performance. This also means that, for the same level of high output, agents can get a bonus payment multiple times. Therefore, when agents decide about their investments they compare the short-term costs of the investment (effort $i_{t}+$ foregone bonus payment) with the sum of the increased bonus payments they get from the higher efficiency level of the resources in place in all future periods. Thus, agents with a longer time horizon are more inclined to use their excess resources to invest them in long-term productivity improvements. However, as the time horizon of the agent decreases, the sum of the future bonus payments gets smaller and investments get relatively less beneficial. As a consequence agents will focus on the short-term output dimension instead of the long-term investments as the time horizon decreases. Therefore, we predict that while the level of investments decreases, the effort spent on the productive task increases when the agent's time horizon gets shorter and the firm commits to not use past performance information in setting new targets.

In contrast, in a target ratcheting scheme the firm uses past performance information of individuals for setting new performance standards. As an agent outperforms his target in one period, his new target for the upcoming period increases. In fact, typically target ratcheting follows an asymmetric pattern, where outperforming the target in one period increases the future target to a larger extent than missing the target would decrease it (Bouwens and Kroos 2011; Leone and Rock 2002). This creates a dynamic incentive problem for agents between the benefits of a bonus payment in the current period and the higher target level in the future (Weitzman 1980). As agents anticipate this target ratcheting behavior, they have an incentive to withhold current output and follow a strategy where they exactly "meet but not beat" the performance targets (Anderson et al. 2010; Weitzman 1980; Indjejikian and Nanda 1999). Thereby, agents make sure that they receive a lump sum payment every period but do not increase the future targets. Prior empirical research has already shown this negative consequence of target ratcheting on the short-term output dimension (Chow et al. 
1991; Bouwens and Kroos 2011). In line with this research, we expect that target ratcheting contracts trigger a relatively constant effort level in the productive task that is lower than the maximum effort level, which they only spend in the last period of an employment relationship.

More importantly, we argue that in a target ratcheting setting where agents can spend effort on short-term output and long-term investments, the standard prediction of previous research tells only half the story. As outperforming the target in a target ratcheting contract decreases future expected bonus payments, agents' costs for making long-term investment are lower than in the exogenously determined target condition. However, a successful investment not only assures that agents could spend lower effort and still achieve their targets in all future periods, but also that the final period's bonus payment increases. Therefore, agents in a target ratcheting setting have an incentive to use their additional capacity and invest in future productivity improvements. However, in contrast to a contract that does not use past performance information in setting new targets, this effort allocation strategy is optimal in a target ratcheting scheme for all periods except the last period of an employment relationship. That is, even if there is only one more period left, agents maximize their wealth by exactly meeting their target and use the excess capacity to invest in future productivity improvements. This indicates that, except for the very last period of an employment relationship, the horizon problem does not influence agents' investment decisions and the investment level will stay relatively constant.

Comparing the predictions laid out above, we expect that, as long as agents are working in a long time horizon condition, they use their excess time for long-term investments irrespective of the target setting condition. However, as the time horizon gets shorter, agents in an exogenously determined target condition will lower their investments and focus on the short-term productive task. In contrast, agents in a target ratcheting condition will still follow their strategy to "meet but not beat" their target and invest the additional capacity in future productivity improvements, except for the last period. This leads to the following two hypotheses:

H1: As the time horizon decreases, target ratcheting leads to lower levels of effort on the short-term output tasks than a commitment to not use past performance information when setting new targets.

H2: As the time horizon decreases, target ratcheting leads to higher investment levels in long-term productivity improvements than a commitment to not use past performance information when setting new targets.

The economics-based prediction laid out above suggests that people in target ratcheting always "meet but not beat" their targets and invest all excess capacity in long-term productivity improvement. Following this prediction, the targets in this condition would stay the same in all periods and therefore are endogenously fixed. Hence, we compare the target ratcheting group to a contract where the company commits to not adjust the performance target but keep the target fixed at the initial level, which we refer to as exogenously fixed 
target. However, while economically optimal agents in the target ratcheting group would always "meet but not beat" their targets, other effects (e.g. time preferences, preferences for spreading outcomes) could potentially lead to over-achievements of targets in earlier periods. This automatically increases the target levels in a target ratcheting scheme, which means that a comparison of target ratcheting and exogenously fixed targets would not only differ with respect to the usage of past performance information in setting new targets, but also in the actual target level assigned. Therefore, we include another condition where the targets increase over time independent of past performance achievements of this group. We refer to this commitment condition as exogenously increasing target condition. Comparing target ratcheting to both of these exogenously determined target conditions allows to separate the effect of using past performance information in setting new targets from the potential byproduct of an asymmetric target ratcheting scheme, i.e., increasing target levels over time.

\subsection{Method}

We recruit 88 students from a large European University to participate in our experiment, which lasts approximately 90 minutes. Participants receive on average 17.28 EUR for their participation. 67 (21) of the participants are Bachelor (Master) students in Business or Economics. $51 \%$ of the participants are female and the average age of participants is 21.3 years. Testing for random assignment shows that there is no significant difference between our experimental groups with respect to gender, age, ability levels and enjoyment and interest of solving the two experimental tasks.

Except for the paper-based instructions and the exit questionnaire, the experiment is programmed and conducted with the software z-Tree (Fischbacher 2007). We manipulate the procedure for setting the performance target in a nested between subjects design in three ways (target ratcheting vs. exogenously fixed targets vs. exogenously increasing targets). Furthermore, as the experiment consists of six periods, time horizon is a within-subject manipulation. This results in a 3 (target setting procedure) x 6 (periods) experimental design.

\subsubsection{Experimental setup}

Similar to the theoretical setting explained before, participants can work individually on two different tasks in every period. The first task (hereafter the bonus task) is to solve two digit multiplications (e.g., Brüggen and Strobel 2007; Hannan et al. 2012). To determine the output $y_{t}$ in this bonus task, the number of multiplications $\left(m_{t}\right)$ solved correctly is multiplied with the productivity factor $\left(p_{t}\right)$ :

$$
y_{t}=m_{t} * p_{t}
$$

In case output $y_{t}$ is equal to or above the target level $b_{t}\left(y_{t} \geq b_{t}\right)$, participants receive a bonus payment for that period. In case $y_{t}$ is below the target level $\left(y_{t}<b_{t}\right)$, they do not receive any compensation for that period. More specifically, 


$$
\begin{array}{rlrl}
\text { if } & y_{t} \geq b_{t} \quad \text { then } & C_{t}=\left(y_{t}-b_{t}\right) * 0.05 \mathrm{EUR}+1.5 \mathrm{EUR} \\
\text { if } \quad y_{t}<b_{t} \quad \text { then } & C_{t}=0 \mathrm{EUR}
\end{array}
$$

The second task of the experiment (investment task) represents the investment of participants in future productivity improvements. In this task participants are counting zeros in tables with numbers (Abeler et al. 2011). Performance in this task does not influence current output $y_{t}$, but influences the expected future productivity parameter $p_{t+1}$. In the first period the productivity factor is set at 2.0 for all participants. However, from the second period onwards it is possible that the productivity factor increases with 0.4. By solving problems of the investment task, participants can increase their probability of getting an increase of their productivity factor. The experimental instructions (Appendix B) show the exact probabilities for the improvement of the productivity factor as a function of the tables submitted. For example, a participant who correctly counts zeros in five different tables has a probability of an increase in the productivity factor of $34 \%$. If $\mathrm{s} /$ he submits eight correct tables, the probability is $50 \%$. It is not possible to carry over tables solved correctly to the next period. If the participant receives an increase of the productivity factor, this higher level does not decrease again, but remains at the higher level for all periods left or can increase further. In six periods, this means that the maximum level of productivity factor that a participant can achieve is 4.0 .

Each of the six experimental periods lasts five minutes. Within these five minutes, participants can switch tasks any time and as often as they want by pressing a button on the computer screen. It is also possible to stay with the bonus task and not invest in future productivity improvements at all. Appendix B shows the screens that participants see during the bonus and investment task. While participants work on the bonus task, they immediately know their current output level $y_{t}$ and output target $b_{t}$. Thus, they always know their performance and whether they already achieved their output target. When participants click the button to switch tasks, a new screen with the investment task appears. On this screen participants can see how many tables they solved correctly. On both screens a timer is running, showing participants the time left for the current period, which period they are currently in, as well as the number of periods in total.

We choose these two real effort tasks to test our prediction for several reasons. Both tasks are relatively simple, effort sensitive, and there are no learning effects. In addition, there is a clear solution to all problems and spending effort on these tasks is costly to the participants. We acknowledge that in practice finding inefficiencies or coming up with creative ideas is often a mentally challenging task. However, the focus of this study is on the level of investment rather than the capability of finding the inefficiencies (e.g., some people might be more creative than others). A comparable situation in practice is a manager's decision to invest excess resources on $R \& D$. The manager does not perform the research activities himself but only decides to spend a certain amount of money and carries the costs. An experimental task that is sensitive to the participants' capabilities of finding inefficiencies would add extra complexity without improving our empirical analysis. Furthermore, counting zeros is an inherently uninteresting task which assures that people do not solve this task out 
of interest, but only because it increases their chances of getting a future productivity improvement.

\subsubsection{Manipulation}

We manipulate the target setting procedure in a nested between subjects design in three ways, as Panel A of Figure 7 shows. The initial target in the first period for all experimental treatments is 20. This target level is based on a pilot-experiment with a different set of students and is set in such a way that the average performer of our experiment can reach the target already in the first period. ${ }^{25}$ From the second period onwards the target develops differently in our three experimental treatments. (1) In the target ratcheting condition targets follow an asymmetric target ratcheting scheme. Thus, in case participants outperformed their target in the previous period, the new target increases to the actual performance level achieved. In case they missed the target, the target remains at the same level as it was before. (2) In the exogenously fixed target condition the target remains the same across all periods. Thus, irrespective of prior performance the target will always remain at 20 in this condition. (3) In the exogenously increasing target group, the targets increase over multiple periods without any relation to prior performance of the participants of this group. The target levels of this treatment are matched to the actual target levels of the target ratcheting condition. Therefore, we first run the target ratcheting treatment and take the median of the actual targets of the target ratcheting treatment for every period and impose them on the exogenously increasing target group. Thus, we make sure that in every period the median target level in target ratcheting and the exogenously increasing target conditions are the same. Importantly, we inform all participants of this group prior to the first period about all future targets and that they are based on the performance of a different set of participants. This control group allows us to separate the effect of using past performance information in setting new targets from the effect of increasing target levels over time, as discussed in the theory section. Panel B of Figure 7 shows the exact wording for all our manipulations. Additionally we also provide participants with an example explaining the particular target setting procedure.

\footnotetext{
${ }^{25}$ In a pretest with 52 participants (who did not participate in the actual experiment) the mean performance in solving multiplications was 11.7 correct solutions in a standardized 5 minutes period (standard deviation $=6.3$ ). Given that the initial productivity factor is 2.0 , we set the target at 20 .
} 


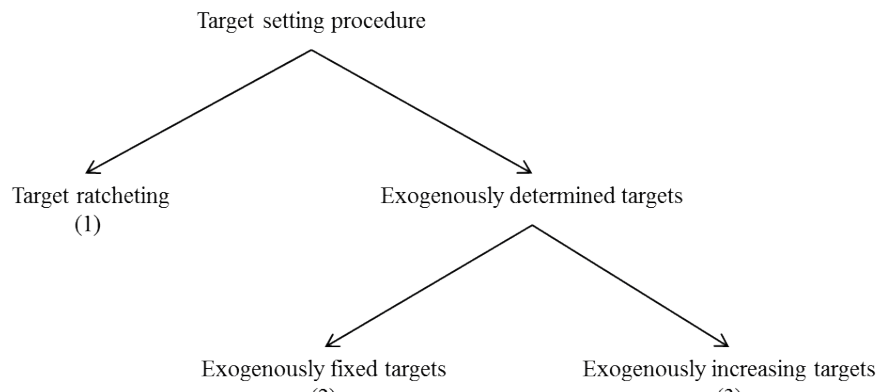

(2)

(3)

\section{Panel B: Experimental Manipulations}

(1) Target ratcheting:

Based on a pilot study among students, the initial output target (b) is 20 units. From the second period on the target will be determined each period based on your previous output. In case you exceeded the target in the previous period, the new target increases to the level of the output achieved. In case you missed the target, the target level is unchanged.

(2) Exogenously fixed targets:

Based on a pilot study among students, the initial output target (b) is 20 units. This target level will be the same for all periods.

(3) Exogenously increasing targets:

Based on a pilot study among students, the initial output target (b) is 20 units. Your output targets (b) for period 2 (20 units), period 3 (22 units), period 4 (24 units), period 5 (25.8 units) and period 6 (27.2 units) are also based on the performance of a different group of students who performed the same task.

Figure 7: Experimental design

The time horizon of the participants is the second manipulation of the experiment, which is manipulated within subjects. The experiment consists of six periods in total. Thus, over time, the number of periods left to benefit from the investment decreases and consequently the horizon problem increases. Participants are informed about the total number of periods in the experimental instructions and also the computer screen includes the current and total number of periods of the experiment. Therefore, during all stages participants know how many periods are left. ${ }^{26}$

\subsubsection{Dependent variables}

To test our hypotheses we use two main dependent variables. First, to get a proxy for the effort spent on the bonus task, we measure the number of correct multiplications solved in

\footnotetext{
${ }^{26}$ In practice there is often uncertainty with respect to the periods left. However, as long as there is the chance that the employee will be in place for at least one more period, none of our predictions would be affected by such uncertainty. Thus, we decided to keep all participants informed about the exact number of periods.
} 
task 1 (EffortT1). This measure of effort is used to test Hypothesis 1 . Second, to examine the investment behavior of participants and test Hypothesis 2, we measure the effort spent on the investment task by counting the number of tables submitted correctly (TabCount). This is the proxy for the investment in future productivity improvements.

\subsubsection{Procedure}

Each of the experimental sessions lasts around 90 minutes and consists of two parts. In the first part, participants get acquainted with the two experimental tasks of solving multiplications and counting zeros in tables. After entering the laboratory and being randomly assigned to the different treatments, all participants receive the same paper-based instructions for the first part of the experiment, which explains both tasks (Appendix B). Participants have five minutes practice time to solve multiplications, which is followed by five minutes in which they receive 0.2 EUR for every multiplication solved correctly. The performance during that time serves as a measure of ability for solving multiplications. After they finish the multiplications task they have three minutes to perform the second task, counting zeros in tables. Again, participants receive 0.2 EUR for every correct table submitted. To finish the first part of the experiment, participants have to answer a few questions about their interest and enjoyment of both tasks.

Once participants finish the first part of the experiment, they raise their hands and receive the instructions for the second part of the experiment (Appendix B), including the manipulation. In this part participants perform the main part of the experiment, which consists of the six experimental periods. Before they can start with the first experimental period, they have to answer a short entry quiz on the computer to check their understanding of the instructions and manipulations. If participants submit a wrong answer, a message pops up explaining them the relevant part of the instructions again and they have to answer the question again. Once participants answer all entry questions correctly they can move on to the main part of the experiment. After they finish the sixth period of the experiment, they get a short paper-based exit questionnaire. Finally, participants receive their compensation and can leave the laboratory.

\subsection{Results}

Table 4 shows the descriptive results of our experiment for 87 participants in our experimental treatments. ${ }^{27}$ Over the six periods participants solve on average 73.3 multiplications correctly in the bonus task and count 37.4 tables in the investment task. Whereas the average number of multiplications in the first period is 8.0, it increases to $17.2 \mathrm{in}$ the last period of the experiment. Conversely, the level of investment in the first period is

\footnotetext{
${ }^{27}$ In total 88 students participated in the experiment. We had to exclude one participant (exogenously fixed target condition) from the data analysis as this participant counted more than 20 tables in the investment task in multiple periods. This strategy does not make any sense (as the probability remains constant at 0.99 from 20 tables onwards) but can only be attributed to a lack of understanding of the experiment or an attempt to sabotage the experiment. In untabulated robustness tests we include this participant in the data analysis and our inferences do not change.
} 
about 9.6 counted tables and decreases to 4.9 in the fifth and 1.2 counted tables in the last period of the experiment.

\subsubsection{Hypothesis 1}

In Hypothesis 1 we predict that, as the time horizon decreases, target ratcheting leads to relatively lower levels of effort on the productive task than a commitment to not use prior performance information. The descriptive statistics (Table 4) and Figure 8 show that initially the difference in the number of multiplications is relatively low between the different groups. While the mean number of multiplications solved in the target ratcheting group in the first period is 7.4 multiplications, the mean is 8.3 and 8.4 in the exogenously fixed and exogenously increasing target conditions, respectively. Similar to the first period, the difference between the target ratcheting group and the exogenously determined target conditions remains at a relatively low level until the fifth period. In period five the difference between the target ratcheting and exogenously determined groups increases considerably. ${ }^{28}$ While participants in the exogenously determined target conditions solve around 16.5 and 15.0 multiplications, participants in the target ratcheting condition solve on average only 11.5 multiplications. In the last period, all groups have the incentive to allocate the maximum capacity on the productive task and as expected the difference between the groups decreases again.

\footnotetext{
${ }^{28}$ Be aware that our theory predicts that a short time horizon affects employees' behavior in the exogenously conditions, while it does not affect it when working under a target ratcheting condition. In the experimental design we manipulate the time horizon by letting all participants work for six periods. As we had no clear prediction as of when the short time horizon starts for the participants, we do not impose any arbitrary cutoff point to distinguish between long- and short time horizon but analyze the results per period. As the descriptive results show, the main difference in the behavior comes in the fifth period, where the horizon is the shortest. That said, when we impose a cut-off point for short/long time horizon and split the sample at periods 2,3 and 4 , the inferences from our analyses do not change.
} 
Table 4: Descriptive Statistics of Main Variables

\begin{tabular}{|c|c|c|c|c|c|c|c|}
\hline \multicolumn{8}{|c|}{ Period } \\
\hline EffortT1 & 1 & 2 & 3 & 4 & 5 & 6 & Total \\
\hline$T R$ & $\begin{array}{c}7.4 \\
(4.3)\end{array}$ & $\begin{array}{c}9.4 \\
(4.8)\end{array}$ & $\begin{array}{l}10.5 \\
(6.1)\end{array}$ & $\begin{array}{l}10.6 \\
(5.8)\end{array}$ & $\begin{array}{l}11.5 \\
(6.5)\end{array}$ & $\begin{array}{l}15.8 \\
(7.1)\end{array}$ & $\begin{array}{l}65.2 \\
(6.3)\end{array}$ \\
\hline$F T$ & $\begin{array}{c}8.3 \\
(5.7)\end{array}$ & $\begin{array}{l}10.9 \\
(6.3)\end{array}$ & $\begin{array}{l}12.9 \\
(6.7)\end{array}$ & $\begin{array}{l}12.0 \\
(5.8)\end{array}$ & $\begin{array}{l}16.5 \\
(8)\end{array}$ & $\begin{array}{l}19.5 \\
(6.1)\end{array}$ & $\begin{array}{l}80.1 \\
(7.4)\end{array}$ \\
\hline$I T$ & $\begin{array}{c}8.4 \\
(5.1)\end{array}$ & $\begin{array}{c}9.8 \\
(5.7)\end{array}$ & $\begin{array}{l}12.2 \\
(5.5)\end{array}$ & $\begin{array}{l}12.8 \\
(5.6)\end{array}$ & $\begin{array}{l}15.1 \\
(7.3)\end{array}$ & $\begin{array}{l}16.2 \\
(6.9)\end{array}$ & $\begin{array}{l}74.5 \\
\text { (6.6) }\end{array}$ \\
\hline Total & $\begin{array}{l}8.0 \\
(5)\end{array}$ & $\begin{array}{l}10.0 \\
(5.6)\end{array}$ & $\begin{array}{l}11.9 \\
(6.2)\end{array}$ & $\begin{array}{l}11.8 \\
(5.7) \\
\end{array}$ & $\begin{array}{l}14.3 \\
(7.5) \\
\end{array}$ & $\begin{array}{l}17.2 \\
(6.9) \\
\end{array}$ & $\begin{array}{r}73.3 \\
(6.8) \\
\end{array}$ \\
\hline TabCount & 1 & 2 & 3 & 4 & 5 & 6 & Total \\
\hline$T R$ & $\begin{array}{l}10.0 \\
(6.7)\end{array}$ & $\begin{array}{c}8.0 \\
(5.8)\end{array}$ & $\begin{array}{c}7.1 \\
(6.9)\end{array}$ & $\begin{array}{c}8.2 \\
(7.1)\end{array}$ & $\begin{array}{c}7.4 \\
(6.5)\end{array}$ & $\begin{array}{l}1.5 \\
(3)\end{array}$ & $\begin{array}{l}42.2 \\
(6.6)\end{array}$ \\
\hline$F T$ & $\begin{array}{l}11.0 \\
(7.8)\end{array}$ & $\begin{array}{c}8.1 \\
(6.7)\end{array}$ & $\begin{array}{c}7.8 \\
(7.5)\end{array}$ & $\begin{array}{c}8.7 \\
(7.2)\end{array}$ & $\begin{array}{c}3.9 \\
(5.7)\end{array}$ & $\begin{array}{c}0.7 \\
(2.5)\end{array}$ & $\begin{array}{l}40.1 \\
(7.2)\end{array}$ \\
\hline$I T$ & $\begin{array}{c}7.7 \\
(6.6)\end{array}$ & $\begin{array}{c}6.4 \\
(6.8)\end{array}$ & $\begin{array}{c}5.4 \\
(4.7)\end{array}$ & $\begin{array}{l}5.6 \\
(6)\end{array}$ & $\begin{array}{l}3.2 \\
(5)\end{array}$ & $\begin{array}{c}1.3 \\
(3.1)\end{array}$ & $\begin{array}{l}29.7 \\
(5.8)\end{array}$ \\
\hline Total & $\begin{array}{c}9.6 \\
(7.1)\end{array}$ & $\begin{array}{c}7.5 \\
(6.4)\end{array}$ & $\begin{array}{c}6.8 \\
(6.5)\end{array}$ & $\begin{array}{c}7.5 \\
(6.8)\end{array}$ & $\begin{array}{l}4.9 \\
(6)\end{array}$ & $\begin{array}{c}1.2 \\
(2.9)\end{array}$ & $\begin{array}{l}37.4 \\
(6.6)\end{array}$ \\
\hline TimeT2 & 1 & 2 & 3 & 4 & 5 & 6 & Total \\
\hline$T R$ & $\begin{array}{l}123.1 \\
(71.7)\end{array}$ & $\begin{array}{l}103.9 \\
(79.2)\end{array}$ & $\begin{array}{c}88.8 \\
(76.3)\end{array}$ & $\begin{array}{c}96.7 \\
(77.1)\end{array}$ & $\begin{array}{c}87.2 \\
(77.4)\end{array}$ & $\begin{array}{c}23.3 \\
(42.6)\end{array}$ & $\begin{array}{l}\mathbf{5 2 3 . 0} \\
(77.3)\end{array}$ \\
\hline$F T$ & $\begin{array}{c}130.5 \\
(92)\end{array}$ & $\begin{array}{c}96.2 \\
(85.5)\end{array}$ & $\begin{array}{c}83.3 \\
(77.3)\end{array}$ & $\begin{array}{l}91.0 \\
(71)\end{array}$ & $\begin{array}{c}44.0 \\
(57.2)\end{array}$ & $\begin{array}{c}8.4 \\
(26.4)\end{array}$ & $\begin{array}{l}453.3 \\
(80.8)\end{array}$ \\
\hline$I T$ & $\begin{array}{l}100.1 \\
(84.3)\end{array}$ & $\begin{array}{c}71.6 \\
(71.7)\end{array}$ & $\begin{array}{c}61.8 \\
(52.9)\end{array}$ & $\begin{array}{c}68.7 \\
(71.8)\end{array}$ & $\begin{array}{c}40.5 \\
(66.9)\end{array}$ & $\begin{array}{c}17.2 \\
(36.7)\end{array}$ & $\begin{array}{l}359.7 \\
(69.9)\end{array}$ \\
\hline Total & $\begin{array}{l}117.9 \\
(82.9)\end{array}$ & $\begin{array}{c}90.6 \\
(79.2)\end{array}$ & $\begin{array}{c}77.9 \\
(69.9)\end{array}$ & $\begin{array}{c}85.5 \\
(73.6)\end{array}$ & $\begin{array}{c}57.2 \\
(\mathbf{7 0 . 5})\end{array}$ & $\begin{array}{c}16.3 \\
(36.1)\end{array}$ & $\begin{array}{l}445.3 \\
(76.8)\end{array}$ \\
\hline $\begin{array}{l}\text { \# of people } \\
\text { who invest }\end{array}$ & 1 & 2 & 3 & 4 & 5 & 6 & Mean/n \\
\hline$T R$ & 29 & 27 & 23 & 25 & 24 & 9 & $22.8 / 30$ \\
\hline$F T$ & 23 & 20 & 19 & 22 & 13 & 4 & $16.8 / 28$ \\
\hline$I T$ & 23 & 19 & 20 & 19 & 11 & 7 & $16.5 / 29$ \\
\hline Total & 75 & 66 & 62 & 66 & 48 & 20 & $56.2 / 87$ \\
\hline
\end{tabular}




\begin{tabular}{|c|c|c|c|c|c|c|c|}
\hline $\begin{array}{l}\text { Productivity } \\
\text { Factor }\end{array}$ & 1 & 2 & 3 & 4 & 5 & 6 & Mean \\
\hline$T R$ & $\begin{array}{c}2.00 \\
(0)\end{array}$ & $\begin{array}{l}2.20 \\
(0.2)\end{array}$ & $\begin{array}{c}2.33 \\
(0.32)\end{array}$ & $\begin{array}{l}2.52 \\
(0.4)\end{array}$ & $\begin{array}{c}2.69 \\
(0.49)\end{array}$ & $\begin{array}{l}2.85 \\
(0.6)\end{array}$ & $\begin{array}{c}2.43 \\
(0.48)\end{array}$ \\
\hline$F T$ & $\begin{array}{c}2.00 \\
(0)\end{array}$ & $\begin{array}{l}2.24 \\
(0.2)\end{array}$ & $\begin{array}{l}2.50 \\
(0.3)\end{array}$ & $\begin{array}{l}2.60 \\
(0.4)\end{array}$ & $\begin{array}{l}2.80 \\
(0.5)\end{array}$ & $\begin{array}{c}2.84 \\
(0.56)\end{array}$ & $\begin{array}{c}2.50 \\
(0.48)\end{array}$ \\
\hline$I T$ & $\begin{array}{l}2.00 \\
(0.0)\end{array}$ & $\begin{array}{l}2.18 \\
(0.2)\end{array}$ & $\begin{array}{c}2.39 \\
(0.29)\end{array}$ & $\begin{array}{c}2.44 \\
(0.36)\end{array}$ & $\begin{array}{c}2.59 \\
(0.45)\end{array}$ & $\begin{array}{c}2.69 \\
(0.52)\end{array}$ & $\begin{array}{c}2.38 \\
(0.42)\end{array}$ \\
\hline Total & $\begin{array}{c}2.00 \\
(0)\end{array}$ & $\begin{array}{l}2.21 \\
(0.2)\end{array}$ & $\begin{array}{c}2.41 \\
(0.31)\end{array}$ & $\begin{array}{c}2.52 \\
(0.39)\end{array}$ & $\begin{array}{c}2.70 \\
(0.48)\end{array}$ & $\begin{array}{c}2.80 \\
(0.56)\end{array}$ & $\begin{array}{c}2.44 \\
(0.46)\end{array}$ \\
\hline Output & 1 & 2 & 3 & 4 & 5 & 6 & Total \\
\hline$T R$ & $\begin{array}{l}14.9 \\
(8.6)\end{array}$ & $\begin{array}{c}20.7 \\
(10.4)\end{array}$ & $\begin{array}{c}24.2 \\
(13.7)\end{array}$ & $\begin{array}{c}26.9 \\
(15.8)\end{array}$ & $\begin{array}{c}31.0 \\
(18.1)\end{array}$ & $\begin{array}{c}46.0 \\
(25.1)\end{array}$ & $\begin{array}{l}163.7 \\
(18.8)\end{array}$ \\
\hline$F T$ & $\begin{array}{c}16.5 \\
(11.5)\end{array}$ & $\begin{array}{c}24.2 \\
(13.3)\end{array}$ & $\begin{array}{c}31.2 \\
(14.7)\end{array}$ & $\begin{array}{c}30.9 \\
(14.2)\end{array}$ & $\begin{array}{c}45.7 \\
(24.3)\end{array}$ & $\begin{array}{c}55.4 \\
(21.8)\end{array}$ & $\begin{array}{l}203.9 \\
(18.8)\end{array}$ \\
\hline$I T$ & $\begin{array}{c}16.8 \\
(10.2)\end{array}$ & $\begin{array}{c}21.5 \\
(12.6)\end{array}$ & $\begin{array}{c}29.4 \\
(13.5)\end{array}$ & $\begin{array}{c}31.6 \\
(14.8)\end{array}$ & $\begin{array}{l}39.9 \\
(22)\end{array}$ & $\begin{array}{c}43.3 \\
(18.9)\end{array}$ & $\begin{array}{l}182.5 \\
(18.2)\end{array}$ \\
\hline Total & $\begin{array}{c}16.0 \\
(10.1)\end{array}$ & $\begin{array}{c}22.1 \\
(12.1)\end{array}$ & $\begin{array}{c}28.3 \\
(14.1)\end{array}$ & $\begin{array}{c}29.8 \\
(14.9)\end{array}$ & $\begin{array}{c}38.9 \\
(22.1)\end{array}$ & $\begin{array}{c}48.3 \\
(22.5)\end{array}$ & $\begin{array}{l}183.4 \\
(19.6)\end{array}$ \\
\hline $\begin{array}{l}\text { Median } \\
\text { Target }\end{array}$ & 1 & 2 & 3 & 4 & 5 & 6 & Median \\
\hline$T R$ & 20 & 20 & 22 & 24 & 25.8 & 27.2 & 22 \\
\hline$F T$ & 20 & 20 & 20 & 20 & 20 & 20 & 20 \\
\hline$I T$ & 20 & 20 & 22 & 24 & 25.8 & 27.2 & 23 \\
\hline Total & 20 & 20 & 22 & 24 & 25.8 & 27.2 & 20 \\
\hline $\begin{array}{l}\text { \# of people } \\
\text { who achieved } \\
\text { the target }\end{array}$ & 1 & 2 & 3 & 4 & 5 & 6 & Total \\
\hline$T R$ & 13 & 19 & 19 & 22 & 21 & 22 & 116 \\
\hline$F T$ & 14 & 20 & 24 & 24 & 26 & 27 & 135 \\
\hline$I T$ & 12 & 16 & 22 & 21 & 22 & 24 & 117 \\
\hline Total & 39 & 55 & 65 & 67 & 69 & 73 & 368 \\
\hline
\end{tabular}

Note: This table provides the means (or \# of people) per treatment of the most important variables during the six experimental periods. The last row of each variable indicates the average across treatments. The last column of the table indicates the total sum or the mean across all six periods.

Standard deviation in parentheses

$T R=$ target ratcheting treatment.

$F T=$ exogenously fixed target treatment.

$I T=$ exogenously increasing targets treatment.

EffortT1 = number of multiplications solved correctly in the bonus task

TabCount $=$ number of tables counted correctly in the investment task.

TimeT2 $=$ time in seconds spent on the investment task.

\# of people who invest = number of people who invest in a certain period. 
ProductivityFactor $=$ productivity factor starts at 2.0 in the first period and can then be increased in future periods.

Output $=$ EffortT1 $\times$ ProductivityFactor.

\# of people who achieved the target = number of people who achieved their targets in a certain period.

Panel A: Effort in bonus task (EffortT1)

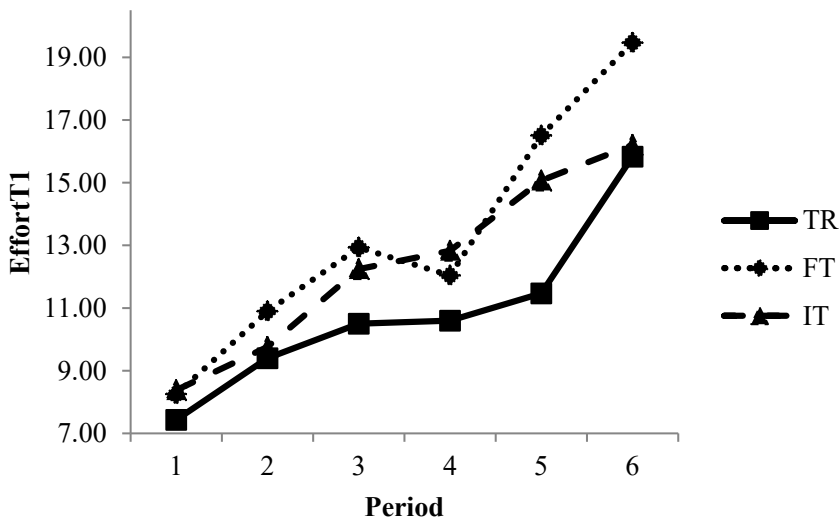

Panel B: Investment (TabCount)

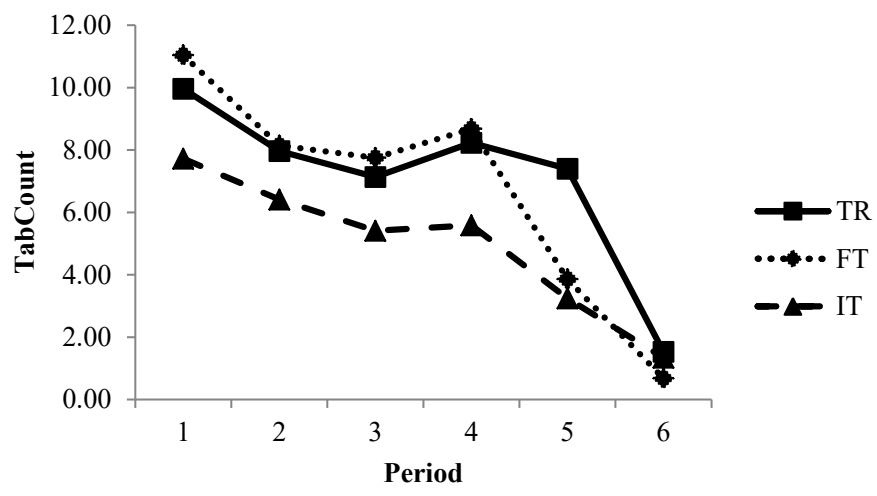

Note: Panel A of this Figure presents per treatment the mean effort that participants spent on the bonus task across the six experimental periods. The effort is measured by the number of correct multiplications submitted (EffortT1).

Panel B of this Figure presents per treatment the mean investment undertaken across the six experimental periods. The investment is measured by correct tables submitted in the investment task (TabCount).TR $=$ target ratcheting treatment. $F T=$ exogenously fixed target treatment. $I T=$ exogenously increasing targets treatment. EffortT1 = number of multiplications solved correctly in the bonus task. TabCount $=$ number of tables counted correctly in the investment task.

Figure 8: EffortT1 and TabCount across the 6 periods 
To statistically test the hypothesis, we run a random effects OLS regression with robust standard errors clustered at the level of participants. ${ }^{29}$ EffortT1 serves as dependent variable and we include period dummy variables $(d u m 2-d u m 6)$ to capture the period effects. To capture the effect of our target ratcheting manipulation, we include the dummy variable $T R$ which is one for target ratcheting and zero for the exogenously determined target contracts. As we predict that the period effect is different for target ratcheting compared to the other groups, we include the interaction variables (TR2 - TRO) of target ratcheting and the period dummy variables. Furthermore, to control for different ability levels in solving multiplications, we also include our ability measure $($ Ability $T 1) .{ }^{30}$ Finally, we also include two separate dummy variables for participants who just missed their output targets (just_below_target equals one if participants missed their target but achieved at least $50 \%$ of it in that period and zero otherwise) in the productive task and those who missed the output target by far (far_below_target equals one if participants achieved less than $50 \%$ of their output targets in that period and zero otherwise). This is important as participants who know that they do not achieve the target might follow completely different strategies (e.g., big bath) from the beginning of the period onwards. Our theory is mainly about the extra capacity that is left once the output target has been achieved, so that we need to control for these strategies by including the dummy variables for those who miss their target. ${ }^{31}$ To facilitate the interpretation of the results, we run the regression separately for a comparison of the target ratcheting group with the exogenously fixed (column 1) and the target ratcheting with the exogenously increasing targets group (column 2). In untabulated tests we also run the regression with all treatment groups and inferences do not change.

\footnotetext{
${ }^{29}$ Our inferences do not change when we test our hypothesis with Wilcoxon-Mann-Whitney tests.

${ }^{30} \mathrm{We}$ include this variable for efficiency reasons. The ability measure is based on the performance of individuals in the five minutes period in which we paid participants 0.2 EUR for each correct multiplication. There is no significant difference of AbilityT1 across the three between participants manipulations (p-value $>$ 0.42). Furthermore, our inferences do not change when we exclude this variable from our analyses.

31 Although the two dummy variables should capture participants' expectations that affect their strategic decisions, they are ex post measures based on realizations following the decisions. Our inferences, however, do not change if we exclude these variables from the model. Furthermore, also when running the analyses just with those observations that achieved the targets, the inferences we draw also do not change.
} 
Table 5: Regression results of EffortT1 and TabCount

\begin{tabular}{|c|c|c|c|c|}
\hline & \multicolumn{2}{|c|}{ EffortT1 } & \multicolumn{2}{|c|}{ TabCount } \\
\hline & $\begin{array}{l}\text { TR vs FT } \\
\text { (1) }\end{array}$ & $\begin{array}{l}\text { TR vs IT } \\
\text { (2) }\end{array}$ & $\begin{array}{c}\text { TR vs FT } \\
\text { (3) }\end{array}$ & $\begin{array}{c}\text { TR vs IT } \\
\text { (4) }\end{array}$ \\
\hline dum 2 & $\begin{array}{l}0.953 * \\
(0.591)\end{array}$ & $\begin{array}{c}0.553 \\
(0.483)\end{array}$ & $\begin{array}{l}-1.365 \\
(1.563)\end{array}$ & $\begin{array}{l}-1.585 \\
(1.494)\end{array}$ \\
\hline dum 3 & $\begin{array}{c}1.814^{* * *} \\
(0.732)\end{array}$ & $\begin{array}{l}1.432 * * \\
(0.749)\end{array}$ & $\begin{array}{l}-0.558 \\
(1.597)\end{array}$ & $\begin{array}{l}-0.583 \\
(1.504)\end{array}$ \\
\hline dum 4 & $\begin{array}{c}0.921 \\
(1.041)\end{array}$ & $\begin{array}{c}2.188^{* * * *} \\
(0.731)\end{array}$ & $\begin{array}{c}0.962 \\
(1.579)\end{array}$ & $\begin{array}{l}-0.649 \\
(1.504)\end{array}$ \\
\hline dum 5 & $\begin{array}{c}4.725 * * * \\
(1.257)\end{array}$ & $\begin{array}{c}4.260^{* * * *} \\
(0.900)\end{array}$ & $\begin{array}{c}-5.048^{* * *} \\
(1.681)\end{array}$ & $\begin{array}{c}-4.643 * * * \\
(1.594)\end{array}$ \\
\hline dum6 & $\begin{array}{c}7.505^{* * *} \\
(1.081)\end{array}$ & $\begin{array}{c}4.912 * * * \\
(0.932)\end{array}$ & $\begin{array}{c}-13.06 * * * \\
(2.070)\end{array}$ & $\begin{array}{c}-8.541 * * * \\
(1.784)\end{array}$ \\
\hline$T R$ & $\begin{array}{l}-0.143 \\
(0.703)\end{array}$ & $\begin{array}{l}-0.808^{*} \\
(0.577)\end{array}$ & $\begin{array}{c}0.267 \\
(1.930)\end{array}$ & $\begin{array}{l}2.533^{*} \\
(1.813)\end{array}$ \\
\hline$T R 2$ & $\begin{array}{l}-0.700 \\
(0.745)\end{array}$ & $\begin{array}{l}-0.278 \\
(0.670)\end{array}$ & $\begin{array}{l}1.237 \\
(2.118)\end{array}$ & $\begin{array}{c}1.275 \\
(2.039)\end{array}$ \\
\hline$T R 3$ & $\begin{array}{l}-0.324 \\
(1.091)\end{array}$ & $\begin{array}{l}0.0840 \\
(1.087)\end{array}$ & $\begin{array}{l}-1.214 \\
(2.142)\end{array}$ & $\begin{array}{l}-1.412 \\
(2.036)\end{array}$ \\
\hline$T R 4$ & $\begin{array}{c}0.290 \\
(1.187)\end{array}$ & $\begin{array}{l}-0.924 \\
(0.960)\end{array}$ & $\begin{array}{l}-1.194 \\
(2.121)\end{array}$ & $\begin{array}{l}-0.0651 \\
(2.033)\end{array}$ \\
\hline TR5 & $\begin{array}{c}-2.748^{* *} \\
(1.491)\end{array}$ & $\begin{array}{c}-2.247^{* *} \\
(1.204)\end{array}$ & $\begin{array}{c}4.272 * * \\
(2.189)\end{array}$ & $\begin{array}{c}3.539 * * \\
(2.094)\end{array}$ \\
\hline TR6 & $\begin{array}{l}-1.607 \\
(1.531)\end{array}$ & $\begin{array}{c}1.022 \\
(1.443)\end{array}$ & $\begin{array}{c}3.331 \\
(2.604)\end{array}$ & $\begin{array}{l}-1.249 \\
(2.345)\end{array}$ \\
\hline AbilityT1 & $\begin{array}{c}0.223^{* *} \\
(0.104)\end{array}$ & $\begin{array}{c}0.294 * * * \\
(0.111)\end{array}$ & $\begin{array}{c}0.378 * * * \\
(0.123)\end{array}$ & $\begin{array}{c}0.347 * * * \\
(0.114)\end{array}$ \\
\hline just_below_target & $\begin{array}{c}-5.155^{* * *} \\
(0.495)\end{array}$ & $\begin{array}{c}-4.930 * * * \\
(0.478)\end{array}$ & $\begin{array}{c}3.899 * * * \\
(1.134)\end{array}$ & $\begin{array}{l}1.768 * * \\
(1.004)\end{array}$ \\
\hline far_below_target & $\begin{array}{c}-9.249 * * * \\
(0.822)\end{array}$ & $\begin{array}{c}-9.163 * * * \\
(0.681)\end{array}$ & $\begin{array}{c}12.01 * * * \\
(1.166)\end{array}$ & $\begin{array}{c}11.07 * * * \\
(1.137)\end{array}$ \\
\hline Constant & $\begin{array}{c}9.344 * * * \\
(1.605)\end{array}$ & $\begin{array}{c}9.166^{* * *} \\
(1.344)\end{array}$ & $\begin{array}{c}0.909 \\
(2.229)\end{array}$ & $\begin{array}{l}-0.183 \\
(1.949)\end{array}$ \\
\hline sigma_u & 3.157 & 2.527 & $\begin{array}{c}4.587 * * * \\
(0.599)\end{array}$ & $\begin{array}{c}4.322 * * * \\
(0.559)\end{array}$ \\
\hline sigma_e & 3.397 & 3.054 & $\begin{array}{c}5.532 * * * \\
(0.292)\end{array}$ & $\begin{array}{c}5.306 * * * \\
(0.281)\end{array}$ \\
\hline$n$ & 348 & 354 & 348 & 354 \\
\hline
\end{tabular}

Note: Column (1) and (2) of this table report the results of an OLS regression with random effects and clustered standard error (participant) on the effort spent on the bonus task (EffortT1). Column (3) and (4) report the results of a Tobit regression with random effects on the effort spent on the investment task (TabCount). In column (1) and (3) exogenously fixed targets is the base group. In column (2) and (4) exogenously increasing targets is the base group.

Standard errors in parentheses.

$* \mathrm{p}<0.1, * * \mathrm{p}<0.05, * * * \mathrm{p}<0.01$ (one-tailed).

87 participants (30 Target ratcheting; 28 exogenously fixed targets; 29 exogenously increasing targets).

EffortT1 $=$ number of correct multiplications. 
OutputT1 = EffortT1 $\times$ ProductivityFactor.

TabCount $=$ Number of Tables counted (Investment).

$T R=$ dummy variable with 1 for target ratcheting.

dum $X=$ period dummy variables.

$T R X=T R \times d u m X$.

Ability $T 1=$ Ability level in solving multiplications.

just_below_target $=$ just below the target (missed the target but achieved at least $50 \%$ of target level).

far_below_target $=$ far below the target (missed the target and achieved less than $50 \%$ of target level).

The results of these regressions, presented in Column (1) in Table 5, show that initially there is no difference between the target ratcheting and the exogenously fixed target condition (TR -.0143, p-value $>0.1$, one-tailed), while the difference between the target ratcheting and exogenously increasing targets is marginally significant (TR -0.808 , p-value $<$ 0.1 , one-tailed). Over time the effort spent on task 1 increases within both exogenously determined target conditions (dum2-dum6). The results confirm that compared to the first period of the experiment, participants in the exogenously determined target conditions show significantly higher effort in the productive task in later periods. Furthermore, in line with our prediction that this effect will be stronger for the exogenously determined target conditions than for the target ratcheting condition, the interaction effect of period and target ratcheting (TR5) is statistically significant in both regressions. While participants in the exogenously fixed target condition solve in period five 4.725 multiplications more than in the first period (dum5 4.725, p-value $<0.01$, one-tailed), in the target ratcheting condition participants solve just around two additional multiplications more than in the first period. This is still significantly higher than in the first period (dum5+TR5, p-value $<0.01$, one-tailed), but, in line with our prediction, significantly lower than in the exogenously fixed target conditions in period five (TR5 $-2.748, p$-value $<0.05$, one-tailed).

Comparing the target ratcheting condition to the exogenously increasing targets leads to a similar result (Column (2) in Table 5). In this condition participants solve around 4.260 (dum5) additional multiplications in period five. The difference in the increase of 2.247 (TR5) multiplications between the target ratcheting and the exogenously increasing target condition is significant at a $5 \%$ level (one-tailed). Thus, taken together, the findings of our regressions show that, as the time horizon gets shorter, the difference between target ratcheting and exogenously determined targets increases, which supports Hypothesis 1.

In the final period, all groups have an incentive to put their full attention on the productive task of solving multiplications. The regression results show that the coefficient of TR6 is not statistically significant ( $\mathrm{p}$-value $>0.1$, one-tailed) in both regressions, which indicates that in period six there is no difference in the effort spent on the bonus task between the target ratcheting group and the exogenously determined target conditions. Furthermore, the results also confirm that the ability in solving multiplications, as well as the two control variables for participants who miss the target have a statistically significant influence on the number of multiplications solved. 


\subsubsection{Hypothesis 2}

In Hypothesis 2, we predict that target ratcheting leads to a higher level of investments than exogenously determined targets, as using past performance information in setting new targets mitigates the horizon problem. Table 4 and Figure 8 show that in the first period the groups on average solved between 7.7 tables of counting zeros in the exogenously increasing, 10.0 in the target ratcheting and 11.0 in the exogenously fixed target group. Across all three treatments the number of tables remains relatively constant until period four. However, in period five the investment declines sharply in the two exogenously determined target groups as their number of tables counted drops to 3.9 in the exogenously fixed target group and 3.2 in the exogenously increasing targets group, while in the target ratcheting group the investment remains at a relatively high level of 7.4 tables counted. The pattern of these investments is in line with our prediction.

To test our prediction statistically, we perform a random effects Tobit regression. Due to the large number of observations without any investment, a standard panel regression or ANOVA with repeated measures are not appropriate to test this prediction. Therefore, to take the censoring at zero investments into account, we apply a Tobit random effects regression. ${ }^{32}$ Our dependent variable is the number of tables counted (TabCount). The independent variables are identical to those used in the analysis of the effort spent on the bonus task.

Column (3) (base line is exogenously fixed targets) and (4) (base line is exogenously increasing targets) in Table 5 present the results of the two regressions. There is no significant difference in the first period between the target ratcheting and the exogenously fixed target group ( $T R 0.267$, p-value $>0.1$ ). In contrast, the main effect of $T R$ in column (4) is 2.533 and statistically significant (p-value $<0.1$, one-tailed), which indicates that people in the exogenously increasing targets invest less in period one than in the target ratcheting condition. However, more important for testing our theory is how the investment level develops throughout the experiment. The analyses show that in the first four periods of the experiment the investment level in all three groups is constant and does not change significantly compared to the first period (dum2-dum4). However, in period five the two exogenously determined target conditions decrease their investment significantly, while the investment in the target ratcheting condition remains at the higher level. In the exogenously fixed target (Column (3) in Table 5) the dum 5 coefficient indicates that people solve in period five 5.048 tables less than in the first period, which is significant at a $1 \%$ level (one-tailed). The interaction coefficient TR5 shows a positive effect of 4.272 (p-value $<0.05$, one-tailed), which indicates that the decrease of the investment in the target ratcheting in period five is less severe than in the exogenously fixed target condition. In fact, when comparing the investment of period five with the investment in period one for the target ratcheting group, the results do not show a significant difference $(d u m 5+T R 5$, p-value $=0.60)$. This is in line with our expectation that the target ratcheting group will show constant investments until the last period of the experiment.

\footnotetext{
${ }^{32}$ Testing the hypothesis with Wilcoxon-Mann-Whitney tests leads to similar inferences.
} 
A similar pattern of results can be found for the comparison of target ratcheting and exogenously increasing targets (Column (4) in Table 5). Again, the dum5 variable has a coefficient of -4.643 and is significant at a $1 \%$ level (one-tailed). This implies that, compared to the first period, the participant in the exogenously increasing targets group decrease their investment significantly. However, the positively significant TR5 coefficient 3.539 (p-value $<$ 0.05 , one-tailed) countervails the negative main effect of period five. Again, when summing up the coefficients of dum5 and TR5, a significance test shows a p-value of 0.44 , which indicates that in the target ratcheting group the level of investments in period five is not significantly different from their investment in first period. These findings provide support for Hypothesis 2 that target ratcheting can mitigate the negative consequences of the horizon problem. $^{33}$

In the last period of the experiment we do not expect any difference between target ratcheting and the exogenously determine target conditions, as all participants will put their full attention to the bonus task. In line with this expectation, the TR6 coefficients are not statistically significant in both regressions ( $\mathrm{p}$-values $>0.1$, one-tailed). The control variables AbilityT1 and dummy variables for missing the targets (just_below_target and far_below_target) are all statistically significant and in the expected direction.

Taken together, the results of our experiment indicate that, in line with prior literature, target ratcheting indeed leads to lower effort on the short-term output dimension compared to the groups with exogenously determined targets. However, target ratcheting also increases investments in long-term productivity improvements by mitigating the employees' horizon problem. Thus, depending on the relative strength of these effects in practice and the potential costs and gains of the investments, companies might favor one of these target setting systems over the others.

\subsection{Conclusions}

In this paper we report the results from a multi-task experiment investigating the tradeoff of individuals in allocating effort between short-term output and long-term productivity improvements when past performance information is used to set new performance targets (i.e. target ratcheting). Consistent with prior research we find that target ratcheting leads to lower effort on a short-term output task. However, we also find that participants in the target ratcheting setting invest significantly more in long-term productivity improvements than participants in exogenously determined target conditions as the time horizon gets shorter. This indicates that target ratcheting mitigates the negative consequences of the horizon problem and thus leads to higher investment in long-term productivity.

This study has implications for accounting research and practice. Target ratcheting is a widely used procedure when setting performance targets for employees. Whereas prior

\footnotetext{
${ }^{33}$ In an untabluated robustness check we test our hypotheses including control variables for the productivity factor and the number of switches among the two tasks. Including these variables does not change the inferences that we draw here.
} 
research has analyzed the consequences of target ratcheting on employees' effort, this study analyzes target ratcheting in light of employees' effort allocation decisions, where agents need to allocate effort between current performance and uncertain future outcomes. We find that while in such a situation target ratcheting leads to lower short-term productive effort, it increases the investments of employees in future productivity improvements. Thus, only examining the short-term output dimension of employees, prior studies have overestimated the negative consequences of target ratcheting and left out potential positive effects for longterm productivity investments. In fact, depending on the specific situation, the negative difference in the current output level could be offset by increased future productivity. This provides one potential explanation for the widespread use of target ratcheting despite the well-established effect of reduced effort in the short run. This study also helps to reconcile seemingly disparate findings in the prior target ratcheting literature. On the one hand studies show that targets increase after good performance in one period (Leone and Rock 2002; Bouwens and Kroos 2011). On the other hand studies report that there often is a positive serial correlation indicating that manager who achieved the target in one period, are also more likely to achieve it the next period (Indjejikian and Nanda 2002; Indjejikian et al. 2014a). As we show that target ratcheting leads employees to invest excess resources in future productivity improvements, this provides a plausible explanation for both of these findings.

Furthermore, by showing that target ratcheting mitigates the negative effects of the horizon problem, this study also provides an explanation why and under which circumstances target ratcheting leads to higher investments than exogenously determined targets. Without a horizon problem, participants in exogenously determined target conditions and target ratcheting condition invest approximately the same level in long-term productivity improvements. However, with a short time horizon, participants in the exogenously determined targets reduce their investment while the target ratcheting group remains at the relatively high level. Thus, target ratcheting can help to overcome the horizon problem that is inherent in many situations in practice (e.g., job uncertainty, job rotation, career concerns, or planned retirement). In such situations employees often tend to focus on short-term outcomes at the expense of long-term investments. Target ratcheting can reduce this myopic behavior and lead employees to invest in long-term projects. It therefore provides an alternative mechanism to explicit incentives in triggering long-term investments, which is especially relevant since the outcome of investments can be highly uncertain and the level of investments is often unobservable or non-contractible (Stein 1989).

This study also contributes to a stream of literature analyzing the trade-off between short-term and long-term benefits. Farrell et al. (2012) experimentally analyze a quantityquality trade-off when contracting on forward-looking performance measures. Webb et al. (2013) show that target difficulty and incentive contracts influence participants' attempts to find new and more efficient ways in performing their task. We contribute to this stream of literature by showing that target setting procedures affect such trade-offs between short-term bonuses and long-term productivity improvements. 
As with any study, there are also some limitations of this study. First, as laboratory experiments use a controlled setting that abstracts from reality to isolate different effects from each other, external validity is always a concern in experiments. In particular, our first manipulation is the way of setting the target. While for experimental purposes we apply a full asymmetric ratcheting system versus a full commitment contract, in practice firms might not use one of the extremes but a mixture of these systems (Indjejikian and Nanda 2002). This, however, does not change the implications from our theory. Similarly, while we manipulate the time horizon within subject in such a way that it is clear from the beginning that the experiment runs over six periods, in practice there might be more uncertainty included in the contract. However, this uncertainty would not affect the general argument that target ratcheting can mitigate the negative consequences of the horizon problem.

Second, we examine target ratcheting in a budget-linear contract. While some academics (Jensen 2001) suggest abandoning budget based contracts altogether, other studies have shown that in practice most companies use some form of targets in their contracts (Murphy 2001). Therefore, we investigate in this study the effect of target setting in budget linear contracts on long-term investments. Different designs of such budget based contracts (e.g. implementing a bonus cap) could potentially lead to a smaller difference in the behavior across the target setting schemes, but it would not change the general implication of our study that using past performance information in setting new performance targets leads to higher investments in long term productivity improvements than a commitment to not use past performance information. 

Chapter 4: The Effect of Input and Output Targets for Routine Tasks on Creative Task Performance 


\begin{abstract}
$^{34}$
In an environment where employees have the freedom to direct some time away from their day-to-day, routine tasks to work on creative endeavors, we examine whether nonbinding targets for the amount of time to spend (input target) and/or the amount of output to produce (output target) on the routine task affects creative task performance. Results of a laboratory experiment demonstrate that providing both an input and output target on the routine task leads to greater creative task performance relative to providing one or none of these targets. This result is consistent with theory suggesting that individuals need guidance as to how much routine work to complete in order to achieve the cognitive closure necessarily for them to think creatively. However, individuals also need guidance as to the amount of time to spend on their relatively comfortable routine work to encourage them to break away and spend time on more open-ended creative endeavors. By setting expectations as to what employees need to achieve on their more routine, day-to-day responsibilities, organizations can increase the efficacy of the growing practice of allowing employees to spend a portion of their work week on creative endeavors.
\end{abstract}

\footnotetext{
${ }^{34}$ This chapter is based on a working paper together with Alexander Brüggen and Michael Williamson.
} 


\section{Introduction}

Many organizations allow employees to allocate some time away from their day-to-day, routine tasks to work on creative activities (Dorenbosch et al. 2005; Elsbach and Hargadon 2006; Sprinkle and Williamson 2004). While controls for routine activities are quite common in companies, often organizations provide little structure or control for the employees' creative time in order to give them the freedom for creative pursuits without the fear of evaluation (Tate 2012). In such an environment, we develop and test theory suggesting that setting targets on employees' routine tasks can actually affect creative task performance. Specifically, we examine whether the presence versus absence of targets that provide guidance about the time to spend (input target) and/or how much output to generate (output target) on a routine task affects creative task performance.

This research is important because, in these environments, the practitioner and academic literatures document and recommend seemingly disparate practices without offering an understanding as to their relative effectiveness at promoting creative task performance. On the one hand, the practitioner literature illustrates that some organizations provide input targets as to the amount of time employees should reserve for their day-to-day activities before engaging in creative pursuits. For example, companies such as Google and 3M recommend that employees spend at least 80 to 85 percent of their work week on their routine responsibilities, giving employees the opportunity to spend the remaining time on creative pursuits if they so desire (Tate 2012). On the other hand, accounting research suggests that organizations set relatively easy output targets for routine tasks to provide employees slack time for creative endeavors (Merchant and Manzoni 1989).

While the literature typically discusses these two practices independently, we develop and test theory suggesting that input and output targets on routine tasks actually play a complementary role in promoting creative task performance. When faced with multiple responsibilities, individuals are naturally inclined to focus their cognitive effort on more than one task at a time, often to the detriment of productivity and especially creativity (Amabile et al. 2002a; Leroy 2009). Merely providing guidance for the allocation of time to tasks would not help in overcoming this inherent challenge. However, goal theory suggests that setting an output target for a routine task can focus attention and increase productivity on that task. By communicating the minimum amount of work to be completed, output targets also provide an opportunity for closure on routine work, which allows individuals to focus fully on their creative endeavors with any remaining work time.

That said, theory also suggests that individuals who are productively engaged in relatively routine work are inclined to continue working on it, even after achieving their output target. Individuals tend to work on tasks in which they feel competent and productive (Bandura 1997; Amabile and Kramer 2011). By focusing individuals' attention, increasing productivity, and enhancing feelings of competency on routine work through target achievement, output targets may discourage individuals from spending sufficient time on creative endeavors, absent guidance suggesting that they have spent enough time on routine work. As such, by assigning not only an output target that focuses attention and provides an opportunity for closure on routine work but also an input target suggesting that individuals 
can limit their time on routine work and spend time on creative endeavors, organizations could potentially better promote creative task performance.

To test this theory, we use a computerized laboratory experiment where participants freely allocate 20 minutes of time across two tasks. First, all participants start by working on a relatively routine task where participants decode letter combinations into numbers. Here, consistent with an environment where individuals' primary responsibility is relatively routine or repetitive work, participants increase productivity by applying relatively known procedures (Hodgson 1997). Second, to represent a task where participants think creatively about their environment, participants develop creative activities for future laboratory experiments. The creative task is open-ended in that participants receive no clear procedures to follow (Amabile 1996). Participants could switch back and forth between these tasks whenever and as often as they desired. To abstract away from challenges of designing explicit incentives across multiple tasks and hence most powerfully test our theory (Holmstrom and Milgrom 1991), we pay our participants a fixed salary. That said, the instructions inform all participants that we value the number of letters decoded on the first task and the number of creative experimental activities described in the second task, as assessed by an independent panel of raters.

We manipulate the following two factors each between participants: (1) the presence/absence of an input target suggesting that participants spend at least half of their available time on the routine task, and (2) the presence/absence of an output target suggesting a minimum amount of routine output to produce. We set the output target such that the average participant could achieve it in half of the total time available, which could leave the remaining time for the creative task. As such, we hold the approximate guidance for allocating effort among the tasks constant across the input and output target conditions. ${ }^{35}$ Across all conditions, however, we inform participants that they can allocate their time and produce/create as much as they prefer, ignoring the guidance from the output and input targets.

Consistent with theory, the presence of both the input and output targets on the routine task motivates greater creative task performance relative to conditions where one or both of these targets are absent. Specifically, we find that the effectiveness of input and output targets at promoting creative task performance increases when used together rather than separate. Supplemental analyses suggest that individuals without an output target use less focused task strategies, to the detriment of performance on both tasks. However, individuals with an output target but no input target reserve less time for the creative task than those with both input and output targets. Collectively, these results support our theory that input and output targets on routine tasks are complementary mechanisms in promoting creative task performance.

\footnotetext{
${ }^{35}$ Some organizations structure input targets as a maximum amount of time to spend on creative relative to routine tasks. Holding the total available work time constant as we do in the experiment, the actual guidance provided by these two forms of input targets are equivalent. By structuring the input target as we do, we hold the implications of guidance constant across our input and output target conditions. Moreover, we bias against finding support for our theory suggesting that input targets encourage individuals to spend enough time on creative endeavors.
} 
These results have a number of important implications. First, our results provide a better understanding of business practice in environments where organizations desire that their employees spend some time away from routine tasks for creative pursuits. While practitioner and academic literatures discuss the practices of either (1) setting input targets for allocating time between routine and creative activities, or (2) setting output targets on routine tasks that provide slack for creative activities, our results suggest that these two factors are complementary design choices. That is, organizations can increase the efficacy of the growing practice of suggesting that employees spend a portion of their work week on creative endeavors by setting expectations about what they need to achieve during their time on the routine work. Moreover, organizations can increase the efficacy of using relatively easy output targets to foster creative pursuits by providing guidance for allocating their resulting slack time.

We also add to the growing body of accounting research suggesting that appropriately designed management control systems can promote creativity and innovation (e.g., Chen et al. 2012; Kachelmeier et al. 2015b) . While prior research primarily focuses on the role of control system design on the creative activities themselves, we find that the design of control mechanisms around routine tasks can also influence creative task performance. Thereby, our results can help explain why aspects of management control systems are used more intensely in high creativity-dependent organizations (Grabner 2014). Moreover, while prior accounting research predominately focuses on the role of formal control systems tied to compensation (Kachelmeier et al. 2008; Kachelmeier and Williamson 2010), our results suggest that informal targets, goals, and other communications can play an important role in promoting creativity from employees (Locke and Latham 1990; Bonner and Sprinkle 2002; Sprinkle and Williamson 2006; Kachelmeier et al. 2015a) .

Additionally, we contribute to the accounting literature demonstrating that control systems for one task can affect performance on a different task without such control. In environments that do not require creativity, prior accounting research predominately focuses on whether/when motivation inspired by behavioral controls or performance-based pay on one task spills over to affect motivation/performance on a secondary task (Hecht et al. 2012; Christ et al. 2012; Christ et al. 2016). Informed by theory from the psychology literature, our results highlight that performance targets can play an important role in encouraging employees to break away from routine tasks in order to improve creative task performance. Collectively, this literature highlights the many roles management accounting practices can play in enhancing performance across employees' multiple responsibilities, which hopefully will inspire more research in the area.

The remainder of this paper is organized into four sections. Section two presents some background information, our theoretical development, and our hypothesis. Section three explains the method we use to test our hypothesis. Section four presents the results, and section five provides a summary and discussion of the results. 


\subsection{Background, Theory, and Hypotheses}

A large body of research in accounting and elsewhere examines the effect of target setting on performance (e.g., Chow 1983; Locke and Latham 1990; Bonner et al. 2000; Hirst and Yetton 1999). This research predominately finds that appropriately designed targets generate positive performance results, even absent financial rewards for meeting performance targets. While prior research predominately focuses on the effects of targets on task performance on which the targets are actually set, we extend this research by examining the effect of targets on individuals' relatively routine tasks on their creative-task performance.

Our investigation is important because, in addition to their day-to-day, routine tasks, organizations are increasingly asking employees to develop creative ideas which are both novel and useful for the company (Tate 2012; Amabile et al. 2002a). These ideas can potentially serve as the basis for future innovation and process improvement for the company (Nonaka 1991). For example, employees across rank and functional areas at companies such as Google and 3M develop innovative product offerings in addition to their routine, day-today activities (Tate 2012). Moreover, management at manufacturing companies such as John Deere and Caterpillar ask rank-and-file employees to not only manufacture products but also develop creative ways to increase the efficiency of production (Sprinkle and Williamson 2004).

Allowing employees to develop creative ideas offers potential benefits to organizations. By attempting to incorporate the unique experiences and knowledge of employees into their creative endeavors, these ideas can potentially serve as the basis for future innovation and process improvement for the company (Nonaka 1991). Moreover, providing employees the opportunity to develop creative ideas enhances job satisfaction and intrinsic motivation toward work activities, which could also lead to more creative ideas from employees (Shalley et al. 2000).

That said, employees assigned both routine and creative tasks face inherent challenges which can potentially impair their productivity on creative endeavors. For example, research suggests that individuals desire to continue working on tasks in which they feel competent and productive (Bandura 1997; Amabile and Kramer 2011). As such, to the extent individuals are productive on their relatively comfortable routine tasks, they may not allocate much time to more open-ended and uncertain creative endeavors where they could feel less productive.

When individuals attempt to spend time working on both routine and creative tasks, cognitive limitations can also impair their ability to do so effectively. First, individuals tend to believe that they are effective multitaskers and may attempt to work on both routine and creative tasks simultaneously rather than sequentially (Rosen 2008). However, research demonstrates that individuals are less efficient and productive when attempting to perform multiple tasks simultaneously (Pashler 1984). Specifically, research suggests that the brain is not well equipped to handle cognitions about multiple tasks which creates an inefficient bottleneck as the brain attempts to handle several stimuli at once (Tombu et al. 2011; Filmer et al. 2013). This performance detriment can be especially problematic if one of the tasks includes cognitively challenging creative work (Amabile et al. 2002b). 
Even if individuals attempt to work on tasks sequentially, research suggests that they often face difficulties when transitioning between tasks. In particular, research suggests that individuals can experience attention residue when making task transitions, which refers to "cognitions about a Task A that persist even though one has stopped working on Task A, transitioned to Task B, and is now working on Task B" (Leroy 2009, p. 168). Again, cognitions about multiple tasks at once can be detrimental to performance. Collectively, research documenting the potential challenges of multiple task assignments suggests that individuals can be more productive if they focus their efforts and achieve cognitive closure on one task before working on a different task.

Our objective is to examine the role input (time) and output targets can play in overcoming the inherent challenges of asking employees to spend time away from their routine tasks to think creatively. Before developing our hypothesis, we begin by explaining key features of our setting of interest. Here, participants freely allocate a fixed amount of time across two tasks. First, consistent with an environment where individuals' primary responsibility is relatively routine work, participants initially work on a task with known, repetitive procedures. Second, participants work on a more open-ended creative task. Participants can switch back and forth between these tasks whenever and as often as they desire.

To powerfully focus on the role of management accounting practices in overcoming the challenges discussed above, we pay participants a fixed salary for their efforts. In doing so, we abstract away from challenges of designing explicit incentives across multiple tasks (Holmstrom and Milgrom 1991). ${ }^{36}$ That said, we inform all individuals that we value both their routine and creative task performance. Prior research suggests that value statements of this nature can motivate performance along the desired dimensions (Kachelmeier et al. 2015a). Moreover, employees in the natural environment often operate with a set of informal expectations in lieu of explicit compensation in many multi-task settings (Milgrom and Roberts 1992; Brickley et al. 2016). Finally, because many organizations desire that their employees have the freedom to engage in creative pursuits without the fear of evaluation (Tate 2012), we place no formal controls on creative task performance. Rather, we examine how the following two pervasive management control practices for routine tasks can ultimately affect creative task performance: (1) an input (time) target suggesting that participants spend at least half of their available time on the routine task, and (2) an output target suggesting a minimum amount of routine output to produce.

\subsubsection{Input (Time) Targets for Routine Tasks}

Research emphasizes that creative thinking is a cognitively challenging task that requires time (Amabile et al. 2002a; Amabile et al. 1996). As such, to the extent organizations value creative output from employees, organizations need to encourage individuals to spend enough

\footnotetext{
${ }^{36}$ Holmström and Milgrom (1991) argue that fixed wage contracts can help overcome problems resulting from distorted effort allocations in environments where efforts are measured with different levels of precision. Another solution to multi-tasking problems put forward in the literature is separating responsibilities and reassigning tasks (Holmstrom and Milgrom 1991; Hemmer 1998). However, as already discussed, many organizations find it beneficial to assign employees both routine and creative work.
} 
time pursuing creative endeavors. To give this time, some organizations assign employees input (time) targets suggesting that employees can limit the working hours they spend on routine, day-to-day tasks to reserve time for less structured creative endeavors. If employees follow this guidance, then an input target could lead them to spend more time on creative endeavors.

However, theory suggests that input targets alone are not sufficient to ensure that individuals make the most efficient use of their work time. Without an output target on the routine task, individuals will both attempt to inefficiently multitask (i.e., attempt to work on both tasks simultaneously) and have difficulty cognitively disengaging from the routine work (Moskowitz 2002). Disengagement would be particularly difficult if individuals have uncertainty as to whether they achieved a desired level of routine task output (Leroy 2009). To the extent that individuals continue to have cognitions about routine work while attempting to think creatively, their ability to think creatively would likely suffer. In sum, while input targets provide guidance to encourage individuals to spend time on creative tasks, input targets alone may not facilitate task focus, which could be detrimental to both routine and creative task performance.

\subsubsection{Easily Achievable Output Targets for Routine Tasks}

Many organizations assign performance targets to their employees specifying a minimum objective or amount of work to achieve in their routine responsibilities. Research documents that some organizations deliberately include slack in their budgets to encourage individuals to spend time thinking creatively (Merchant and Manzoni 1989). For example, if a firm sets an output target for a routine task such that it requires 80 percent of employees' available work time, then the employee has the opportunity to spend the remaining portion of their work time on creative endeavors.

According to goal theory, an output target on routine tasks potentially helps to overcome important challenges of an environment where individuals work on both routine and creative tasks. Individuals often have a strong intrinsic desire to achieve the targets and goals assigned to them. Thus, when assigned such a target, they devote their full attention to achieving it (Latham and Locke 1991; Bonner and Sprinkle 2002), thereby eliminating possible distractions of multitasking while engaged in routine work. This focused attention on the routine task should enhance the productivity of this time. Moreover, achieving an output target offers an opportunity for individuals to feel a sense of accomplishment for their time on the routine task and, as such, provide a sense of closure necessary to devote full attention to creative pursuits, if individuals choose to do so (Locke and Latham 1990; Leroy 2009).

However, while an output target on routine tasks can potentially overcome the cognitive challenges of a multitask environment, output targets alone may not motivate individuals to direct enough time to creative pursuits. Specifically, output targets can exacerbate the motivational challenge of encouraging individuals to spend a significant amount of time thinking creatively. By promoting productivity on routine work and providing a sense of accomplishment that enhances individuals' sense of competency for routine work (Locke and Latham 1990), easily attainable output targets may further discourage individuals 
to break-away from their comfortable routine tasks to spend time thinking creatively. To the extent creative output requires sufficient time to develop, the failure to spend enough time thinking creatively could be detrimental to creative performance.

\subsubsection{Complementary Role of Output Targets and Input Targets}

Ultimately, the theory discussed above suggests that easily achievable output targets and input targets play a complementary role in overcoming the challenges of assigning both routine and creative tasks to employees. Easily achievable output targets can focus individuals' efforts on routine work. Moreover, achieving the output target can provide individuals a sense of closure on the routine work so that they can devote their full cognitive resources to the creative task. That said, by promoting productivity on routine work, an output target may lead individuals to continue working on their relatively comfortable routine tasks rather than spending time on creative endeavors. To counteract this tendency, input targets could encourage individuals to break away from their routine tasks and spend enough time thinking creatively.

Thus, while guidance provided by input targets can encourage individuals to spend more time on creative work, output targets can ensure that individuals have the cognitive closure necessary on routine work to devote their full cognitive attention to creative tasks. If so, input and output targets on routine tasks would be complementary design choices in promoting creative task performance (Grabner and Moers 2013; Milgrom and Roberts 1995). Accordingly:

Hypothesis: Providing both an input and output target on routine tasks leads to greater creative task performance relative to providing one or none of these targets.

\subsection{Method}

We recruited 97 volunteers from an undergraduate management accounting course at a large European University to participate in experimental sessions which lasted approximately 45 minutes. Forty percent of the participants were female and the average age of all participants was 21 years. Participants received course credit and a fixed payment of 10 EUR for their participation. With the exception of the paper-based instructions and the exit questionnaire, participants completed the experiment using a z-Tree computer program (Fischbacher 2007).

\subsubsection{Experimental Tasks}

Participants individually worked on two experimental tasks for a total of 20 minutes. First, to represent a routine task (labeled task 1 in the experimental instructions), we adopted a letter decoding task from prior research. Here, participants decoded letter combinations into numbers, using a decoding table that we provided to them (Chow 1983; Fisher et al. 2002). We labeled this task routine because it required individuals to follow known procedures to increase productivity. ${ }^{37}$

\footnotetext{
${ }^{37}$ Employees often have a lot of experience with their routine, day-to-day work such that they develop rules and/or procedures for most features of this work (Hodgson 1997).
} 
Second, to represent creative work (labeled task 2 in the experimental instructions), we asked participants to develop ideas for future experimental tasks and describe these tasks in a few sentences. Specifically, we asked participants to develop new, innovative and useful tasks that researchers can use in their experiments. Furthermore, we provided four criteria that tasks need to fulfill in order to be useful: task performance is easy to measure, the task is easy to understand, it is a real effort task, and the task is sensitive to effort. ${ }^{38}$ As such, consistent with creative task definitions in the psychology literature (e.g., Amabile 1996), this task required participants to develop innovative, but useful solutions to a problem. Moreover, the task is open-ended in that participants completed it without any known procedures to follow.

We chose the development of experimental tasks as our creative activity for a couple of reasons. First, it approximates many real-world settings where, in addition to their routine activities, employees develop creative ideas within the same general domain to further the strategic mission of the organization (Tate 2012). That is, since participants worked on an effort-intensive routine task (the letter-decoding task), we asked them to also develop ideas for future effort-intensive tasks since this is within a similar domain. Second, we believe that our participants had the knowledge to help them with this particular creative task. Specifically, student volunteers solicited for our experiment were from an undergraduate program where scholarly research in accounting is heavily integrated into the curriculum. Students also regularly participate in experiments that take place at that university. In fact, the average number of experiments that the participants attended prior to the experiment described in this study is 3.4 experiments. ${ }^{39}$ Thus, students had exposure to the research process and the type of questions typically asked of accounting scholars.

The computer presented each task on a separate screen. On the routine-task screen, participants saw the letter combination to decode and a field for entering their result. On the creative-task screen, participants saw a blank field to describe their next creative idea and the ideas that they already submitted. Participants could only see one of the two task screens at a time. Initially they saw the routine task screen. However, participants were free to switch back and forth between the tasks whenever and as many times as they desired by pressing a button

\footnotetext{
${ }^{38}$ The usefulness of an experimental task would ultimately depend on the general type of research question being pursued. Thus, we provided explicit criteria for this dimension of the creativity definition. Because participants were actively engaged in (and, thus have experience with) a real-effort, letter-decoding task in our experiment, the explicit criteria suggested that useful tasks would help examine research questions with a real-effort component. That said, we did not provide additional criteria for what is deemed new and innovative. To the extent that we provided examples or criteria for what is deemed innovative and participants followed these examples, our raters would likely not deem the resulting output as very new/innovative and, thus, not very creative. Consistent with this concern, prior creativity research demonstrates that output patterned after instructional examples typically receives lower creativity evaluations than output that is not patterned after the instructions (Kachelmeier et al. 2008).

${ }^{39}$ We observe no significant difference of the number of prior experiments across experimental conditions $\left(\mathrm{F}_{3,93}\right.$ $=0.68$, p-value $>0.5$ ). Moreover, we do not observe an incremental effect of prior experience participating in experiments and the creativity of the experimental tasks developed $(t=0.71, p$-value $>0.4)$. Potentially, participants' exposure to experiments in the curriculum usurped any incremental effect of participating in additional experiments. Alternatively, many of the experiments in which our subject pool participate are judgment-related studies in marketing or experimental markets in economics, which may not have helped participants in generating creative real-effort tasks.
} 
on the screen. ${ }^{40}$ Additionally, both task screens presented summary information which included the following: the number of correctly decoded letter combinations, the total amount of time spent on the routine task screen, and the amount of the original 20 minutes remaining to work on the tasks.

We informed all participants that we value the number of decoded letter combinations on the routine task and the number of creative ideas described on the creative task. However, as clearly described in the experimental instructions, all participants received a fixed amount of compensation of 10 EUR, which is completely independent of their performance on any of these two tasks.

\subsubsection{Design}

We employed a $2 \times 2$ between-participants design that manipulated the presence versus absence of an input target, and output target on the routine task, resulting in the following four experimental conditions: (1) no target, (2) input target only, (3) output target only, and (4) input and output targets. For the input target manipulation, we varied the presence/absence of a nonbinding target in the experimental instructions suggesting that participants spend at least ten minutes on the letter-decoding task (i.e., the routine task). For the output target manipulation, we varied the presence/absence of a nonbinding target in the experimental instructions suggesting that participants decode at least 100 letter combinations.

We developed the specifics of these manipulations with two primary thoughts in mind. First, we desired to hold constant the guidance provided by the input and output target for allocating time across tasks. As such, we set the output target based on the average ten-minute performance of participants completing a pilot study. ${ }^{41}$ Moreover, we structured the targets as a minimum amount of work or time to spend on the routine task, offering no such guidance on the creative task. In doing so, we examined the presence/absence of input and output targets for the routine task, holding constant the guidance that these targets provide about allocating time across the routine and creative tasks.

Second, to capture the inherent flexibility that many organization provide employees to use their time as they see fit, we structured both input and output targets as guidance as opposed to mandates. Specifically, we communicated the target as a minimum amount of output and/or time to achieve on the routine task and did not require participants to either meet these targets or to change tasks once they achieved these targets. In fact, we also

\footnotetext{
${ }^{40}$ By utilizing this design choice, our computer program could track the precise amount of time participants spent on each task screen. Of our 97 participants, 94 percent worked on the routine task for at least the first minute, and 91 percent worked on the routine task for at least two minutes. These percentages are consistent with our premise that participants view the routine task as their initial or primary task and the creative task as their secondary task.

${ }^{41}$ In a pilot where 12 participants worked on our decoding task, the mean performance was 102.5 correctly decoded letters in 10 minutes. Participants in the pilot were recruited from the same population as those in our experiment, but did not participate in our actual experiment.
} 
informed all participants that they are free to allocate their time and effort in any way. ${ }^{42}$ This design choice allows us to powerfully test our theory.

In our input target only condition, participants received the following statement in their instructions:

As a guide, we ask you to spend at least 10 minutes on the decoding task. That said, you are free to allocate your time and work effort across the two tasks in any way you want.

In the output target only condition, participants receive the following instructions:

As a guide, we ask you to decode at least 100 letter combinations into numbers. That said, you are free to allocate your time and work effort across the two tasks in any way you want.

In the input and output targets condition, we provide the following instructions:

As a guide, we ask you to spend at least 10 minutes on the decoding task and decode at least 100 letter combinations into numbers. That said, you are free to allocate your time and work effort across the two tasks in any way you want.

Finally, in our no target condition, we provide the following instruction:

You are free to allocate your time and work effort across the two tasks in any way you want.

\subsubsection{Procedures}

When participants entered the computer laboratory, they were randomly assigned to one of the four treatments conditions and read through their paper-based experimental instructions. Before entering the main stage of the experiment, participants correctly answered all questions of a short quiz. ${ }^{43}$ This quiz contained questions to confirm participants' understanding about their compensation, the value statement for both tasks, and their specific experimental condition.

Upon completion of the quiz, participants entered the main stage of the experiment where they work for 20 minutes on the two experimental tasks. Afterwards, participants completed a post-experimental questionnaire and received their 10 EUR compensation before leaving the experimental session.

\footnotetext{
${ }^{42}$ Many performance targets in organizations convey thresholds rather than specific points of achievement. For example, many output targets convey minimum achievement thresholds (Murphy 2001). Moreover, many input targets in settings such as ours convey either a minimum amount of time that should be spent on day-to-day activities or a maximum amount of time that should be spent on creative pursuits (Tate 2012).

${ }^{43}$ Participants submitting a wrong answer received text explaining the experimental instructions covered by the quiz question. They were then required to answer the quiz question again.
} 


\subsubsection{Creativity ratings}

Ten students from a graduate-level management accounting course volunteered to rate the creativity of participants' ideas for new experimental tasks. As part of their graduate program, these raters all had exposure to accounting research. More specifically, the compulsory literature of the program contains 22 research studies in major accounting journals, including many laboratory experiments. Further, the students followed a compulsory course on research methods, which included topics on experimental research design. Thus, our raters had significant knowledge about experimental research on which to draw when evaluating the creativity of participants' output.

All raters participated in a single two-hour rating session and received 25 EUR for their participation. The rater instructions explained that we asked a group of participants to develop new, innovative, and useful tasks that researchers can use in their experiments. Furthermore, we provided the same four requirements for the usefulness of the ideas as we did in the main experiment.

For rating purposes, we randomized the order of the 535 ideas for experimental tasks. Each rater evaluated a subset of 283 ideas. To calibrate all raters similarly, we held constant the first 31 ideas they evaluated. We randomly assigned and randomly ordered the other 252 ideas evaluated by each individual rater, such that each idea received five ratings (with the exception of the first 31 ideas which received ten ratings).

For each idea evaluated, raters entered a score between 1 (lowest creativity) and 10 (highest creativity) into a computer spreadsheet. The Cronbach's Alpha for the rating of all ideas is 0.67 and 0.71 for the 31 ideas rated first, which indicates sufficient agreement across the 10 raters. To determine the creativity score of each idea, we take the average score assigned by our raters. Overall, the average creativity score of the ideas is $4.97(\mathrm{SD}=1.15)$, and it ranges between 1 and 8.6.

To give a better idea about the creativity range of ideas generated during the experiment, Table 6 gives examples of three ideas receiving relatively low creativity ratings and three ideas receiving relatively high creativity ratings. When examining the low-creativity ideas, our raters likely did not perceive the first task listed in Table 6 (i.e., "students must let their hair grow for a year; the more hair the better") as very useful, since we requested tasks that are sensitive to effort. Moreover, the other two low-creativity ideas listed in Table 6 are simple extensions of one of the examples we provided participants in their instructions. Specifically, the two other low-creativity tasks listed in Table 6 ask participants to perform simple calculations, which is a simple extension of our example (i.e., "Participants must solve multiplication problems"). As such, our raters likely did not view these tasks as very new or innovative. Consistent with this, across our entire sample of experimental tasks, those ideas patterned after an instructional example received a lower creativity rating on average than those not patterned after an instructional example $(\mathrm{t}=2.67, \mathrm{p}<0.01) .{ }^{44,}{ }^{45}$ Alternatively, the

\footnotetext{
${ }^{44}$ Out of the 535 ideas, we identified 140 experimental tasks that utilized decoding or calculation tasks, which were simple extensions of the two examples we provided to the participants in the instructions (i.e., "Participants must decode letter combinations into numbers" and "Participants must solve multiplication problems.")
} 
three high-creativity ideas listed in Table 6 are not extensions of the instructional examples and meet the requirements for usefulness that we provided to our experimental participants. Collectively, these evidences suggest that our raters considered both the innovativeness and usefulness of experimental tasks when assessing creativity. ${ }^{46}$

Table 6: Three Ideas Receiving High (Low) Creativity Ratings

\begin{tabular}{|l|c|}
\hline Three Ideas with High Creativity Ratings & $\begin{array}{c}\text { Average } \\
\text { Rating }\end{array}$ \\
\hline $\begin{array}{l}\text { Participants must create different solutions for a single problem. The more } \\
\text { solutions that solves the probllem pracially they have the higheir their } \\
\text { performance. }\end{array}$ & 8.0 \\
\hline $\begin{array}{l}\text { Participants must find the way through labyrinths by shifting blocks. The } \\
\text { more labyrinths are solved, the higher the performance. }\end{array}$ & 7.8 \\
\hline $\begin{array}{l}\text { Participants are given a list of short problems with unnecessarily complex } \\
\text { formulation. Participants are asked to explain the core problem in the } \\
\text { simplest way possible. They are only allowed to use a limited amount of } \\
\text { words in total. }\end{array}$ & 7.6 \\
\hline Three Ideas with Low Creativity Ratings & 2.8 \\
\hline students must let their hair grow for a year; the more hair the better & 3.0 \\
\hline $\begin{array}{l}\text { Sum up different number. The more summings correct, the higher the } \\
\text { performance }\end{array}$ & \\
\hline Sudents must do a calculation by hand; faster the better & \\
\hline
\end{tabular}

Note: This table shows three ideas from our experimental participants that received relatively high and low creativity ratings. The ideas are presented here as they were originally submitted by participants (including spelling mistakes and typos). The creativity raters saw the ideas of the participants in this original form when they assessed the creativity of each idea on a scale from 1 (lowest creativity) to 10 (highest creativity).

Consistent with the value statement provided to all experimental participants, the main dependent variable of interest is the number of high-creativity ideas submitted by each participant. For the purposes of the analyses reported in the next section, we classify ideas receiving a score at or above the median rating of five as highly creative. This cutoff gives us a total of 283 high-creativity ideas. That said, our results are robust when taking other cutoff points for high-creativity ideas such as the top quartile.

\footnotetext{
${ }^{45}$ All reported p-values are two tailed unless otherwise stated.

${ }^{46}$ To further validate the creativity ratings, we provided the experimental instructions and eight experimental task ideas generated during our experiment to a professor outside the author team with experience designing experiments. We asked this professor to identify the high-creativity and the low-creativity ideas. The four ideas identified as high (low) creativity received an above (below) median creativity score from our raters, suggesting that asking individuals with greater experimental design expertise would not materially affect our creativity ratings and results.
} 


\subsection{Results}

\subsubsection{Hypothesis test}

Our hypothesis predicts that providing both an input and output target on routine tasks leads to greater creative task performance relative to providing one or none of these targets. Table 7 presents descriptive statistics for variables of interest by experimental condition, including the number of high-creativity ideas produced. Figure 9 provides a graphical depiction of the average number of high-creativity ideas by experimental condition. Consistent with our hypothesis, participants in our input and output target condition submitted an average of 4.00 high-creativity ideas, while participants in the no target, output target only, and input target only conditions submitted an average of 3.00, 2.36, and 2.33 high-creativity ideas respectively.

Panel A of Table 8 reports the results of an ANOVA where the number of highcreativity ideas submitted is the dependent variable and input target and output target are the independent variables. The ANOVA yields a statistically significant output target $\times$ input target interaction $\left(\mathrm{F}_{1,93}=10.82, \mathrm{p}<0.01\right) .{ }^{47}$ Panel B Table 8 of presents the planned contrast analysis that we use for testing our hypothesis. According to Buckless and Ravenscroft (1990), planned contrasts are best used for testing ordinal interactions such as the one predicted in our hypothesis. In line with our prediction we attach the values of -1 to the no target, - 1 to the output target only, -1 to the input target only conditions, and +3 to the combined input and output target condition. The results in Panel B show that the predicted pattern is statistically significant $\left(\mathrm{F}_{1,93}=12.49, \mathrm{p}<0.01\right)$. Furthermore, an untabulated ANOVA shows that there is no significant difference in the number of high-creativity ideas among the no target, the input target only, and the output target only conditions $\left(\mathrm{F}_{2,70}=1.61, \mathrm{p}\right.$ $>0.20)$. Collectively, these results are consistent with our hypothesis.

\footnotetext{
${ }^{47}$ Consistent with our hypothesis, an untabulated simple main effect analysis shows that providing an output target increases the number of high-creativity ideas in the presence of the input target $\left(\mathrm{F}_{1,93}=11.19, \mathrm{p}<0.01\right)$, but not in the absence of the input target $\left(\mathrm{F}_{1,93}=1.68, \mathrm{p}>0.10\right)$.
} 
Table 7: Descriptive Statistics

\begin{tabular}{|c|c|c|c|c|c|}
\hline & \multicolumn{2}{|c|}{ No input target } & \multicolumn{2}{|c|}{ Input target } & \multirow[b]{2}{*}{$\begin{array}{c}\text { Total } \\
\text { (5) }\end{array}$} \\
\hline & $\begin{array}{l}\text { No output } \\
\text { target } \\
\text { (1) }\end{array}$ & $\begin{array}{c}\text { Output } \\
\text { target } \\
(2)\end{array}$ & $\begin{array}{c}\text { No output } \\
\text { target } \\
\text { (3) }\end{array}$ & $\begin{array}{c}\text { Output } \\
\text { target } \\
(4)\end{array}$ & \\
\hline $\begin{array}{l}\text { Number of high- } \\
\text { creativity ideas }\end{array}$ & $\begin{array}{c}3.00 \\
(1.62)\end{array}$ & $\begin{array}{c}2.36 \\
(1.29)\end{array}$ & $\begin{array}{l}2.33 \\
(1.47)\end{array}$ & $\begin{array}{c}4.00 \\
(2.36)\end{array}$ & $\begin{array}{c}2.92 \\
(1.83)\end{array}$ \\
\hline Number of ideas & $\begin{array}{l}5.75 \\
(2.64)\end{array}$ & $\begin{array}{l}5.16 \\
(2.46)\end{array}$ & $\begin{array}{c}4.21 \\
(2.53)\end{array}$ & $\begin{array}{c}6.96 \\
(3.94)\end{array}$ & $\begin{array}{c}5.52 \\
(3.07)\end{array}$ \\
\hline Time on creative task & $\begin{array}{c}612.22 \\
(256.00)\end{array}$ & $\begin{array}{c}504.73 \\
(210.83)\end{array}$ & $\begin{array}{c}397.36 \\
(173.32)\end{array}$ & $\begin{array}{c}536.82 \\
(160.64)\end{array}$ & $\begin{array}{c}512.70 \\
(214.84)\end{array}$ \\
\hline $\begin{array}{l}\text { Productivity creative } \\
\text { task }\end{array}$ & $\begin{array}{c}0.0054 \\
(0.0033)\end{array}$ & $\begin{array}{c}0.0047 \\
(0.0023)\end{array}$ & $\begin{array}{c}0.0063 \\
(0.0040)\end{array}$ & $\begin{array}{c}0.0074 \\
(0.0037)\end{array}$ & $\begin{array}{c}0.0059 \\
(0.0035)\end{array}$ \\
\hline Correct routine task & $\begin{array}{l}104.46 \\
(58.96)\end{array}$ & $\begin{array}{l}140.00 \\
(46.78)\end{array}$ & $\begin{array}{l}146.29 \\
(52.72)\end{array}$ & $\begin{array}{l}130.04 \\
(44.81)\end{array}$ & $\begin{array}{l}130.30 \\
(52.75)\end{array}$ \\
\hline $\begin{array}{l}\text { Productivity routine } \\
\text { task }\end{array}$ & $\begin{array}{c}0.170 \\
(0.035)\end{array}$ & $\begin{array}{c}0.202 \\
(0.032)\end{array}$ & $\begin{array}{c}0.178 \\
(0.035)\end{array}$ & $\begin{array}{c}0.195 \\
(0.036)\end{array}$ & $\begin{array}{c}0.186 \\
(0.036)\end{array}$ \\
\hline$N$ & 24 & 25 & 24 & 24 & 97 \\
\hline \multicolumn{6}{|c|}{$\begin{array}{l}\text { Number of high-creativity ideas }=\text { Number of ideas submitted with ratings equal or higher than the median rating } \\
\text { Number of ideas }=\text { Number of ideas submitted irrespective of their creativity rating } \\
\text { Time on creative task = Time spent on the creative task in seconds (total time } 1200 \text { seconds) } \\
\text { Productivity on the creative task = Number of high-creativity ideas divided by time spent on the creative task; } \\
\text { excluding two participants who did not spend any time on the creative task }\end{array}$} \\
\hline \multicolumn{6}{|c|}{$\begin{array}{l}\text { Correct routine task }=\text { number of correct letter combinations decoded on the routine task } \\
\text { Productivity routine task }=\text { Correct responses divided by Time on routine task in seconds; excluding two } \\
\text { participants who did not decode any letter combination } \\
N=\text { Number of participants in each condition }\end{array}$} \\
\hline
\end{tabular}


Table 8: Effect of Input and Output Targets on the Number of High-Creativity Ideas

Panel A: ANOVA model of number of high-creativity ideas

\begin{tabular}{lcccc}
\hline Source & $d f$ & Mean Square & $F$ & $p$-value \\
\hline Input target & 1 & 5.74 & 1.93 & 0.17 \\
Output target & 1 & 6.39 & 2.14 & 0.15 \\
Input target $\times$ Output target & 1 & 32.25 & 10.82 & $<0.01$ \\
Residual & 93 & 2.98 & & \\
\hline
\end{tabular}

Panel B: Planned Contrast

$\begin{array}{lccc}\text { Contrast } & 1 & 12.49 & <0.01 \\ \text { Residual } & 93 & & \end{array}$

Note: Panel A shows the results of an ANOVA with the number of high-creativity ideas as dependent variable and input target, output target and an interaction of input and output target as independent variable. Given our directional predictions the interaction $\mathrm{p}$-value is one tailed, while main effect p-values are two tailed.

Panel B shows planned contrast analysis for testing the hypothesis. The values attached are $-1,-1,-1$, and +3 for the no target, input target only, output target only, and the combined input and output target groups, respectively.

Number of high-creativity ideas $=$ Number of ideas submitted with ratings equal or higher than the median rating

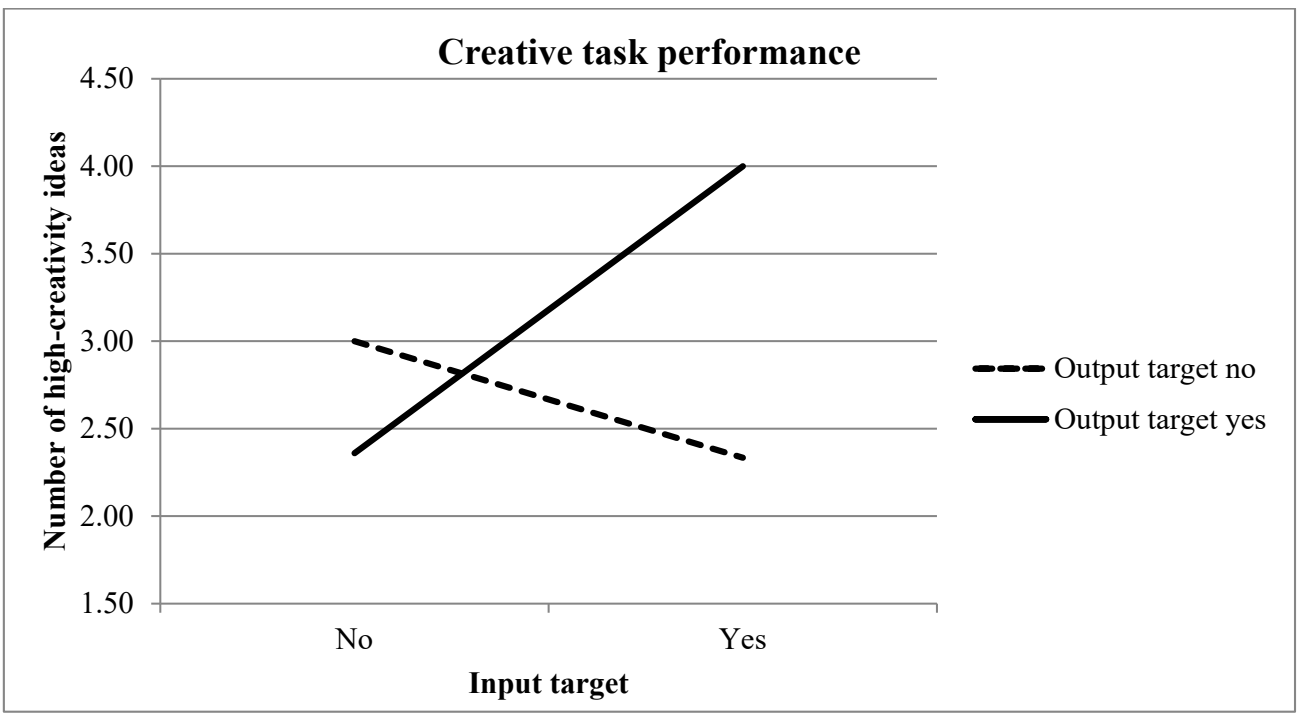

Note: This figure shows the effect of input and output targets on the number of high-creativity ideas submitted by the experimental participants.

Number of high-creativity ideas $=$ Number of ideas submitted with ratings equal or higher than the median rating

Figure 9: The Effect of Input and Output Targets on Creative Task Performance 


\subsubsection{Supplemental Analyses}

In developing our hypothesis, we argue that the presence of output targets could lead individuals to more strongly focus on the task at hand to the benefit of productivity on these tasks. Moreover, input targets can encourage individuals to reserve sufficient time for the creative task, especially for individuals provided with output targets. As further tests of these specific processes, we provide several additional analyses. First, we analyze the effect of output targets on individuals' task focus. Second, we examine how the increased task focus from output targets influences the productivity of participants on the routine and the creative tasks. Finally, we examine how input targets influence the time that participants with output targets reserve for the creative task.

\subsubsection{Output Targets and Task Focus}

To investigate whether output targets indeed increase the extent to which participants focus on the task at hand, we analyze their responses to two open-ended questions in the postexperimental questionnaire. Specifically, the questionnaire invited responses to the following two statements: (1) Describe in a few sentences your strategy for how you allocated your time across the two tasks, and (2) Explain why you chose the strategy you just described. A doctoral student blind to both the purpose of our study and our experimental manipulations evaluated whether each participant reported focusing on the task at hand rather than attempting to multi-task by working on tasks simultaneously. In evaluating whether a participant focused on the task at hand, the doctoral student responded to each set of participant responses (presented in a randomized order) either "yes" or "no." 48 Most of the 64 percent of responses coded as "yes" suggested that the participants worked on a task, reached a stopping point, and then worked on the other task. Most of the 36 percent of responses coded as "no" suggested that the participant attempted to develop creative ideas while working on the routine task and/or haphazardly switched back and forth between tasks. ${ }^{49}$

Overall, based on their reported strategies, participants with output targets are significantly more focused on the task at hand than participants without output targets. While our independent rater assessed 84 percent of participants with output targets as focused on the task at hand (88 percent of participants in output target only condition and 79 percent of participants in the input and output target condition), the rater classified only 44 percent of the participants without output targets as focused on the task at hand (46 percent of participants in the no target condition and 42 percent of participants in the input target only condition). Using this task focus measure as the dependent variable, we estimate an ANOVA with input target and output target as the independent variable. We find a significant main effect of output

\footnotetext{
${ }^{48}$ To validate the evaluation of our rater, one of the authors independently provided a similar evaluation for each set of participant responses. The author's evaluations agreed with those of the rater for 75 percent of the participants. Given this high level of agreement, we take the independent ratings of the doctoral student as our dependent measure.

49 A representative example of a task coded as "yes" is as follows: "I first started with task 1 and worked on this task for 10-11 minutes. Then I switched to task 2 and spent all the remaining time on task 2." Representative examples coded as "no" are as follows: (1) "Started with task 1 and doing task 1, tried to think of certain ideas for task 2," (2) "I had no real strategy. At a certain point I was interested to see what task 2 entailed and then switched to that. After that, I would switch back to task 2 every time I come up with an idea...," (3) "Randomly switched back and forth. As soon as I had no fun doing one anymore."
} 
target $\left(\mathrm{F}_{1,93}=19.45, \mathrm{p}<0.01\right)$, no significant input target main effect $\left(\mathrm{F}_{1,93}=0.52, \mathrm{p}=0.474\right)$, and no significant input target $\times$ output target interaction $\left(\mathrm{F}_{1,93}=0.07, \mathrm{p}=0.80\right) .{ }^{50}$

\subsubsection{Output Targets and Productivity on Routine and Creative Tasks}

To investigate whether the increased task focus promoted by output targets increased productivity, we first examine the impact of output targets on routine task productivity, operationalized as the number of correctly decoded letter combinations divided by the number of seconds spent on this task. Table 7 summarizes the average productivity on the routine task by experimental condition. Using routine-task productivity as the dependent variable, we estimate an ANOVA with input target, output target and an interaction of input and output targets as the independent variables. This analysis yields only a significant output target main effect $\left(\mathrm{F}_{1,93}=7.45, \mathrm{p}<0.01\right)$. This result supports our expectation that the presence of an output target increases focus during the time spent on the routine task, which results in significantly higher productivity on the routine task. ${ }^{51}$

Furthermore, the more focused task strategy motivated by an output target could also increase participants' productivity per second on the creative task (i.e., the number of highcreativity ideas divided by the number of seconds on the creative task). That is, achieving the output target provides the opportunity for cognitive closure on the routine task so that individuals can focus on the creative task. Table 7 summarizes the average productivity on the creative task by experimental condition. As suggested by these means, an output target without an input target does not enhance productivity on the creative task relative to no targets $(\mathrm{t}=0.81 ; \mathrm{p}=0.42)$. However, participants in the combined input and output target condition are, on average, more productive on the creative task than the average productivity level of participants across the other three conditions $(t=2.36$, one-tailed $p=0.01)$, suggesting that the more focused task strategy motivated by an output target increases productivity on the creative task only in the presence of an input target.

\subsubsection{Time on the Creative Task}

We now investigate whether providing an input target increased the time participants with an output target reserved for the creative task. Providing those with an output target an input target increased the time spent on the creative task from 504.73 seconds (median $=510.33$ seconds) to 536.82 seconds (median $=574.01$ seconds). Comparing time across these conditions with a Wilcoxon signed-rank test to reduce the impact of extreme values, we find that, for participants with an output target, providing an input target increases the time participants spend on the creative task $(\mathrm{Z}=1.81, \mathrm{p}=0.04) .{ }^{52,53}$

\footnotetext{
${ }^{50}$ To provide a more objective measure of task focus, we also examine the number of times participants switched tasks after spending at least five seconds on the previous task. Consistent with our conclusions from the openended responses, participants without output targets switched tasks significantly more than participants with output targets [mean $4.56(\mathrm{sd}=3.13)$ versus $3.55(\mathrm{sd}=2.02), \mathrm{t}=1.90$, one-tailed $\mathrm{p}=0.03$ ].

${ }^{51}$ Of the participants who decoded at least one letter-number combination, all but two, those with a focused task strategy are marginally more productive on the routine task than participants evaluated as having an unfocused task strategy [mean $0.190(\mathrm{sd}=0.034)$ versus $0.179(\mathrm{sd}=0.04), \mathrm{t}=1.38, \mathrm{p}=0.09$ ].

${ }^{52}$ As suggested by the descriptive statistics reported in Table 7, the time spent on the creative task is the lowest for those in the input target only condition (all pairwise comparisons $t>1.94, p<0.058$ ). While this result might raise concerns about our operationalization of the input target, our theory can explain this finding. First, absent
} 
Collectively, our results provide support for our theory that a combination of input and output targets increases the creativity of individuals by ensuring that people fully focus on generating creative ideas while working on this task and reserve enough time for the creative task. As a final test of this complementarity, we examine whether an output target increases the efficacy of the time spent on the creative task. Specifically, we estimate a regression with productivity on the creative task as the dependent variable and the following as independent variables: the presence of an output target, time on the creative task, and the interaction between the output target and time spent on the creative task. Consistent with our theory, we find a significantly positive effect of the interaction variable $(t=1.63$, one-tailed $p=0.05)$. That is, the output target on the routine task increases productivity on the creative task more if participants spend more time on the creative task.

\subsection{Conclusions}

In environments where employees have the freedom to direct some time away from their routine, day-to-day tasks to pursue creative endeavors, we examine how output and input targets on a routine task affects creative task performance. We do so using a laboratory experiment where individuals can freely allocate time between a routine task (a decoding task) and a creative task (develop creative ideas for future experiments). We manipulate the presence/absence of targets that provide guidance about the amount of time to spend on the routine task (input target) and the amount of routine task output to produce (output target).

Our results indicate that creative task performance is greatest in the presence of both an output target that increases individuals' focus on the task at hand and an input target that increases the time individuals spend on the creative task. This result is consistent with theory suggesting that an output target not only increases individuals' attention during that task, but also enables cognitive closure once they achieve the target. This cognitive closure allows individuals to fully focus on creative ideas while working on the creative task. Furthermore, in the presence of an output target, the input target encourages individuals to break away from the relatively comfortable routine task and spend more of this focused time thinking creatively. Collectively, these findings support our theory that input and output targets on routine tasks are complementary mechanisms in promoting creative task performance.

\footnotetext{
an output target, individuals have difficulties achieving cognitive closure on the routine task such that they continually work on it. Second, participants report that they think creatively while working on the routine task which suggests that the time spent on the creative task screen likely understates the time these participants actually worked on the creative task. Both of these reasons can explain why participants with an input target only spend significantly more time on the routine task screen than in the other conditions. This lack of focus is also reflected in the lower output in both the routine task (one-tailed $\mathrm{p}=0.01$ ) and the creative task (one-tailed $\mathrm{p}=$ 0.07 ) relative to those in the input and output target conditions, when controlling for the time they spend on these tasks.

${ }^{53}$ As suggested by the descriptive statistics reported in Table 7, our results highlight that those with no targets spend more time on the creative task than participants across the other three conditions $(t=2.70, p<0.01)$. This result suggests that providing any target may have signaled to participants that we wanted them to spend more time on the routine task. Consistent with our theory, participants with no targets still generated fewer highcreativity ideas than participants with both an input and output target despite spending more time on the creative task $(\mathrm{t}=1.71$, one-tailed $\mathrm{p}<0.05)$.
} 
Our results contribute to a better understanding of current business practices. For example, the practitioner literature often touts the benefits of companies such as Google and $3 \mathrm{M}$ encouraging their employees to spend a portion of their work week engaged in unstructured, uncontrolled creative thought (Tate 2012). Moreover, prior research in accounting highlights that some organizations set relatively easy output targets on routine work to encourage employees to spend slack time on more creative pursuits (Merchant and Manzoni 1989). While these practices are typically discussed separately, our results suggest that they are complementary design choices. Specifically, our results suggest that organizations may be able to enhance the effectiveness of the time employees spend on creative pursuits by providing them with a target that communicates what they are expected to accomplish on their routine work. Moreover, in the presence of an output target, an input target helps to ensure that individuals break away from their primary routine task to pursue their creative endeavors.

We also contribute to the accounting literature examining the role of appropriately designed control systems to promote desired behavior and outcomes. While prior accounting research in this area predominately examines environments where participants work solely on a relatively routine (algorithmic) task (e.g., Christ et al. 2016) or a creative task (e.g., Kachelmeier et al. 2008; Kachelmeier and Williamson 2010), our study highlights unique control challenges of encouraging employees to engage in creative pursuits in addition to their routine, day-to-day responsibilities. In this environment, we highlight that even non-binding targets for the routine task improve creative-task performance. Our results also indicate that the higher creativity of individuals with input and output targets does not come with lower productivity during the time they spend on routine work. This result has important implications for practice as many organizations not only rely on the creativity of their employees but also require high day-to-day, routine task performance of their employees. Our study suggests that by designing appropriate targets for the routine task, firms can achieve higher productivity on both tasks.

While our results suggest that output targets on routine tasks can effectively promote creative-task performance in the presence of input targets, future research can explore other situations that either improve or impair the efficacy of input and output targets in multi-task environments. For example, in the only other study in which we are aware that examines the effect of an output target on a routine task on creative task performance, Madjar and Shalley (2008) find that placing an output target only on the routine task does not increase creative task performance. However, important differences between Madjar and Shalley (2008) and our study likely contribute to these disparate results. First, in this prior study, participants worked on both the routine and creative tasks for a fixed amount of time (i.e., ten minutes each). As such, they did not examine the tension brought on by allowing individuals to choose how much time to spend on each task (as is often the case in practice). Therefore, Madjar and Shalley (2008) could not study the interactive effect of output and input targets on the routine task on creative task performance, as is the aim of our study. Second, in the prior study, the output target was set at such a challenging level that participants could not achieve it. Here, participants may not have achieved the necessary cognitive closure on the routine task to effectively think creatively. That said, given the different results, future research can explore 
the specific factors that must be present in order for output targets on routine tasks to enhance creative task performance.

Limitations of our study provide additional opportunities for future research. For example, to hold guidance constant across our input and output target conditions, our input target provides guidance as to the minimum amount of time to spend on the routine task. Some organizations, on the other hand, provide input targets as to the maximum amount of time to spend on the creative task (i.e., spend at most one day a week on creative endeavors). A potential concern of our operationalization is that while those with only an input target spend less time on the creative task, a different operationalization could potentially encourage these individuals to spend more time on the creative task. That said, even when we control for the time individuals spend on each task, those with only an input target are less productive on both the routine and creative task. Future research can explore whether our conclusions are robust to a different operationalization of the input target.

Finally, while we informed our experimental participants that we value their performance on both the routine and creative tasks, several design choices we made likely suggested to participants that the routine task was the primary responsibility and the creative task was the secondary responsibility. As such, nearly all our participants first worked on the routine task before working on the creative task. Thus, our results most directly speak to the pervasive environment where employers allow employees to allocate some time away from their primary, routine tasks for creative pursuits. That said, in other environments, creative endeavors would be the day-to-day, primary task and routine tasks such as administrative duties would be secondary. Given our supported theory suggests that input and output targets help individuals compartmentalize the tasks so that they can devote their full cognitive effort to one task before being encouraged to move to the next, our results could generalize to this setting as well. Moreover, our supported theory could also generalize to a setting where individuals must devote attention to other cognitively challenging tasks that do not necessarily involve creativity in addition to their relatively routine responsibilities. Future research could explore these possibilities to gain a better understanding as to the specific settings where input and output targets on one task affects performance on a different task without such targets. 


Chapter 5: Conclusions 


\section{Conclusions}

In this dissertation I examine supervisors' target setting decisions and employees' reactions to performance targets. Being part of the management control system, performance targets can support organizations in translating their overall strategy in smaller pieces and align the objectives of the organization with the objectives of the individual members. By setting clear performance targets for individual employees, companies communicate their expectations and ensure that employees follow the directions of the firm. This should induce employees to take the necessary actions that contribute to the overall success of the company. Furthermore, setting performance targets also directly impacts the motivation of employees. Thus, performance targets not only help to coordinate the actions across departments and individuals, but also impact the motivation and performance of employees.

In this thesis I investigate three major aspects related to target setting. First, I examine the information that supervisors use when setting performance targets and how their own experience on the employees' task influence their target setting decisions. Second, I study how the use of employees' past performance information when setting performance targets and the evolvements of targets over time influence employees' tradeoff between short-term output maximization and long-term investments. Finally, I investigate how targets around routine tasks influence the creative task performance of individuals. The section that follows discusses the findings of each of these three studies, followed by the main contributions, limitations and potential avenues for future research.

\subsection{Summary}

In chapter 2 of this dissertation, I investigate what information supervisors use when setting performance targets for their employees and whether this depends on their own background. More and more companies implement policies where they encourage their future managers to gain experience in multiple areas and functions within a company (e.g., job rotation, internal labor markets, long-term training programs), whereas in other companies this is less common. Gaining experience on the tasks can increase the understanding of the company and the tasks they supervise later on. In addition, the performance and their own experiences on these tasks can also influence their target setting behavior. Therefore, I examine whether supervisors who have worked themselves on the task of their employees before set different targets than supervisors without such experiences on the employees' task. In an experiment where I hold the task understanding and the information about the expected performance constant, I find that supervisors with task experience discount relevant information about expected employees' performance and overemphasize their own experiences. The results show that supervisors with task experience and good performance set higher target levels than supervisors with task experience and low performance, and supervisors without task experience. Furthermore, supervisors with task experience but low performance tend to react overly strong to changes in the operating environment. This leads them to change targets more than supervisors with task experience and high performance and supervisors without task experience. These findings are consistent with projection theory suggesting that individuals tend to project their own experiences on other individuals, while also engaging in self-serving attributions where individuals explain their own low performance mainly by external factors 
(i.e., task difficulty, bad luck) whereas they explain own high performance primarily by internal sources (i.e., ability, effort).

In chapter 3, I investigate how targets that increase over time as supervisors use employees' past performance information when setting new targets (i.e., target ratcheting) influences employees' long-term investment decisions. Despite the negative consequences that have been documented in prior literature about target ratcheting, many companies use past performance information when setting targets for employees. While most of these studies investigate a single task setting, in chapter 3, I investigate a setting where employees work on multiple tasks. Employees either work on a task that maximizes short-term output or they work on a task that increases the chances to achieve long-term productivity improvements. In such a setting I develop and test theory showing that target ratcheting can mitigate the horizon problem and keep the investment levels constant even though the managers' time horizon decreases. To test this theory, I perform a multi-period experiment where I compare the investments in future productivity increases from a group where past performance directly affects the new targets (target ratcheting), a group where targets increase over time but this increase is unrelated to own past performance, and a group where targets stay the same. The findings are in line with my prediction that the investments in the target ratcheting groups stay longer at a high level, whereas investment goes down for the other two groups as the time horizon decreases. This means that using past performance information when setting new performance targets leads to higher investment levels in long-term projects by reducing employees' horizon problem.

In chapter 4, I examine how input and output targets around a routine task can affect creative task performance. Many organizations encourage their employees to spend a portion of their work week away from their day-to-day routine tasks to pursue creative activities that ultimately should lead to benefits for the company. While the practitioner literature often highlights the success of policies where companies provide time guidance (e.g., Google, 3M) for how to allocate the time across tasks, academic literature discusses the role of budgetary slack to foster creative output. Hence, I investigate in how far input (time) and output targets around the routine task affect creative task performance. I argue that input and output targets are complementary design choices where the provision of both leads to greater creative task performance than providing just one of these targets alone, or none of them at all. In an experiment where individuals are free to allocate time and effort between a routine and a creative task, I find support for this hypothesis. Specifically, I find that providing just an input or an output target around the routine task does not affect creative task performance compared to no target at all, while a combination of input and output targets leads to significantly higher performance than any other group. Furthermore, consistent with the theory developed, the results show that the output target around the routine task provides individuals with increased task focus and the necessary cognitive closure to increase their creative task performance. Moreover, for those individuals with an output target, the additional input target encourages them to reserve enough time for creative pursuits. Thus, the combination of both leads to the highest creative task performance. 


\subsection{Contributions and implications}

Each study's individual contribution is discussed separately in the corresponding chapter. However, I would like to highlight some of the key contributions of this dissertation. First, I contribute to the literature examining supervisors' target setting decisions and what kind of information they consider. Accounting and psychology have examined the relevance of the target level for motivation (Merchant and Van der Stede 2007; Latham and Locke 1991). To derive the appropriate performance target levels, supervisors usually have various information sources available such as past performance information, peer performance, market studies of future developments, and other information (Merchant and Van der Stede 2007; Aranda et al. 2014). So far, most literature has focused on subordinate characteristics to show how supervisors use their discretion during the target setting process (e.g., Anderson et al. 2010; Bol et al. 2010). In contrast, I show that also task experience of supervisors on their employees' task and the performance they achieved on that task influences how supervisors use their discretion. Showing that own task experience can distort the incorporation of relevant information is important to increase the effectiveness of the budgeting and target setting systems. For example, companies can better identify supervisors who might set distorted targets for their employees and also increase manager's awareness of such potential problems in their manager training programs. Furthermore, in light of the increasing number of organizations that incorporate policies to foster future managers gaining experience in various functions and areas of the organization, it is important to identify potential caveats of such policies with respect to their future leadership role.

Second, this dissertation contributes to the growing streams of management accounting literature on control system designs in multi-task environments (Christ et al. 2012; Hecht et al. 2012; Brüggen and Moers 2007; Christ et al. 2016) and environments where companies face a tradeoff between short-term profit maximization and long-term investments (Farrell et al. 2008). For example, I show how target ratcheting affects individuals' tradeoff between maximizing short-term output and long-term investments. Furthermore, I also show how targets around the routine task affect creative task performance. Therefore, I contribute to a better understanding of how companies can use their target setting systems in order to achieve a balance between short-term output maximization and setting the ground for future success in form of long-term investments.

Furthermore, this dissertation contributes to the literature examining the use of past performance information for setting targets and the ratchet effect. This literature often highlights the negative consequences of target ratcheting for the effort of individuals in a single task setting (e.g., Bouwens and Kroos 2011; Weitzman 1980). However, I show that in a multi-task setting where employees can invest in uncertain long-term productivity improvements, target ratcheting can mitigate potential horizon problems. This could provide one potential explanation for the widespread use of target ratcheting, despite the known negative consequences. Furthermore, many organizations face situations where they need to find a balance between maximizing short-term output and at the same time invest in future success. While horizon problems can lead to distorted investments, I show that by applying 
target ratcheting companies ensure that employees keep their investment levels high even though their time horizon decreases.

Finally, I contribute to the management accounting literature on creativity and control. Over the last years a growing stream of literature has developed examining the effect of management control practices on creativity of individuals (Kachelmeier et al. 2008; Kachelmeier and Williamson 2010; Grabner 2014) and groups (Chen et al. 2012). However, as these studies examine mainly settings where employees are responsible just for creative tasks, they focus on control systems that companies install around the creative task. In contrast, I examine a setting where employees are responsible for creative tasks in addition to their day-to-day routine tasks. Showing in such a setting that input and output targets are complementary design choices reconciles the separate discussions of business press promoting time guidance as a means to foster creativity - and academic literature - talking about budgetary slack to promote creative thinking of employees. My study shows that by installing one of these mechanisms companies can increase the effectiveness of the other. This provides companies with insights for how to increase the effectiveness of their systems.

\subsection{Limitations and future research}

As with any study, this dissertation is subject to certain limitations that provide avenues for future research. While I discuss the limitations of the single studies in each of the chapters, I want to discuss common limitations for all chapters here. In all three studies I have to abstract away from certain management decisions in order to better isolate and understand the effect that the policies of interest have on individuals' behavior. For example, by examining a setting where supervisors have to define a quantitative target for the output of individuals in chapter 2, I abstract away from the decision which dimensions of a task to include in a target. In certain type of jobs it might not only be relevant to achieve a high output, but avoiding errors could be more important than maximizing the output (e.g., a mistake by a surgeon might not decrease the number of surgeries per day, but the costs of such a mistake could be severe for the patient and the hospital). In such settings, supervisors would set targets on other dimensions of a task or include multiple dimensions in the targets. Examining how the supervisors' background influences the choices of measures for which to set the targets could be an interesting avenue to follow. Furthermore, in chapter 3 and 4, I examine the effect of target setting on employees' choice between short-term output maximization and investments that build the basis for future success of the firm. Thus, I take the company's choice to combine multiple tasks in one job as given in order to focus on the effect of target ratcheting on long-term investment and the effect of providing targets around routine tasks to foster creativity. While combining these tasks in one position reflects a large portion of jobs in business practice, in some companies these duties might be separated. Future research could try to expand our knowledge about the determinants and consequences for combining these tasks in one position and thus, contribute to a better understanding on the debate about specialization versus generalization.

Furthermore, conducting rigorous research often requires to focus on specific aspects of an area instead of explaining everything at once. For example, in chapter 2, I examine how the supervisors' background (i.e., task experience on employees' task) influences the target 
levels that they set for their employees. As I discuss in the chapter, there is large variation in the experience that supervisors have on the tasks of their employees and more and more companies implement policies where they require their future managers to gain such experiences. However, task experience is only one form of supervisors' background that could influence their target setting decisions. Future research could investigate other aspects such as personality traits or other personality characteristics and their effect on the target setting behavior. In a similar vein, in chapters 3 and 4, I examine in multi-task settings how target ratcheting and targets around a routine task can influence the long-term investments and the creativity of employees. While I discuss the relevance of these settings and policies in each chapter, future research could extent my studies by looking at other formal and informal mechanisms to foster such long-term investments and the creativity of individuals in these settings. That said, while the three studies focus on specific aspects of target setting, they all contribute to a better understanding of the very complex area of target setting in organizations.

However, also the choices with respect to the research method provide avenues for future research. Creating abstract environments in a laboratory where everything is held constant and participants are randomly assigned across conditions helps to control for external (potentially confounding) factors and isolate treatment effects. Nevertheless, in practice the decision of supervisors to adapt certain management techniques for individual employees might be an endogenous choice. Furthermore, employees might also look for positions and companies that are in line with their personal preferences. Importantly, the theories and predictions that I develop in all three chapters would likely not be affected by such endogenous choices. That said, the self-selection of employees to companies that apply certain policies and the effect of supervisors' management choices on employees' behavior are in itself interesting research questions that future research could address. Furthermore, researcher could also verify the results of my studies using different specifications of the experimental settings and manipulations such as changing the incentive contracts, using different tasks, and perform the experiments with different populations groups. Finally, creating highly abstract settings in experiments raises potential concerns about external validity. While the theories of the chapters in this dissertation also likely generalize to the outside world, future research could verify my studies using different research methods, including field-/case studies with internal company data. 


\section{References}

Abeler, J., A. Falk, L. Goette, and D. Huffman. 2011. Reference points and effort provision. The American Economic Review 101 (2):470-492.

Alicke, M. D., M. L. Klotz, D. L. Breitenbecher, T. J. Yurak, and D. S. Vredenburg. 1995. Personal contact, individuation, and the better-than-average effect. Journal of Personality and Social Psychology 68 (5):804.

Amabile, T., and S. Kramer. 2011. The progress principle: Using small wins to ignite joy, engagement, and creativity at work: Harvard Business Press.

Amabile, T. M. 1996. Creativity in context.

Amabile, T. M., R. Conti, H. Coon, J. Lazenby, and M. Herron. 1996. Assessing the work environment for creativity. Academy of management journal 39 (5):1154-1184.

Amabile, T. M., C. N. Hadley, and S. J. Kramer. 2002a. Creativity under the gun. Harvard Business Review 80 (8):52-61, 147.

Amabile, T. M., J. S. Mueller, W. B. Simpson, C. N. Hadley, S. J. Kramer, and L. Fleming. 2002b. Time pressure and creativity in organizations: A longitudinal field study.

Anderson, S. W., H. C. Dekker, and K. L. Sedatole. 2010. An empirical examination of goals and performance-to-goal following the introduction of an incentive bonus plan with participative goal setting. Management Science 56 (1):90-109.

Aranda, C., J. Arellano, and A. Davila. 2014. Ratcheting and the Role of Relative Target Setting. The Accounting Review.

Arnold, M. C., and M. Artz. 2015. Target difficulty, target flexibility, and firm performance: Evidence from business units' targets. Accounting, Organizations and Society 40:6177.

Bandura, A. 1986. The explanatory and predictive scope of self-efficacy theory. Journal of social and clinical psychology 4 (3):359-373. 1997. Self-efficacy: The exercise of control: New York: Freeman.

Bebchuk, L. A., and L. A. Stole. 1993. Do Short-Term Objectives Lead to Under- or Overinvestment in Long-Term Projects? The Journal of Finance 48 (2):719-729.

Bol, J. C., T. M. Keune, E. M. Matsumura, and J. Y. Shin. 2010. Supervisor discretion in target setting: An empirical investigation. The Accounting Review 85 (6):1861-1886.

Bol, J. C., and J. B. Lill. 2015. Performance Target Revisions in Incentive Contracts: Do Information and Trust Reduce Ratcheting and the Ratchet Effect? The Accounting Review 90 (5):1755-1778.

Bonner, S. E., R. Hastie, G. B. Sprinkle, and S. M. Young. 2000. A Review of the Effects of Financial Incentives on Performance in Laboratory Tasks: Implications for Management Accounting. Journal of Management Accounting Research 12 (1):19-64.

Bonner, S. E., and G. B. Sprinkle. 2002. The effects of monetary incentives on effort and task performance: theories, evidence, and a framework for research. Accounting, Organizations and Society 27 (4):303-345.

Bouwens, J., and P. Kroos. 2011. Target ratcheting and effort reduction. Journal of Accounting and Economics 51 (1-2):171-185.

Brickley, J., C. W. Smith Jr, and J. Zimmerman. 2016. Managerial Economics \& Organizational Architecture. New York, NY: The McGraw-Hill Companies, Inc.

Brüggen, A., and F. Moers. 2007. The role of financial incentives and social incentives in multi-task settings. Journal of Management Accounting Research 19 (1):25-50.

Brüggen, A., and M. Strobel. 2007. Real effort versus chosen effort in experiments. Economics Letters 96 (2):232-236. 
Buckless, F. A., and S. P. Ravenscroft. 1990. Contrast coding: A refinement of ANOVA in behavioral analysis. Accounting Review:933-945.

Cappelli, P. 2013. HR for neophytes. Harvard Business Review 91 (10):3.

Charness, G., P. Kuhn, and M. C. Villeval. 2011. Competition and the Ratchet Effect. Journal of Labor Economics 29 (3):513-547.

Chartered Insitute of Management Accountants. 2004. Better Budgeting - A report on the Better Budgeting forum from CIMA and ICAEW, edited by Chartered Insitute of Management Accountants. London: Silverdart Ltd.

Chen, C. X., M. G. Williamson, and F. H. Zhou. 2012. Reward system design and group creativity: An experimental investigation. The Accounting Review 87 (6):1885-1911.

Chow, C. W. 1983. The Effects of Job Standard Tightness and Compensation Scheme on Performance: An Exploration of Linkages. The Accounting Review 58 (4):667-685.

Chow, C. W., J. C. Cooper, and K. Haddad. 1991. The effects of pay schemes and ratchets on budgetary slack and performance: A multiperiod experiment. Accounting, Organizations and Society 16 (1):47-60.

Christ, M. H., S. A. Emett, W. B. Tayler, and D. A. Wood. 2016. Compensation or feedback: Motivating performance in multidimensional tasks. Accounting, Organizations and Society 50:27-40.

Christ, M. H., K. L. Sedatole, and K. L. Towry. 2012. Sticks and carrots: The effect of contract frame on effort in incomplete contracts. The Accounting Review 87 (6):19131938.

Dechow, P. M., and R. G. Sloan. 1991. Executive incentives and the horizon problem: An empirical investigation. Journal of Accounting and Economics 14 (1):51-89.

Dekker, H. C., T. Groot, and M. Schoute. 2012. Determining performance targets. Behavioral Research in Accounting 24 (2):21-46.

Dohmen, T., A. Falk, D. Huffman, U. Sunde, J. Schupp, and G. G. Wagner. 2011. Individual risk attitudes: Measurement, determinants, and behavioral consequences. Journal of the European Economic Association 9 (3):522-550.

Dorenbosch, L., M. L. v. Engen, and M. Verhagen. 2005. On-the-job Innovation: The Impact of Job Design and Human Resource Management through Production Ownership. Creativity and innovation management 14 (2):129-141.

Elsbach, K. D., and A. B. Hargadon. 2006. Enhancing creativity through "mindless" work: A framework of workday design. Organization science 17 (4):470-483.

Farrell, A. M., K. Kadous, and K. L. Towry. 2008. Contracting on Contemporaneous versus Forward-Looking Measures: An Experimental Investigation. Contemporary Accounting Research 25 (3):773-802.

Farrell, A. M., K. Kadous, and K. L. Towry. 2012. Does the Communication of Causal Linkages Improve Employee Effort Allocations and Firm Performance? An Experimental Investigation. Journal of Management Accounting Research 24 (1):77102.

Filmer, H. L., J. B. Mattingley, R. Marois, and P. E. Dux. 2013. Disrupting prefrontal cortex prevents performance gains from sensory-motor training. The Journal of neuroscience 33 (47):18654-18660.

Fischbacher, U. 2007. z-Tree: Zurich toolbox for ready-made economic experiments. Experimental economics 10 (2):171-178.

Fisher, J. G., J. R. Frederickson, and S. A. Peffer. 2000. Budgeting: An experimental investigation of the effects of negotiation. The Accounting Review 75 (1):93-114. 2006. Budget negotiations in multi-period settings. Accounting, Organizations and Society 31 (6):511-528. 
Fisher, J. G., L. A. Maines, S. A. Peffer, and G. B. Sprinkle. 2002. Using budgets for performance evaluation: Effects of resource allocation and horizontal information asymmetry on budget proposals, budget slack, and performance. The Accounting Review 77 (4):847-865.

Grabner, I. 2014. Incentive System Design in Creativity-Dependent Firms. The Accounting Review.

Grabner, I., and F. Moers. 2013. Management control as a system or a package? Conceptual and empirical issues. Accounting, Organizations and Society 38 (6-7):407-419.

Hannan, R. L., G. P. McPhee, A. H. Newman, and I. D. Tafkov. 2012. The effect of relative performance information on performance and effort allocation in a multi-task environment. The Accounting Review 88 (2):553-575.

Hansen, S. C., and W. A. Van der Stede. 2004. Multiple facets of budgeting: an exploratory analysis. Management Accounting Research 15 (4):415-439.

Hecht, G., I. Tafkov, and K. L. Towry. 2012. Performance Spillover in a Multitask Environment. Contemporary Accounting Research 29 (2):563-589.

Hemmer, T. 1998. Performance measurement systems, incentives, and the optimal allocation of responsibilities. Journal of Accounting and Economics 25 (3):321-347.

Hirst, M. K., and P. W. Yetton. 1999. The effects of budget goals and task interdependence on the level of and variance in performance: a research note. Accounting, Organizations and Society 24 (3):205-216.

Hodgson, G. M. 1997. The ubiquity of habits and rules. Cambridge journal of economics 21 (6):663-684.

Holmes, D. S. 1978. Projection as a defense mechanism. Psychological Bulletin 85 (4):677.

Holmstrom, B., and P. Milgrom. 1991. Multitask principal-agent analyses: Incentive contracts, asset ownership, and job design. Journal of Law, Economics, \& Organization:24-52.

Holthausen, R. W., D. F. Larcker, and R. G. Sloan. 1995. Annual bonus schemes and the manipulation of earnings. Journal of Accounting and Economics 19 (1):29-74.

Indjejikian, R., and D. Nanda. 1999. Dynamic incentives and responsibility accounting. Journal of Accounting and Economics 27 (2):177-201.

Indjejikian, R. J., M. Matejka, K. A. Merchant, and W. A. Van der Stede. 2014a. Earnings Targets and Annual Bonus Incentives. The Accounting Review.

Indjejikian, R. J., M. Matejka, and J. D. Schloetzer. 2014b. Target Ratcheting and Incentives: Theory, Evidence, and New Opportunities. The Accounting Review.

Indjejikian, R. J., and D. Nanda. 2002. Executive Target Bonuses and What They Imply about Performance Standards. The Accounting Review 77 (4):793-819.

Jensen, M. 2001. Corporate budgeting is broken, let's fix it. Harvard Business Review 79 (11).

Kachelmeier, S. J., B. E. Reichert, and M. G. Williamson. 2008. Measuring and motivating quantity, creativity, or both. Journal of Accounting Research 46 (2):341-373.

Kachelmeier, S. J., T. A. Thornock, and M. G. Williamson. 2015a. Communicated Values as Informal Controls: Promoting Quality While Undermining Productivity? Contemporary Accounting Research:n/a-n/a.

Kachelmeier, S. J., L. W. Wang, and M. G. Williamson. 2015b. The Role of Incentives in Sustaining High-Creativity Production. Working paper.

Kachelmeier, S. J., and M. G. Williamson. 2010. Attracting creativity: The initial and aggregate effects of contract selection on creativity-weighted productivity. The Accounting Review 85 (5):1669-1691.

Kawada, C. L., G. Oettingen, P. M. Gollwitzer, and J. A. Bargh. 2004. The projection of implicit and explicit goals. Journal of Personality and Social Psychology 86 (4):545. 
Kelly, K. O., R. A. Webb, and T. Vance. 2014. The Interactive Effects of Ex Post Goal Adjustment and Goal Difficulty on Performance. Journal of Management Accounting Research 27 (1):1-25.

Kim, S., and J. Y. Shin. 2016. Executive Bonus Target Ratcheting: Evidence from the New Executive Compensation Disclosure Rules. Working paper.

Krueger, J. I. 2008. From social projection to social behaviour. European review of social psychology 18 (1):1-35.

Latham, G. P., and E. A. Locke. 1991. Self-regulation through goal setting. Organizational Behavior and Human Decision Processes 50 (2):212-247.

Lent, R. W., S. D. Brown, and P. A. Gore Jr. 1997. Discriminant and predictive validity of academic self-concept, academic self-efficacy, and mathematics-specific self-efficacy. Journal of Counseling Psychology 44 (3):307.

Leone, A. J., and S. Rock. 2002. Empirical tests of budget ratcheting and its effect on managers' discretionary accrual choices. Journal of Accounting and Economics 33 (1):43-67.

Leroy, S. 2009. Why is it so hard to do my work? The challenge of attention residue when switching between work tasks. Organizational Behavior and Human Decision Processes 109 (2):168-181.

Libby, R., and K. Rennekamp. 2012. Self-serving attribution bias, overconfidence, and the issuance of management forecasts. Journal of Accounting Research 50 (1):197-231.

Libby, T., and R. M. Lindsay. 2010. Beyond budgeting or budgeting reconsidered? A survey of North-American budgeting practice. Management Accounting Research 21 (1):5675.

Locke, E. A. 2004. Guest Editor's Introduction: Goal-Setting Theory and Its Applications to the World of Business. The Academy of Management Executive (1993-2005) 18 (4):124-125.

Locke, E. A., and G. P. Latham. 1990. A theory of goal setting \& task performance: PrenticeHall, Inc. . 2002. Building a practically useful theory of goal setting and task motivation: A 35year odyssey. American psychologist 57 (9):705.

Madjar, N., and C. E. Shalley. 2008. Multiple tasks' and multiple goals' effect on creativity: Forced incubation or just a distraction? Journal of management.

Mahlendorf, M. D., M. Matejka, and U. Schäffer. 2015. Target Ratcheting and Achievability of Earnings Targets. Working paper Available at SSRN 2654475.

Merchant, K. A., and J.-F. Manzoni. 1989. The Achievability of Budget Targets in Profit Centers: A Field Study. The Accounting Review 64 (3):539-558.

Merchant, K. A., and W. A. Van der Stede. 2007. Management control systems: Performance measurement, evaluation and incentives: Pearson Education.

Mezulis, A. H., L. Y. Abramson, J. S. Hyde, and B. L. Hankin. 2004. Is there a universal positivity bias in attributions? A meta-analytic review of individual, developmental, and cultural differences in the self-serving attributional bias. Psychological Bulletin $130(5): 711$.

Milgrom, P., and J. Roberts. 1992. Economics, Organization and Management. Upper Saddle River, New Jersey 07458: Prentice Hall. . 1995. Complementarities and fit strategy, structure, and organizational change in manufacturing. Journal of Accounting and Economics 19 (2-3):179-208.

Moore, D. A. 2007. Not so above average after all: When people believe they are worse than average and its implications for theories of bias in social comparison. Organizational Behavior and Human Decision Processes 102 (1):42-58.

Moritz, B. 2014. Keeping Millennials Engaged. Harvard Business Review 92 (11):4. 
Moskowitz, G. B. 2002. Preconscious effects of temporary goals on attention. Journal of Experimental Social Psychology 38 (4):397-404.

Murphy, K. J. 2001. Performance standards in incentive contracts. Journal of Accounting and Economics 30 (3):245-278.

Nonaka, I. 1991. The knowledge-creating company. Harvard Business Review 69 (6):96-104.

Oettingen, G., J. N. Ahn, P. M. Gollwitzer, A. Kappes, and C. L. Kawada. 2014. Goal projection and giving help. Journal of Experimental Social Psychology 54:204-214.

Pashler, H. 1984. Processing stages in overlapping tasks: evidence for a central bottleneck. Journal of Experimental Psychology: Human Perception and Performance 10 (3):358.

Robbins, J. M., and J. I. Krueger. 2005. Social projection to ingroups and outgroups: A review and meta-analysis. Personality and Social Psychology Review 9 (1):32-47.

Rosen, C. 2008. The myth of multitasking. The New Atlantis (20):105-110.

Shalley, C. E., L. L. Gilson, and T. C. Blum. 2000. Matching creativity requirements and the work environment: Effects on satisfaction and intentions to leave. Academy of management journal 43 (2):215-223.

Sherman, S. J., L. Chassin, C. C. Presson, and G. Agostinelli. 1984. The role of the evaluation and similarity principles in the false consensus effect. Journal of Personality and Social Psychology 47 (6): 1244.

Sprinkle, G. B., and M. G. Williamson. 2004. The evolution from Taylorism to employee gainsharing: A case study examining John Deere's continuous improvement pay plan. Issues in Accounting Education 19 (4):487-503.

- 2006. Experimental research in managerial accounting. Handbooks of Management Accounting Research 1:415-444.

Stein, J. C. 1989. Efficient Capital Markets, Inefficient Firms: A Model of Myopic Corporate Behavior. The Quarterly Journal of Economics 104 (4):655-669.

Tate, R. 2012. The 20\% doctrine: How tinkering, goofing off, and breaking the rules at work drive success in business. New York: HarperCollins.

Tombu, M. N., C. L. Asplund, P. E. Dux, D. Godwin, J. W. Martin, and R. Marois. 2011. A unified attentional bottleneck in the human brain. Proceedings of the National Academy of Sciences 108 (33):13426-13431.

Umapathy, S. 1987. Current budgeting practices in US industry: the state of the art: Praeger Pub Text.

Van der Stede, W. A. 2000. The relationship between two consequences of budgetary controls: budgetary slack creation and managerial short-term orientation. Accounting, Organizations and Society 25 (6):609-622.

Webb, A., M. G. Williamson, and Y. M. Zhang. 2013. Productivity-Target Difficulty,TargetBased Pay and Outside-the Box Thinking. The Accounting Review 88 (4):1433-1457.

Weiner, B. 1985. An attributional theory of achievement motivation and emotion. Psychological review 92 (4):548.

Weitzman, M. L. 1980. The "Ratchet Principle" and Performance Incentives. The Bell Journal of Economics 11 (1):302-308.

Woodruff, S. L., and J. F. Cashman. 1993. Task, Domain, and General Efficacy: A Reexamination of the Self-Efficacy Scale. Psychological Reports 72 (2):423-432. 



\section{Appendix A - Experimental Details for Chapter 2}

\subsection{Instructions for Part I of the experiment (treatment without task experience)}

Welcome,

Thank you for participating in this experiment. Today's session will last for about 50 minutes. On top of a 4 EUR show up fee, you can earn a considerable amount of money based on your performance, as will be explained in the instructions throughout the experiment. You will get your total compensation in cash at the end of the session. Read all the instructions carefully! Should you have any question, raise your hand and ask the instructor. Please do not communicate with any of the other participants or use your phones while the experiment is running.

The experiment consists of two parts. The instructions below refer to part I. After you have finished part I, you will receive further instructions about part II.

You will be randomly assigned the role as Player A or Player B and keep this role throughout the entire experiment. In part I, Player A will answer questions about a short text that (s)he has to read, while Player B will work on a task of counting zeros in tables. Both tasks are explained in further detail below.

\section{Answering questions}

As Player A you have 5 minutes to read a text on the computer screen. Once the 5 minutes are over, the text disappears and you have 3 minutes to answer 12 multiple choice about the text you read. (Be aware that the remaining time shown on the screen is based on the total time of 8 minutes and not just the time left for reading the text). For every correct answer that you give, you receive a compensation of 0.50 EUR.

\section{Counting zeros}

As Player B you will work for 8 minutes on a task where you have to count zeros in tables of numbers consisting of zeros and ones. The tables will be displayed on your computer screen. Once you have solved a table, fill in your result on the screen and click on "Next". If the result is correct, a new table will be provided. If the result is not correct, you receive an error message and you have to solve the table again until you fill in the correct result.

The tables you have to solve vary in their difficulty level (i.e., their length). They consist either of 10 columns with 2 rows (easy table) or 10 columns with 4 rows (difficult table). Below you can find examples of these tables and the corresponding results: 
Easy table:

\begin{tabular}{|llllllllll|}
\hline 0 & 1 & 1 & 1 & 0 & 0 & 0 & 1 & 0 & 1 \\
0 & 1 & 1 & 0 & 0 & 1 & 1 & 0 & 0 & 1 \\
\hline
\end{tabular}

$\underline{\text { Result }=10}$
Difficult table:

\begin{tabular}{llllllllll}
\hline 0 & 1 & 1 & 0 & 0 & 1 & 1 & 0 & 1 & 0 \\
1 & 1 & 1 & 0 & 0 & 1 & 1 & 1 & 0 & 1 \\
1 & 0 & 0 & 1 & 0 & 0 & 0 & 1 & 0 & 0 \\
1 & 1 & 1 & 0 & 0 & 1 & 0 & 1 & 0 & 1
\end{tabular}

$\underline{\text { Result }=19}$

As you work through the tables, there is a $50 \%$ probability that the next table you have to solve is an easy table (and consequently a 50\% probability that it is a difficult one). Although difficult tables require more time to solve than easy tables, you will be paid 0.10 EUR for every table solved correctly, irrespective of its difficulty level. You have 8 minutes to solve as many tables as possible. On the screen you can see how much time if left.

Once the computer program starts, you will learn your role as Player A or B. Afterwards you have to answer a few questions on the computer screen and then can start with the 8 minutes task period. When the task period is over, you will receive the instructions for part II.

You now have to wait until the instructor starts the computer program! 


\subsection{Instructions for part II of the experiment (the same for all treatments):}

\section{Part II}

In part II you will keep your assigned role as Player A or B and every Player A is matched with one Player B.

\section{Experimental tasks}

Player B has 8 minutes to work on the task of counting zeros in tables. Player A's task is to set a performance target for Player B. This performance target influences the compensation of both Players, as described below. To set an appropriate target, Player A receives information about the performance on the counting zeros task of 20 randomly drawn participants from earlier sessions. These participants worked for 8 minutes on the task of counting zeros, received a piece rate of 0.10 EUR per table solved and there was a $50 \%$ probability that the next table to solve was an easy one.

Player B works again on the task of counting zeros in tables of zeros and ones. However, in this part of the experiment Player B will face one of three different scenarios with respect to the probability that the next table to solve is an easy (or difficult) one:

1. A $70 \%$ probability of an easy table ( $\rightarrow$ higher task productivity)

2. Again a $50 \%$ probability of an easy table ( $\rightarrow$ same task productivity)

3. A $30 \%$ probability of an easy table ( $\rightarrow$ lower task productivity)

As easy tables usually require less time than difficult tables, these probabilities influence the overall task productivity. Player A has to assign performance targets for all three possible scenarios. After Player A has set these performance targets, a computer will randomly determine which one of these scenarios will be played by Player B during the 8 minute period. Player B will only see the performance target for the scenario played out.

\section{Compensation Player A}

Player A's compensation ( $\operatorname{CompPA}$ ) is defined as follows:

$$
\begin{aligned}
\text { CompPA } & =3 \text { EUR base wage }+ \text { Revenue }- \text { CompPB } \\
& =3 \text { EUR base wage }+(0.20 \text { EUR } * \text { Output })-\text { CompPB }
\end{aligned}
$$

Thus, Player A receives a base wage of 3 EUR which will increase or decrease depending on the Revenue generated and the compensation paid to Player B (CompPB). In fact, if the Revenue, which is a 0.20 EUR piece rate for every table that Player B solves correctly (Output), exceeds the compensation paid to Player B ( СотpPB), then Player A's compensation increases. If the Revenue is lower than $\operatorname{CompPB}$, then Player A's compensation will be lower than the 3 EUR base wage. However, note that it is never possible that Player A's compensation falls below 0 .

\section{Compensation Player B}

Player B's compensation $(C o m p P B)$ is defined as follows: 


$$
\begin{aligned}
& \text { if Output } \geq \text { Target } \rightarrow \text { CompPB }= \\
& 3 \text { EUR fixed salary }+(\text { Output }- \text { Target }) * 0.10 \text { EUR } \\
& \text { if Output }<\text { Target } \rightarrow \text { CompPB }=3 \text { EUR fixed salary }
\end{aligned}
$$

Thus, Player B receives a fixed salary of 3 EUR and a bonus depending on his/her performance. Specifically, if Player B's Output (=number of tables (s)he solves correctly) is equal or higher than the performance target assigned by Player A (Target), then Player B receives the fixed salary of 3 EUR plus a bonus of 0.10 EUR for every unit beyond the target. If Player B does not achieve the target (Output $<$ Target), (s)he only gets the 3 EUR fixed salary.

Below you can find some illustrative examples for the calculation of the compensation.

Example 1: Player A sets a target of 35 and Player B solves 50 tables. Compensation...

...Player A: 8.5 EUR (3 base wage +10 Revenue $(=0.2 * 50$ Output $)-4.5$ CompPB $)$

...Player B: 4.5 EUR (3 fixed salary +(50 Output -35 Target $) * 0.1)$

Explanation:

As Player B achieved the target of 35, (s)he gets the fixed salary of 3 EUR plus a bonus of 1.5 EUR $((50$ Output -35 Target $) * 0.1$ EUR $) \rightarrow 4.5$ EUR

For Player A, the revenue generated is 10 EUR $(0.2$ EUR $* 50$ Output). Thus, Player A gets the base wage of 3 EUR plus 10 EUR revenue, minus the compensation for Player B (4.5 EUR) $\rightarrow$ 8.5 EUR

Example 2: Player A sets a target of 45 and Player B solves 50 tables. Compensation...

...Player A: 9.5 EUR (3 base wage +10 Revenue $(=0.2 * 50$ Output $)-3.5$ CompPB $)$

...Player B: 3.5 EUR (3 fixed salary + (50 Output -45 Target)*0.1)

Example 3: Player A sets a target of 45 but Player B solves only 10 tables. Compensation...

...Player A: 2 EUR (3 base wage +2 Revenue $(=0.2 * 10$ Output $)-3$ CompPB)

...Player B: 3 EUR (3 fixed salary +0 bonus (as Output $<$ Target))

As you click the OK button on the computer screen you will again see your role as Player A or B and have to answer a few questions to check your understanding of the instructions. When all participants have answered these questions correctly, Player A sets the performance targets for Player B. Then the computer randomly determines which scenario is played out and Player B works for 8 minutes on the task. Player A has to wait during that time. Once the task is over, Players A and B learn their compensation of part II and can continue with the exit questionnaire of the experiment. 


\subsection{Screen that principals see when setting the performance targets}

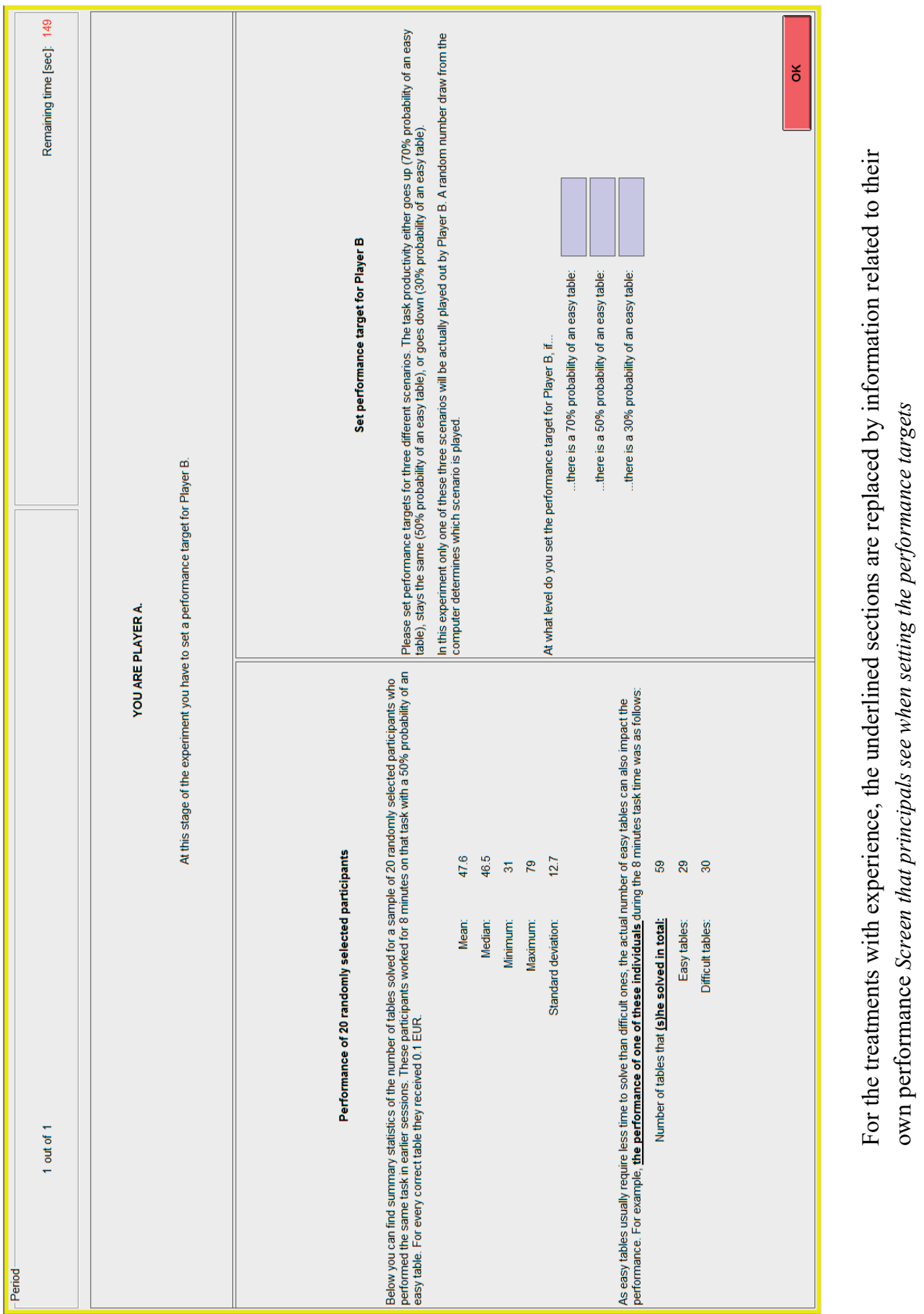





\section{Appendix B - Experimental Details Chapter 3}

\subsection{Paper-based Instructions - Part I}

Welcome,

Thank you for participating in this experiment. Today's session will last about 90 minutes. During this session you will work on two different tasks. In addition to the show up fee of 3 EUR, you can earn a considerable amount of money depending on your performance. You will get your total compensation after you finished the session.

Read all the instructions carefully! Should you have any question, please raise your hand and ask the instructor. Please do not communicate with any of the other participants while the experiment is running. During the entire experiment, you are NOT allowed to use any calculators, mobile phones, paper or pen.

\section{Task 1 - solve multiplications}

In the first task you have to solve mathematical multiplications (e.g. 44 × $24=1056$ ), which will be displayed on the computer screen. Once you solved a calculation, fill in your result on the screen and click on "Next". Then, a new multiplication will be provided. The computer screen also shows the number of multiplications you submitted correctly.

\section{Task 2 - count zeros in tables of numbers}

The setup of the second task is similar to the first one. However, in this part you do not need to solve multiplications but count zeros in tables of numbers (showing zeros and ones). The tables will be displayed on the computer screen. Once you solved a table, fill in your result on the screen and click on "Next". Then, a new table will be provided. The computer screen also shows the number of tables you submitted correctly.

In the first step of the experiment you will perform both of these tasks individually. Therefore you will start with a 5 minutes practice period for solving multiplications. Afterwards you have a 5 minutes period where you get paid 0.2 EUR per multiplications submitted correctly. After you finished this period you have a 3 minutes period for counting zeros in tables of numbers. You will get 0.2 EUR for each table submitted correctly. (Be aware that there is no practice period for task 2 - counting zeros in tables of numbers, but that you will start immediately with the performance period.)

Please fill in the experimental ID you received and follow the instructions on the computer screen that guide you through the experiment. Once you have finished this first stage of the experiment, the computer screen will show you a message and the instructors will provide you with the instructions for the second part of the experiment. 


\subsection{Paper-based instructions Part II (target ratcheting treatment)}

\section{Experimental instructions - Part II}

The second part of the experiment consists of 6 periods, lasting 5 minutes each. You can work on the two tasks you have been working on during the previous part (solve multiplications and count zeros). How much time you allocate to each of these tasks in each period is your decision. In every period you can switch back and forth between the tasks as often as you want, by pressing the button on the screen.

However, in this part of the experiment your output $(y)$ of task 1 (multiplications) does not only depend on the number of multiplications solved correctly $(m)$, but also on a production factor $(p)$, which can be influenced by task 2 (count zeros). Therefore, your output is the product of the following two factors:

$$
y=m * p
$$

Below you find examples for the calculation the output:

\begin{tabular}{|ccc|}
$\begin{array}{c}\text { No. of Multiplications } \\
\text { solved correctly }\end{array}$ & Production factor & Output \\
\hline 14 & 2.4 & 33.6 \\
\hline 10 & 2.0 & 20.0 \\
\hline 13 & 2.8 & 36.4 \\
\hline
\end{tabular}

The production factor in the first period of the experiment will be 2.0. However, by solving task 2 (counting zeros) you can increase the probability that the production factor will increase by 0.4 from the next period onwards.

With each table solved correctly you increase the probability for an improvement of the production factor. The table below summarizes the probability distribution. Be aware that your tables solved correctly do not accumulate over multiple periods, but reset to 0 at the beginning of each period.

\begin{tabular}{cc}
\hline $\begin{array}{c}\text { Tables solved } \\
\text { correctly }\end{array}$ & Probability \\
\hline $\mathbf{0}$ & 0.00 \\
$\mathbf{1}$ & 0.10 \\
$\mathbf{2}$ & 0.17 \\
$\mathbf{3}$ & 0.23 \\
$\mathbf{4}$ & 0.29 \\
$\mathbf{5}$ & 0.34 \\
$\mathbf{6}$ & 0.40 \\
$\mathbf{7}$ & 0.45 \\
$\mathbf{8}$ & 0.50 \\
$\mathbf{9}$ & 0.54 \\
$\mathbf{1 0}$ & 0.59 \\
\hline
\end{tabular}

\begin{tabular}{cc}
\hline $\begin{array}{c}\text { Tables solved } \\
\text { correctly }\end{array}$ & Probability \\
\hline 11 & 0.63 \\
12 & 0.68 \\
13 & 0.72 \\
14 & 0.76 \\
15 & 0.80 \\
16 & 0.84 \\
17 & 0.88 \\
18 & 0.92 \\
19 & 0.96 \\
20 & 0.99 \\
$>=20$ & 0.99 \\
\hline
\end{tabular}

Once a higher level of the production factor has been reached it cannot decrease again. It will remain at the higher level for all the upcoming periods and can even be further increased to a higher level, depending on your performance on task 2 .

Example: In period t Participant $Z$ decides to spend time on task 2 and solves 8 tables. Therefore, his probability for getting an increase of the production factor starting from $t+1$ is $50 \%$. In period $t+1$ he solves 6 tables. Thereby his probability for getting a (further) increase of the production factor $p$ is $40 \%$. 


\section{Compensation}

In this part of the experiment, your compensation for each period is calculated as follows:

$$
\begin{array}{lll}
C=(y-b) * 0.05 \mathrm{EUR}+1.5 \mathrm{EUR} & \text { if } & y \geq b \\
C=0 \text { EUR } & \text { if } & y<b
\end{array}
$$

Thus, the compensation $(\boldsymbol{C})$ depends only on your output of task $1(y)$. If the output of task $1(y)$ equals or exceeds the target level (b), you will get a lump sum bonus payment of 1.5 EUR plus 0.05 EUR for each output unit above the target level. In case your output of task $1(y)$ is below the target level (b) you will get no compensation for that period. Your total compensation for that part of the experiment is the sum of all periods.

Based on a pilot study among students, the initial output target (b) is 20 units. From the second period on the target will be determined each period based on your previous output. In case you exceeded the target in the previous period, the new target increases to the level of the output achieved. In case you missed the target, the target level is unchanged. The figure below gives an illustrative EXAMPLE:

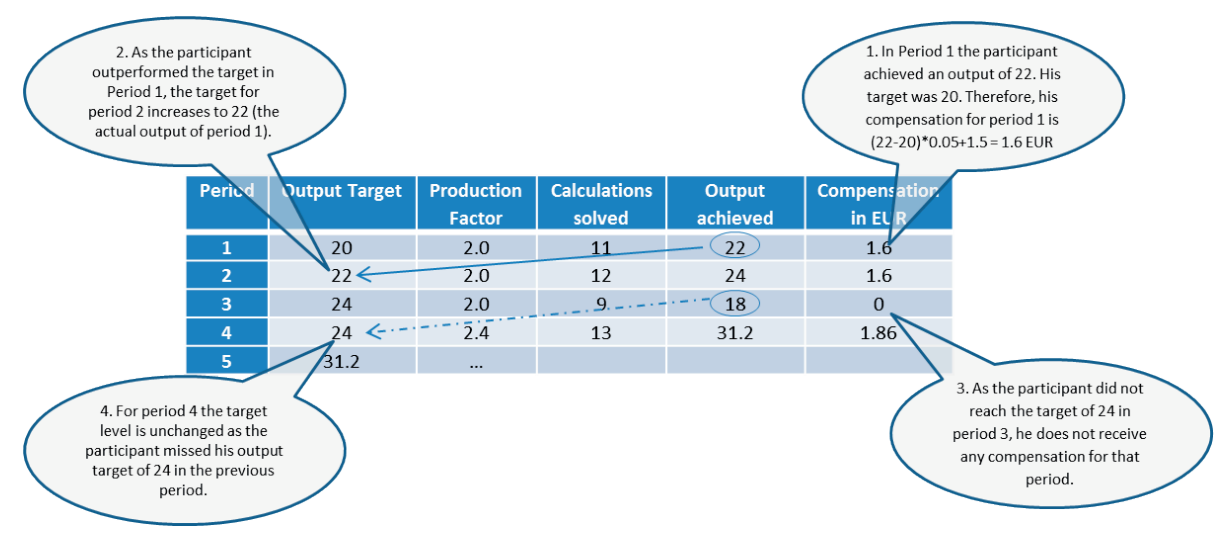

The experiment consists of 6 periods, 5 minutes each. Before you can start the experiment you need to fill in a short quiz on the computer.

To start, please fill in your experimental ID on the computer screen and follow the instructions!!! 
8.3 Screen that participants saw during the productive task

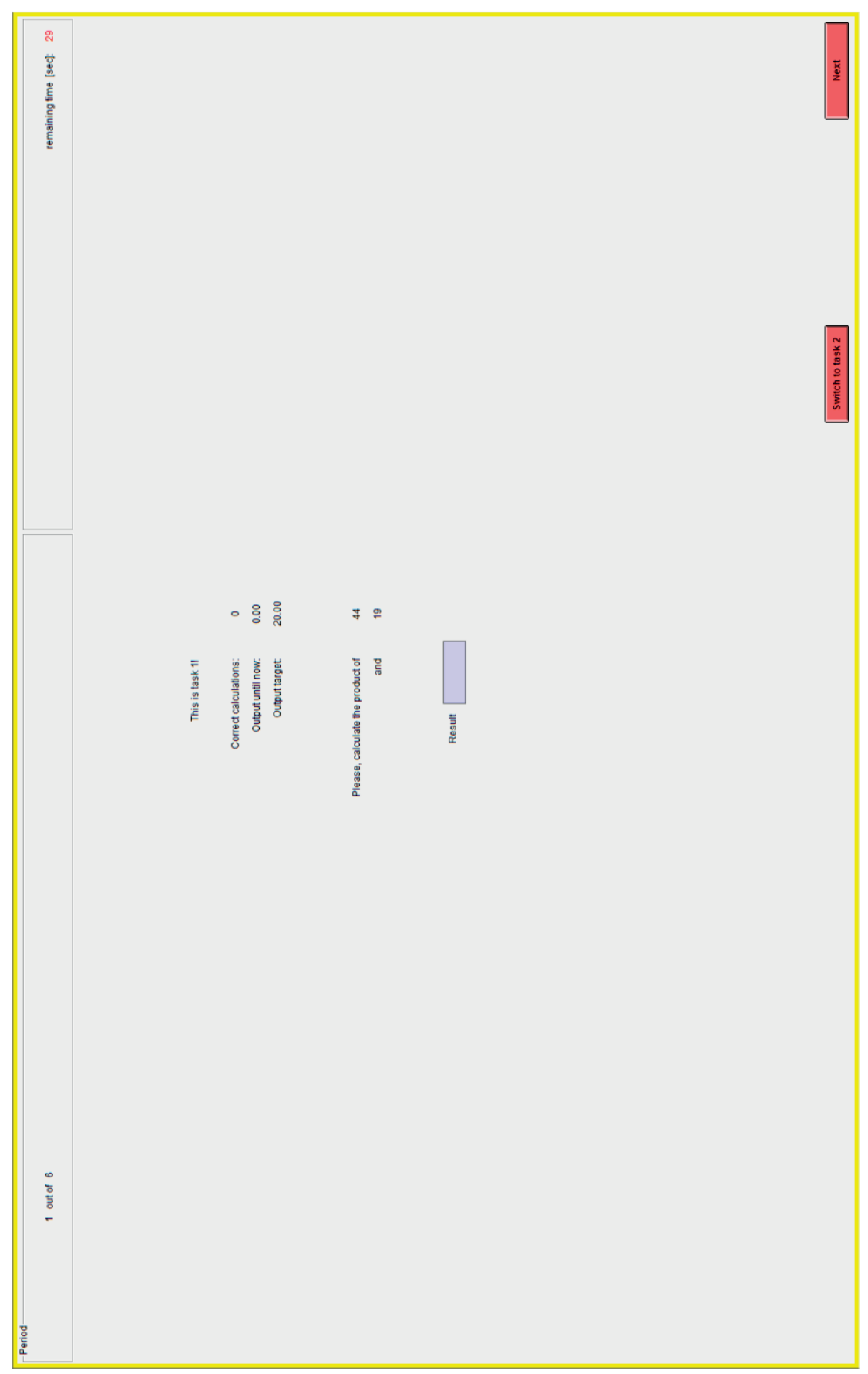




\subsection{Screen that participants saw during the investment task}

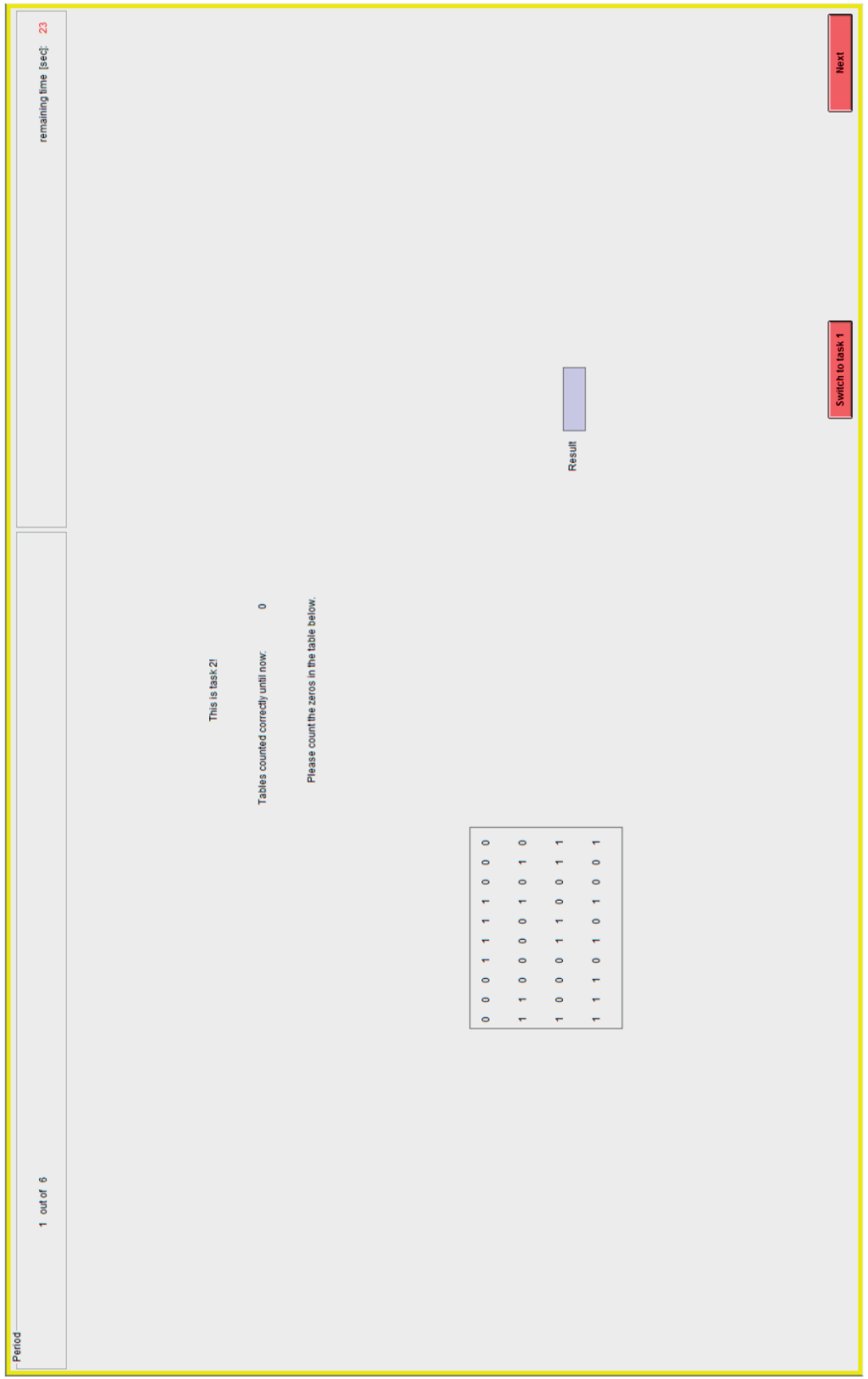





\section{Appendix C - Experimental Details for Chapter 4}

\subsection{Paper-based instructions (for Input and Output Target Treatment)}

Welcome,

Thank you for participating in this experiment. Today's session will last approximately 50 minutes. You will be compensated with 10 EUR for your participation. Please use your experimental ID for all forms you fill out so that you remain anonymous. In the following instructions you will find all information necessary for this experiment. Please read all the instructions carefully. Communication with other participants is not allowed during the entire experiment.

In this experiment you will work on two different tasks. The first task is decoding letter combinations into numbers. The second task is generating ideas for new experimental tasks. Below you can find a description for each of the tasks.

\section{Task 1 - Decoding letters into numbers}

On the computer screen you will be presented letter combinations that you need to translate into numbers by using the translation key below. The first letter specifies the row, and the second letter specifies the column of the table where you can find the decoded numbers. For example, to decode the letter combination "cu" you will find the decoded number in the $3^{\text {rd }}$ row and the $4^{\text {th }}$ column. The decoded number is thus 26 . The decoded value for the letter combination "hv" is the number " 53 ". Please fill in the number in the results space on the computer screen and then click "Next" to proceed to the next decoding letter combination.

\begin{tabular}{|c|c|c|c|c|c|c|c|c|c|}
\hline & r & s & t & u & v & w & x & y & z \\
\hline a & 37 & 46 & 27 & 12 & 99 & 95 & 23 & 44 & 65 \\
\hline b & 86 & 62 & 40 & 72 & 92 & 49 & 51 & 20 & 28 \\
\hline c & 18 & 30 & 93 & 26 & 69 & 87 & 16 & 15 & 84 \\
\hline $\mathbf{d}$ & 73 & 94 & 32 & 63 & 54 & 78 & 60 & 22 & 13 \\
\hline e & 45 & 90 & 56 & 67 & 55 & 61 & 98 & 88 & 48 \\
\hline $\mathbf{f}$ & 25 & 97 & 75 & 39 & 50 & 42 & 24 & 66 & 19 \\
\hline $\mathbf{g}$ & 47 & 89 & 58 & 68 & 91 & 57 & 82 & 29 & 70 \\
\hline $\mathbf{h}$ & 38 & 85 & 52 & 71 & 53 & 21 & 80 & 41 & 59 \\
\hline $\mathbf{i}$ & 77 & 96 & 11 & 76 & 79 & 31 & 33 & 74 & 81 \\
\hline
\end{tabular}

Task 2 - Generating ideas for new experimental tasks

In our experiments we use tasks such as the one described above to help us investigate various research topics. We would like for you to describe new, innovative, and useful tasks that researchers can use in their experiments. To be useful, your experimental tasks should have the following features: 
- Performance on the task is easy to measure. That is, regardless of the type of performance measured (productivity, creativity, problem solving, etc.), we will be able to easily tell who performed better and who performed worse.

- Easy to understand for student participants. That is, students will be able to perform that task with simple instructions and no prior knowledge of the task.

- Students need to spend real effort on a task (e.g. decode letters, solve multiplications)

- Sensitive to effort (the harder participants work, the higher their performance)

Please describe the experimental tasks you develop as clearly and efficiently as possible in the blue box on the computer screen for task 2, and press enter to submit an idea (once you submitted the idea, you cannot change or add anything). Examples of descriptions can be found below:

Idea: Participants must decode letter combinations into numbers. The more letters they decode the higher their performance.

Idea: Participants must solve multiplication problems. The more multiplication problems they solve the higher their performance.

Idea:

(Please use a new row for each idea and do not use more than 300 characters to describe it).

You will have a total of 20 minutes to work on both tasks. During this time, you can switch back and forth between the tasks as many times as you want, by using the "Switch task" button on the computer screen. On the right hand side of the screen you will see a summary of the number of decoded letter combinations you submitted and the time you spent on this task. Furthermore, in the upper right hand corner you will see the total time remaining.

On task 1, we value the number of letter combinations you decode. On task 2, we value the number of creative experimental tasks you describe.

As a guide, we ask you to spend at least 10 minutes on the decoding task and decode at least 100 letter combinations into numbers. That said, you are free to allocate your time and work effort across the two tasks in any way you want.

Before you can start with the experiment, you have to answer a couple of questions on the computer screen to check your understanding of the instructions. If you have any question please notify the experimenter.

Once you finished the experiment you will receive an exit questionnaire. Upon completion of the exit questionnaire you will receive your payment.

Please start the experiment by filling out your experimental ID on the computer screen! 


\subsection{Screen that participants saw during task I - decoding task}

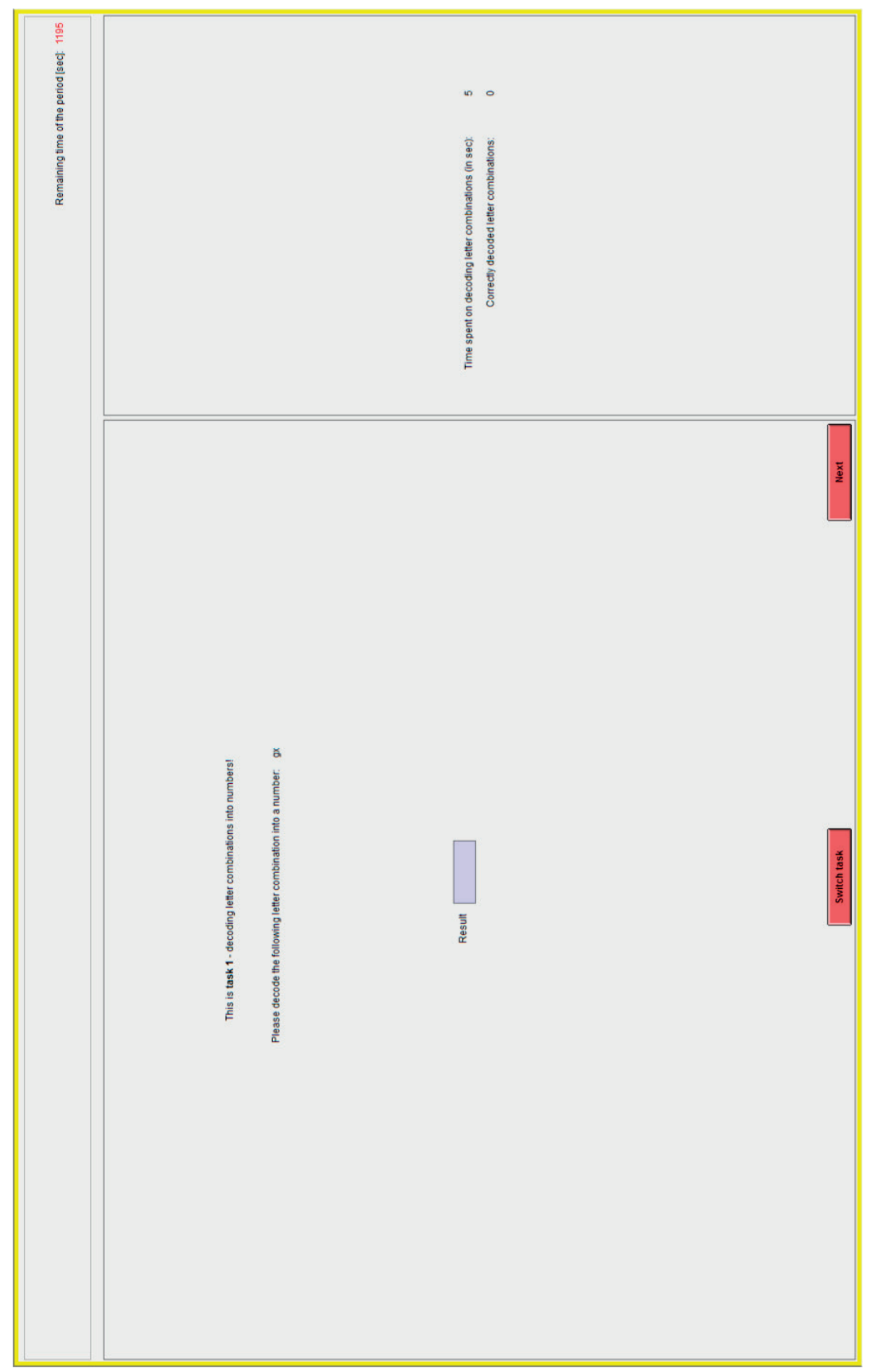


9.3 Screen that participants saw during Task II - creative task

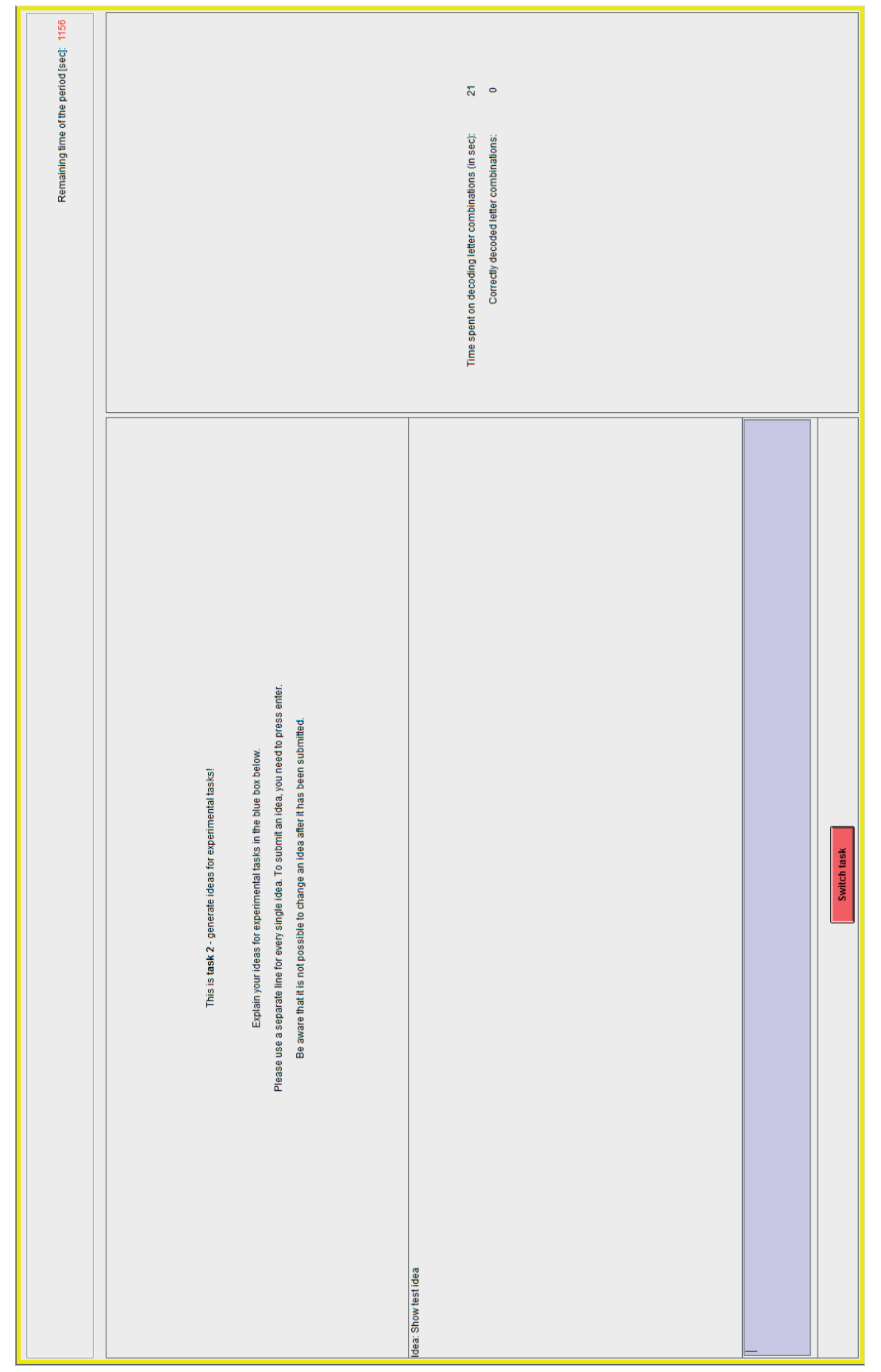




\section{Appendix D: Valorization-addendum}

Target setting is a highly relevant topic for organizations and their members. As already outlined in the introduction, studies show that up to $97 \%$ of the companies use budgets and targets to coordinate the actions within the organization and motivate their employees (Umapathy 1987; Libby and Lindsay 2010; Hansen and Van der Stede 2004). Thereby, these targets are not only relevant for specialized accounting departments and their members, but every single employee within an organization is affected. Investigating supervisors' target setting decisions as well as the effect that targets have on the motivation and investment decision of employees can increase the effectiveness of such systems.

The three studies I describe in this dissertation address common issues firms are facing and have concrete implications for organizations. For example, many companies have policies in place - or consider implementing policies - where supervisors gain experience in various functions and areas within a company. This certainly can benefit the understanding of the business model and the different tasks necessary. However, as I show in my study, it also has implications for the target setting decisions that supervisors make. Specifically, supervisors' task experience on the employees' task can lead supervisors to overemphasize their own experiences and discount relevant other signals that they receive about the expected performance of employees. Thus, having own task experience on employees' tasks could mislead supervisors in their decision making. Incorporating the findings of my study in organizational training programs can help increasing supervisors' awareness of these potential problems and thus mitigate these issues. This not only leads to a more effective use of target setting systems for planning and coordination, but can also assure that targets are set at achievable levels for employees and maximize their motivation. Thereby, target setting systems can lead to higher success of the company and to greater employees' well-being.

Furthermore, to succeed in the long-run, companies need to find a balance between maximizing short-term output and investing in projects that build the basis for future success. As a consequence, individual employees are often responsible for both short-term output and long-term investments. However, as the effort is hard to observe and the success of such longterm investments is highly uncertain, companies need to find other ways to prompt them. In this dissertation I show that the use of past performance information in setting new targets triggers such investments by reducing the negative effects of the horizon problem. While prior research has shown that using past performance information leads to lower effort of individuals, I show that it can increase long-term investments. Thus, even though policies where targets increase over time because of good performance are often alleged to reduce the effort employees spend, I show that employees use the additional time to invest in future success that can build the ground for firms' future success. Furthermore, from the employees' perspective, it also means that even though targets increase over time, this not necessarily means that they get more challenging. Hence, my study shows that companies that heavily rely on long-term investments or where the horizon problem of employees plays a major role, can use their target setting systems to provide implicit incentives for such investments. This 
means that the predominantly negative perspective of target ratcheting may be adjusted to provide a better reflection of the expected behavior induced by such policies. This also means that executive teaching and (under-)graduate teaching programs can be enriched by the findings of the study. Consequently, current and future managers could get a more diverse understanding of the effects of using past performance information in setting targets which helps them to make better judgements about the costs and benefits of their decision in the future.

Furthermore, in a setting where individual employees are responsible for both shortterm output production and creative activities, I show that the creativity of employees is affected by the target setting system around the short-term output task. Specifically, the results of my study suggest that a combination of input targets that provide guidance about the time allocation and output targets suggesting a minimum level of short-term output to achieve can increase the creative task performance of employees. As companies' often depend on the idea generation and creativity of their employees, identifying control mechanism and combinations to foster creative performance has immediate implications for such companies. Specifically, while companies often provide their employees with time guidance for spending time away from their routine tasks to pursue creative activities, this study shows that companies can increase the efficacy of such policies by also telling employees what to achieve on the routine task. Ideas generated by such policies have already led to great innovations from some companies in the past. Publishing the results in practitioner journals and present it at practice oriented conferences can help managers to identify aspects of how to improve their own systems in order to maximize their success probabilities. Furthermore, also on an individual level, people can benefit from having clear expectations what they need to have achieved before they switch to another task. By achieving cognitive closure about certain tasks, the effectiveness of the time spent on other tasks can be improved. Thus, by increasing the public knowledge about the study, both companies and individuals can benefit from the findings and implications.

To sum up, the three studies of this dissertation examine target setting from supervisors' and employees' perspectives. All studies have direct practical implications for managers and employees as outlined throughout the studies and summed up in this section. By incorporating the findings of the studies in teaching materials, publishing it in academic and practitioner oriented journals, and presenting the results at various practice workshops and conferences, this dissertation can help managers to improve the effectiveness of organizational target setting systems and employees to better cope with the challenges arising from multi-task jobs. 


\section{Curriculum Vitae}

Christoph Feichter was born on June $24^{\text {th }}, 1985$ in the beautiful city of Vienna, Austria. From 2005-2010 he studied business administration (specializations accounting and strategic management) at WU Vienna (Austria) and Nanyang Technology University (Singapore). After he graduated, he worked at WU Vienna as teaching and research associate. In 2012 he became a PhD Candidate at Maastricht University at the Department of Accounting and Information Management, focusing on Management Accounting research. During his doctoral studies, he has been visiting scholar at the University of Texas at Austin (USA) and University of Waterloo (Canada). He presented his work at various accounting conferences such as the Annual Meeting of the American Accounting Association (AAA), the midyear Meeting of the Management Accounting Section of the AAA, the Global Management Accounting Research Symposium, Conference on New Directions in Management Accounting, and the European Accounting Association Doctoral Colloquium and workshops at the University of Bern, Erasmus University Rotterdam, Maastricht University, Tilburg University, and the University of Waterloo. Since September 2016 he works as Assistant Professor at the Department of Accounting and Information Management at Maastricht University. 
